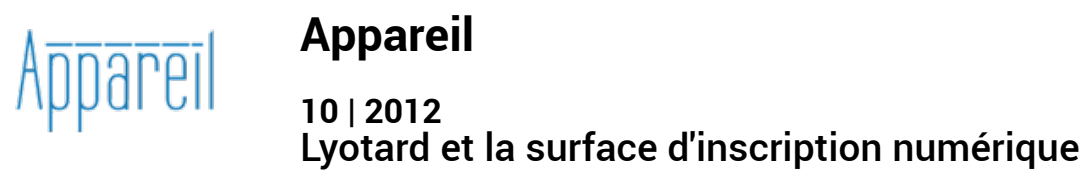

\title{
Art, fantasme, idéologie
}

L'esthétique libidinale de Jean-François Lyotard

\section{Abigail Heathcote}

\section{CpenEdition}

\section{Journals}

Édition électronique

URL : http://journals.openedition.org/appareil/1507

DOI : 10.4000/appareil. 1507

ISSN : 2101-0714

Éditeur

MSH Paris Nord

\section{Référence électronique}

Abigail Heathcote, "Art, fantasme, idéologie », Appareil [En ligne], 10 | 2012, mis en ligne le 20

décembre 2012, consulté le 31 juillet 2020. URL : http://journals.openedition.org/appareil/1507 ; DOI :

https://doi.org/10.4000/appareil.1507

Ce document a été généré automatiquement le 31 juillet 2020.

\section{(c)}

Appareil est mis à disposition selon les termes de la Licence Creative Commons Attribution - Pas d'Utilisation Commerciale - Pas de Modification 4.0 International. 


\section{Art, fantasme, idéologie}

L'esthétique libidinale de Jean-François Lyotard

\section{Abigail Heathcote}

\section{NOTE DE L'AUTEUR}

Mémoire de master $2:$ «Philosophie et critiques contemporaines de la culture », sous la direction de Jean-Louis Déotte, département de philosophie, Paris 8 université

Vincennes-Saint Denis, 2010.

\section{Abréviations}

Les titres des ouvrages de Lyotard cités dans le texte sont abrégés de la façon qui suit:

DMF : Dérive à partir de Marx et Freud, UGE, 1973.

DF : Discours, figure, Klincksieck, 1971.

DP : Des dispositifs pulsionnels, UGE, 1973.

EL : Économie libidinale, Minuit, 1974.

E : L'Enthousiasme. La critique kantienne de l'histoire, Galilée, 1986.

IH : L'inhumain, Galilée, 1988.

PE : Pérégrinations, Galilée, 1990.

\section{Introduction}

\section{Le figural}

2 Au début de Discours, figure ${ }^{1}$ (1971), Lyotard établit une opposition entre deux espaces distincts : celui du langage, de la communication et du discours, et celui de la forme, de la couleur, de tout ce qui est visuel. Le premier espace, au service de la communication et de la signification, ne peut contenir que ce qui a été anticipé par le système, et le système, pour fonctionner, ramène tout ce qui est en dehors de lui à l'intérieur, il sacrifie l'altérité pour promouvoir la répétition du même. Le deuxième espace, que Lyotard nomme figural, est l'espace de tout ce que le discours ne peut pas dire, tout ce 
qui élude la signification. Libéré des contraintes de la signification, ce dernier est l'espace du sens et de l'expérience, et des intensités qui existent pour elles-mêmes.

Fidèle à son statut de ce qui ne peut être signifié, le figural résiste à toute tentative de le capturer, de le définir concrètement, il reste insaisissable tout au long de Discours, figure. En effet, Lyotard change même radicalement les termes utilisés pour le définir. Dans la première partie, une critique phénoménologique du discours et de la théorie, le figural est conçu principalement en termes visuels. En effet, dans cette première partie, Lyotard qualifie son livre comme " une défense de l'œil ${ }^{2}$ ». Cependant, dans ce qui peut être considéré comme étant la deuxième partie de Discours, figure, le vocabulaire phénoménologique de Lyotard laisse place à un vocabulaire psychanalytique. La figure n'est plus conçue principalement en termes visuels, mais plutôt en termes de libido. L'essence du figural est maintenant le processus primaire inconscient de Freud. Or ce changement de vocabulaire pour décrire le figural est conforme à sa nature même. Car le figural, pour Lyotard, possède une valeur critique, qui dépend de son caractère insaisissable. S'il est trop déterminé ontologiquement, son potentiel critique, qui vient de son altérité radicale, serait minimisé. Il doit rester élusif et au-delà de la signification, la tension entre discours et figure ne doit pas être résolue.

On pourrait supposer qu'en opposant discours et figure, Lyotard est en train de suggérer que le philosophe devienne peintre, qu'on devrait se passer du discours pour que l'altérité soit rendue visible. Mais cette distinction établie au début est rendue de moins en moins claire au fur et à mesure que le livre avance. Lyotard affirme par la suite que la figure est autant au travail dans le discours qu'à l'extérieur, autant un aspect du langage qu'un aspect de la peinture. Il écrit : «il n'est pas question de passer de l'autre côté du discours. Seulement de l'intérieur du discours, on peut passer à et dans la figure. [...] [O]n peut passer dans la figure sans quitter le langage parce qu'elle y est logée [...] La figure est dehors et dedans ${ }^{3}$. » Le rôle du théoricien devient donc celui de l' ouverture du discours à ce qu'il ne peut pas signifier: "on veut que les mots disent la prééminence de la figure, on veut signifier l'autre de la signification », revendique Lyotard ${ }^{4}$.

5 Signifier l'autre de la signification, telle est la tâche que Lyotard donne à la philosophie et à la pensée en général. Mais cette tâche est impossible, car dès que l'autre est signifié, c'est-à-dire intégré au système de la signification, il n'est plus autre, quelque chose est perdu lors du processus. Comment Lyotard propose-t-il alors de dire ce qui ne peut pas être dit tout en restant à l'intérieur des limites du discours et de la représentation ? Comment un processus qui sépare le dedans et le dehors, un processus qui est forcément à l'œuvre dans tout système symbolique, peut-il être renversé pour que le figural, ce qui élude la représentation, soit porté au discours? Ce qu'il cherche est à première vue analogue au processus de la psychanalyse, dont le patient est guéri une fois que le refoulé est apporté au conscient et exprimé en mots.

6 Pour apprécier pourquoi Lyotard accorde à la philosophie cette tâche impossible, il est nécessaire de considérer brièvement le contexte de la problématique « libidinale » du Lyotard des années 1970, et le climat philosophique et politique dans lequel il s'est trouvé. 


\section{Des disputes poststructuralistes autour de la nature du langage}

7 Comme l'a soutenu Peter Dews, la philosophie française des années 1960 peut être divisée en deux phases: une phase structuraliste, dominée par des personnalités comme Saussure en linguistique et Lévi-Strauss en anthropologie, et une phase poststructuraliste, incarnée par Derrida et Lacan ${ }^{5}$. La phase poststructuraliste continue la préoccupation structuraliste pour l'auto-réflexivité du discours et le décentrement du sujet (des préoccupations qui vont contre l'idée du savoir absolu chez Hegel) tout en renversant ce qui est considéré comme étant la naïveté de la prétendue objectivité du poststructuralisme. Pour Derrida et Lacan, toute prétention à l'objectivité doit forcément ignorer son statut linguistiquement médié. La conclusion radicale de Derrida est que l'idée même d'une réalité en dehors du langage est illusoire. Une préoccupation pour le texte est donc centrale à la critique derridienne et lacanienne du structuralisme.

Discours, figure inaugure ce qui peut être considéré comme une deuxième vague du poststructuralisme ${ }^{6}$, qui se pose contre le logocentrisme même qui donne à la première phase son avantage critique. Comme l'a succinctement exprimé Lyotard : « on ne rompt pas du tout avec la métaphysique en mettant du langage partout ${ }^{7}$.» L'accent passe du langage comme ce qui médie inévitablement la réalité aux forces qui étayent et déforment le langage. Contrairement à Derrida, Lyotard affirme que l'impossibilité de saisir à travers le langage une réalité indépendante du langage ne veut pas dire que cette réalité n'existe pas. En revanche, elle souligne l'insuffisance du langage pour tenir compte de la réalité. Dans les premières pages de Discours, figure, Lyotard met en évidence sa défense du visible contre le textuel, en forgeant une distinction entre deux espaces différents qu'il nommera plus tard lettre (espace graphique) et ligne (espace figural) $)^{8}$ :

Ce livre-ci proteste : que le donné n'est pas un texte, qu'il y a en lui une épaisseur, ou plutôt une différence, constitutive, qui n'est pas à lire, mais à voir; que cette différence, et la mobilité immobile qui la révèle, est ce qui ne cesse de s'oublier dans le signifier (DF 9).

9 En prenant le parti du visible, Lyotard critique une tendance qu'il juge présente dans la philosophie depuis Platon. Depuis Platon, la philosophie a bel et bien sapé la couleur du monde sensible, en le reléguant, en tant qu'apparence et matérialité à un statut secondaire au nom de la vérité supérieure du logos. Lyotard entend le relever :

[1]a pénombre qu'après Platon la parole a jetée comme un voile de gris sur le sensible, qu'elle a thématisée sans cesse comme un moins-être, dont le parti n'a que très rarement été pris vraiment, pris en vérité, parce qu'il était entendu que son parti est celui de la fausseté, du scepticisme, du rhéteur, du peintre, du condottiere, du libertin, du matérialiste $[. .].(D F, 11)$.

\section{Le contexte politique à la préoccupation pour le figural}

Le déplacement philosophique vers une préoccupation pour les forces qui sous-tendent les systèmes symboliques naît aussi de préoccupations politiques, en particulier l'irruption de mai $1968^{\circ}$. Pour Lyotard, mai 1968 a démontré que les structures sociales sont plus complexes que nous fait croire le structuralisme. Plutôt que d'exister en tant que systèmes de communication, ou d'« échange symbolique» qui se perpétuent, les structures sociales sont sujettes à des forces externes; au pouvoir d'en haut et au désir 
d'en bas. L'introduction des concepts de désir et de pouvoir représente une fusion idiosyncrasique de Marx et de Freud. Ce sont les forces du pouvoir et du désir qui deviendront de plus en plus le centre d'intérêt de la théorie contre les modes de pensée institués.

Les systèmes sociaux ne peuvent pas être compris purement en termes d'eux-mêmes. Ils doivent être compris dans le contexte des relations de pouvoir mais aussi dans les termes de l'investissement et du désinvestissement du désir. Comme l'exprime Lyotard dans Dérive à partir de Marx et Freud :

[U]ne approche guidée par le seul modèle de la linguistique structurale ne permet pas de comprendre le fonctionnement de systèmes symboliques comme ceux que décrit Mauss, ni non plus l'apparition d'événements (« révolutionnaires») dans un système sémantiquement "bien réglé » comme le capitalisme moderne. Dans le premier cas comme dans le second, il y a une dimension de force qui échappe à la logique du signifiant: excès de puissance que l'échange symbolique ne parvient jamais à régler, et que la culture " primitive » thématise comme dette ; « désordre » qui secoue parfois le système capitaliste et y produit des événements d'abord interchangeables ( Le 23 mars », DMF, 310-11).

12 En tant que membre du groupe d'extrême-gauche Socialisme ou Barbarie pendant les années 1950 et 1960 (un groupe qui partage un grand nombre des idées-clés de mai 1968), mais aussi du Mouvement du 22 mars, Lyotard était très engagé politiquement. Il fait lui-même le lien entre les événements politiques et le développement de sa pensée politique pendant les années 1970 :

L'importance du mouvement du 22 mars tient aussi à ce qu'il oblige [...] à construire une conception du système capitaliste bureaucratique et de son désordre qui rompt vraiment aussi bien avec le discours des origines que celui des fins, avec Rousseau qu'avec Hegel, avec le spontanéisme qu'avec le bolchevisme. Ce "par-delà » que Marx a laissé en friche, c'est avec Freud (mais sans Marcuse ou Reich) qu'on peut l'entrevoir et l'esquisser grossièrement.

[...] Le mouvement s'est avéré de cette façon, prenant au dépourvu de qui est institué, pensé (y compris la pensée révolutionnaire), offrant une figure de ce qui est refoulé ou dénié dans cette société, une figure de son désir inconscient. C'est en considération de ce mode de "vérité " qu'il faut non pas faire sa place au mouvement au sein d'un système de connaissance, mais plutôt essayer de montrer comment il a défait la distribution des places imposée par le système capitaliste bureaucratique («Le 23 mars », DMF, 309-10).

Ce mémoire se centrera en grande partie sur la deuxième partie de Discours, figure, où Lyotard adopte un vocabulaire freudien. Le problème du rapport entre discours et figure, du langage et des forces qui la sous-tendent, est ici posé dans les termes du rapport entre l'art et ses formations fantasmatiques. L'art, pour Lyotard, montre la voie à une critique de l'idéologie, et comme le fantasme est, pour Freud, « le fait primitif de l'art » $(D M F, 55)$ la valeur de l'art dépend de son auto-reflexivité, ou de la distance qu'elle forge entre la forme et le contenu hallucinatoire. Cependant, une brève discussion des problèmes traités dans la première partie du livre nous permettra de comprendre pourquoi Lyotard considère nécessaire d'adopter en premier lieu un vocabulaire psychanalytique. 


\section{Discours, figure I : Une dialectique hégélienne en tant que forme, une dialectique négative en tant que contenu}

14 La première partie de Discours, figure peut donc être interprétée comme une tentative phénoménologique de démontrer l'insuffisance d'une tradition intellectuelle logocentrique quand il s'agit de tenir compte de la production du sens dans les systèmes symboliques. Elle prend la forme d'une série de critiques de formes linguistiques et philosophiques qui empêchent le langage de s'ouvrir à son autre, le visible ou le référent. La séparation du sensible et du discursif forme l'idée centrale à ce stade.

Comme l'a suggéré David Carroll, la première partie de Discours, figure, peut être considérée comme une dialectique hégélienne dans sa forme, mais qui est néanmoins fragmentée de plus en plus dans son contenu. Ceci mène à une forme de dialectique négative et une crise de la connaissance qui atteignent leur point le plus haut avec Mallarmé, chez qui la poétique triomphe sur la dialectique :

Si Hegel représente pour Lyotard le moment dialectique-métaphysique de la totalisation, une synthèse de toute la philosophie à partir de Platon, le structuralisme (Saussure) et la phénoménologie critique (Merleau-Ponty) sont traités comme des formes différentes de la fragmentation de ce processus de totalisation et puis sont montés l'un contre l'autre afin de révéler les limitations de chaque forme de fragmentation et négation non-dialectisable. Le rôle de la poétique critique de Mallarmé est d'incarner l'extrême limite de chaque forme de négation ${ }^{10}$.

17 Les pages qui suivent résumeront brièvement les plusieurs "moments" de cette dialectique.

\section{1. Saussure}

Même si Lyotard accepte la vision structuraliste du langage comme système de relations différentielles qui précèdent la parole, il ne concède pas que nous pouvons limiter notre compréhension du langage à ce seul système. Pour lui, ce que le structuralisme ne réfléchit pas est la dimension référentielle du langage, le fait que le langage cherche à saisir quelque chose : « ce ne sont pas des signes qui sont donnés, mais quelque chose à signifier ${ }^{11} »$. Certes, il y a une dimension universelle et fermée au langage, mais il y a aussi une dimension particulière, une dimension ouverte :

[...] il y a un fait que notre expérience de la parole ne nous permet pas de récuser, c'est que tout discours est lancé en direction de quelque chose qu'il cherche à saisir, qu'il est incomplet et ouvert, un peu comme le champ visuel est partiel, borné et prolongé par un horizon. Comment tenir compte de cette propriété quasiment visuelle du parler à partir de cet objet clos en principe, refermé sur soi en une totalité suffisante, qu'est le système de la langue ? (DF, 32).

La question est de savoir comment articuler ces deux aspects apparemment contradictoires. Quel est le rapport entre les dimensions structurales et «quasiment visuelles » du langage?

La façon dont Lyotard rend compte de cette dimension double du langage est de postuler deux formes différentes de la négativité. D’abord, il y a la négativité dans le 
système même, comme quand Saussure prétend que le langage se compose de différences sans termes positifs. Mais il y a aussi ce que Lyotard caractérise comme une «négativité intentionnelle ${ }^{12}$ ». Avec cette deuxième forme de la négativité, la négation n'est pas seulement vue comme une caractéristique du discours, mais comme ce qui génère le discours en premier lieu :

Le Non ne doit pas alors être pris seulement comme la position de l'exclusion au sein du système de la langue, on peut, et il faut, l'entendre aussi comme la position de l'exclusion au sein de laquelle s'actualise tout discours. La négation n'est pas seulement la qualité du jugement, elle est sa possibilité ; pas seulement une catégorie du discours, mais son lieu: le parleur s'est arraché à ce dont il parle, ou cela s'est arraché à lui, et il ne cesse, en parlant, de le tenir de loin, comme l'objet de son discours, dans une « vision» $(D F, 118)$.

\section{2. La phénoménologie}

21 La phénoménologie essaie de réconcilier la négativité du système avec la négativité de la transcendance. En essayant de découvrir un espace en dessous de la relation sujetobjet, un espace dans lequel notre contact avec les choses est intuitif, avant la verbalisation, Merleau-Ponty contourne les catégories du sujet et de l'objet sans pourtant essayer, comme le fait Saussure, d'absorber le sensible dans le dicible.

Or malgré le fait que Lyotard partage la distinction faite par la phénoménologie entre le langage et le monde sensible ainsi que son rejet de l'affirmation structuraliste qui tient que la signification est entièrement transmise par le langage, Lyotard, en fin de compte, va dans un autre sens. Ceci est dû au fait qu'il accepte l'idée structuraliste que le langage, en tant que système de relations différentielles, précède et rend possible la parole de l'individu. Comme nous l'avons vu, pour Lyotard, le langage est «ce qui a rendu possible et ne cesse de rendre possible la polarisation de l'objet et du sujet, de la chose et de l'image, de la science et de l'art ${ }^{13}$ ». Le sujet et l'objet sont des «fragments en provenance d'une déflagration première dont le langage a été l'étincelle initiale ${ }^{14}$ ". La subjectivité est donc inextricablement liée au langage plutôt que, comme la phénoménologie le pense, en quelque sorte en dehors de lui.

Étant donné la primauté du "système anonyme ${ }^{15}$ » du langage, la tentative de la phénoménologie de fonder le sens dans un geste pré-linguistique, comme si la parole précédait la langue, n'est pas convaincante. Pour Lyotard, il n'y a pas de parole avant le langage, car la signification est un produit du système linguistique lui-même. La pensée critique sur le langage ne peut pas se contenter d'un renversement dialectique du langage de la même façon que la critique socio-politique cherche à renverser le système social. Il est impossible d'instaurer un nouveau langage de la même façon qu'on pourrait imaginer d'instaurer une nouvelle société : tandis que «la "dialectique" peut paraître une expression légitime de la réalité socio-économique du capitalisme [...] [t]el n'est pas le cas pour le langage ${ }^{16} »$. Lyotard continue :

[L]a critique socio-politique ne peut s'effectuer qu'en rompant avec les contraintes qui caractérisent le système capitaliste, qu'en portant atteinte aux écarts invariants selon lesquels ses termes sont distribués. Au contraire un discours sur le langage se fait entièrement dans le langage, et s'il peut lui arriver de porter atteinte aux invariances sémantiques, syntaxiques, voire phonologiques, c'est toujours, sous peine de non-sens, dans les limites de la communicabilité, c'est-à-dire sous la loi de la langue. [...] La langue précède la parole en ceci qu'aucun locuteur ne peut prétendre avoir, même modestement, institué la première, ni songer à en instituer 
une autre, et que toute tentative de la réformer se heurte à ce cercle qu'elle est notre outillage, tout l'outillage dont nous disposons pour la changer $(D F, 34)$.

\section{désir figural. Or, Dews souligne la continuité dans la pensée de Lyotard en dépit de} cette rupture apparente. Dews suggère que « la nature non-articulée et changeante du champ perceptif pourrait être prise comme une sorte d'analogue pour ce que Freud décrit le "processus primaire", la mobilité des cathexis dans l'inconscient ${ }^{19}{ }^{\text {». }}$

\section{3. Hegel} Discours, figure, est la dialectique hégélienne, pour la façon dont elle essaie de dire l'indicible. Comme l'exprime Lyotard, Hegel,

[...] n'a évidemment pas de mal à manifester dans son discours que la singularité revendiquée par la certitude sensible est impensable, indicible, et qu'il faut la fonder, alors il faut la dire, donc la placer dans un champ sémantique qui l'introduit 
à l'universalité. Mais ce qu'il ne parvient pas à incorporer, c'est le montrer, le manifester lui-même $(D F, 41)$. significatif), il ne peut pas incorporer l'acte de montrer: «La négativité qui ouvre sa distance entre l'œil et l'objet est celle de la forme, non celle de la catégorie. Le sensible est dans un écart insuppressible avec le sensé20 ${ }^{2}$. Le problème vient du fait d'ontologiser le langage : « le langage ne constitue pas [l'épaisseur de la chose] [...] il en est la raison phénoménologique ${ }^{21} »$. Lyotard lance un défi non seulement à la dialectique hégélienne ici, mais aussi à ceux qui, comme Hegel, essayaient d'assimiler le sensible au rationnel, en surmontant la séparation :

Quand la dialectique étend sa prétention à l'objet, à l'autre du concept qu'est le sensible, alors elle excède sa propre portée, et de savoir se mue en idéologie. On peut bien affirmer que tout est dicible, c'est vrai ; mais ce qui ne l'est pas, c'est que la signification du discours recueille tout le sens du dicible. On peut dire que l'arbre est vert, mais on n'aura pas la couleur dans la phrase [...] L'espoir d'enfermer l'objet tout entier dans le discours doit être abandonné si on le nourrit de cette façon-là, et c'est à quoi il faut s'en prendre dans Hegel $(D F, 52)$.

\section{4. Mallarmé et la surréflexion}

31 Ayant critiqué le logocentrisme de Saussure et de Hegel et le naturalisme naï ${ }^{22}$ de la phénoménologie, Lyotard se demande par la suite à quoi ressemblerait une philosophie qui nie son propre désir pour la totalité, qui habite farouchement la tension entre le sensible et le discours. Pour répondre à cette question, il a recours à l'art et au concept merleau-pontien de la "surréflexion ». Ceci nous ramène à l'idée, présentée plus haut, que pour Lyotard, il n'est pas question de devenir peintre, c'est-à-dire, de travailler à l'extérieur du discours, mais d'apprendre de la peinture. Le philosophe doit apprendre à " peindre » avec les mots:

Tant que le philosophe ne se fera pas peintre également, il lui faudra rester dans l'orbe de la langue, de l'inconscience structurale. Mais l'effort que peut encore accomplir la parole, c'est de réaliser sur son langage même cette transgression des espacements, cette mobilité, cette profondeur qui caractérisent la référence du discours et que le structuralisme omet. Ce n'est pas dessiner ou peindre même, c'est peindre et dessiner avec et dans les mots ; Merleau-Ponty appelait cela surréflexion $(D F, 53)$.

Or comment « peindre » avec les mots ? Comment la transgression, que Lyotard appelle peindre avec les mots, marche-t-elle? Lyotard insiste sur le fait que le philosophe refuse de respecter les intervalles et les règles déterminés par le système linguistique pour la communication. Une transparence de communication donne lieu à l'ambiguïté et la suggestivité et la métaphore devient une caractéristique fondamentale du langage. Les mots doivent être traités comme des «choses». Cette idée rappelle les trois dimensions du sens de Barthes dans L'Obvie et l'obtus ${ }^{23}$. Ce que préconise Lyotard ici est proche du «troisième sens » de Barthes, qui ouvre le champ du sens, perturbe le système établi de la signification, en restant ouvert aux liaisons hasardeuses, témoignant du sensible. Comme l'exprime Barthes :

Il me semble distinguer trois niveaux de sens :

Un niveau informatif, ce niveau est celui de la communication.

Un niveau symbolique, et ce second niveau, dans son ensemble, est celui de la signification.

Est-ce tout? Non. Je lis, je reçois, évident, erratique et têtu, un troisième sens. Je ne 
sais quel est son signifié, du moins je n'arrive pas à le nommer, ce troisième niveau est celui de la signifiance.

Le sens symbolique s'impose à moi par une double détermination: il est intentionnel [...] et il est prélevé dans une sorte de lexique général, commun, des symboles: c'est un sens qui va au-devant de moi. Je propose d'appeler ce signe complet le sens obvie. Quant à l'autre sens, le troisième, celui qui «vient en trop ", comme un supplément que mon intellection ne parvient pas bien à absorber, à la fois têtu et fuyant, lisse et échappé, je propose de l'appeler le sens obtus ${ }^{24}$.

L'obtu, ce qui transgresse l'obvie, est central dans Discours, figure. La poésie et les rêves servent comme modèles pour Lyotard pour montrer comment la communication et la signification peuvent être transgressées. Pour lui, ils exemplifient ce que veut dire Merleau-Ponty par la surréflexion :

Si la surréflexion peut s'incliner du côté de la poésie ou du rêve, c'est que l'un comme l'autre suppose évidemment la langue, mais la langue défaite, évidemment l'intervalle invariant de la table, mais cet intervalle travaillé et soumis à distorsion, « vibrant jusqu'à se disjoindre ». Défaire le code, sans pourtant détruire le message, mais au contraire en délivrant le sens, les réserves sémantiques latérales, que masque la parole charpentée, c'est accomplir un ensemble d'opérations que Freud nommait travail du rêve $[. .].(D F, 55)$.

Plus le discours philosophique est proche de la poésie et des rêves, plus transgressif il est :

Comment les deux formes de la négation se recoupent, comment celle du montrer peut entrer dans celle du discourir, comment le texte peut se faire figure, voilà ce qui intéresse la surréflexion, ce qui peut la guider. On ne s'étonnera pas qu'ici aussi la philosophie vienne trop tard et qu'elle ait tout à apprendre des poètes $(D F, 60)$.

Mallarmé est le poète sur lequel Lyotard se concentre, car la poésie de Mallarmé rend visible la tension entre la négativité au travail dans le discours, qui est de nature purement systématique, et la négativité transcendante en dehors du discours mais de laquelle néanmoins il dépend. En tant qu'exemple du troisième sens de Barthes, la « poésie radicale » de Mallarmé rend visible la « coexistence des deux négativités, celle de la structure et celle de la forme ${ }^{25} »$. Avec Un coup de dés jamais n'abolira le hasard, dit Lyotard,

Mallarmé dérobe radicalement le langage articulé à sa fonction prosaïque, de communication; il révèle en lui un pouvoir qui l'excède, le pouvoir d'être « vu » et pas seulement lu-entendu; le pouvoir de figurer et pas seulement de signifier (DF, 62).

Une telle poésie cherche une "figure de la pensée " (Valéry), en perturbant les fondations mêmes du discours :

Elle descend jusqu'au plus bas échelon de la hiérarchie des unités linguistiques et elle importe l'agitation, l'insurrection, non plus seulement dans la prosodie traditionnelle, c'est-à-dire dans les contraintes d'appoint par lesquelles le discours poétique est connoté, mais dans les règles fondamentales du discours communicable lui-même $(D F, 62)$.

Le pouvoir extra-discursif d'une poésie radicale comme celle de Mallarmé est enraciné dans sa nature spatiale, dans la ligne par opposition à la lettre, dans la forme visuelle du poème mais aussi dans la fonction métaphorique ou figurative de son langage.

Lyotard ne s'intéresse pas à l'originalité de la poésie, mais à la façon dont la poésie et l'art modernistes poussent l'écart entre le langage et le monde à bout, le radicalisent, pour que le langage devienne quasiment personnel : 
La poétique de Mallarmé paraît mener à son terme la propriété fondamentale du langage, que Saussure élaborait en même temps, l'arbitraire du signe par rapport à l'objet qu'il signifie. L'«élimination » mallarméenne, c'est l'approfondissement de l'espacement de référence comme distance infranchissable qui sépare le verbe et la chose et garantit au premier sa portée d'idéalité $(D F, 63)$.

Un exemple extrême de cette tendance serait les compositions musicales d'Anton Webern. Pour le théoricien allemand T.W. Adorno, Webern objectifie la subjectivité, il emmène l'expressionnisme à un point où la subjectivité est, en quelque sorte, invertie. Comme l'exprime Adorno :

La difficulté et l'exclusivité des œuvres de Webern sont dues au fait que dans ses œuvres, la tension entre forme donnée et liberté personnelle est complètement dissolue, car ces œuvres attribuent le droit de donner forme au seul individu. Alors qu'il est d'habitude précisément à travers la tension qui gouverne le rapport entre l'individu [...] et la communauté [...] que l'intelligibilité de la musique [...] est achevée, ce que la communauté trouve intelligible sert à ratifier l'individu et ouvre la communauté à la volonté explosive de l'individu. Dans le cas de Webern, la volonté de l'individu a explosé définitivement la gamme constitutive de formes qui correspondent à la communautée ${ }^{26}$.

Or, à la différence de l'esthétisme extrême de Webern qui dissout la tension significative entre le particulier et l'universel, la poésie qui intéresse Lyotard cherche plutôt à maintenir le pôle de référence, tout en le distanciant, le problématisant, dans une tentative paradoxale de ramener le langage à son autre :

L'œuvre, parce qu'elle parle dans la vacance de toute condition extrinsèque au pur discours et ne donne que la notion, doit abolir le hasard, c'est-à-dire l'autre du langage, sa référence. Mais ce que dit le Coup de dés, c'est que le langage n'abolit pas son autre, que l'œuvre elle-même fait partie du sensible [...] Que le langage et son autre soient inséparables, c'est la leçon [...] de Mallarmé. Mais on va voir comment cette indissociabilité, Mallarmé entend qu'on s'y consacre et s'y soumette : non d'un coup de chapeau donné poliment du sein du langage, en la signifiant; mais en la faisant voir $[\ldots](D F, 64)$.

41 Mallarmé donc rend visible le rapport, quoique problématique, entre le langage et le monde, en ouvrant l'espace hermétique du langage et en offrant une nouvelle configuration. Il réintroduit le référent dans le discours, il élargit la lettre pour inclure la ligne. Le poète donc représente ce que cherchait Merleau-Ponty : « Il a fait entrer en lui le sensible, il ne parle plus seulement par sa signification, il exprime par ses blancs, ses corps, le pli de ses pages $^{27} »$. Le référent réside non pas dans l'existence physique des mots, mais dans la nouveauté de leur forme, leur distribution :

La poésie radicale exhibe qu'il y a du sensible en puissance dans le sensé. Où est-il logé ? Pas directement dans la "matière » des mots (quelle est-elle au juste ? leur figure écrite, imprimée ? leur sonorité ? la « couleur » des lettres ?), mais dans leur arrangement. On va dire que le sensé aussi, la signification, tient entièrement à l'arrangement des unités. Mais notre arrangement, la dispersion poétique sur la page est un dérangement de l'arrangement qui fait la signification, il dérange la communication $(D F, 69)$.

L'effondrement de l'opposition entre discours et figure dans la poésie de Mallarmé est compris par Lyotard comme une inversion de la dialectique hégélienne. Chez Hegel, le discursif assimile le sensible. Chez Mallarmé le sensible nie et assimile le discursif. Ici la différence n'est pas surmontée au nom de l'identité, comme chez Hegel, mais l'identité est déstabilisée au nom de la différence. Le poème critique est donc un discours-figure qui témoigne d'une crise de la connaissance : 
Avec Mallarmé, la crise du savoir s'approfondit : car non seulement elle se dit dans un discours de signification qui en un sens maintient le savoir dans son élément et dans sa présomption, mais la réflexion saisit précisément ce discours de signification comme un leurre, comme un tour que le savoir joue au non-savoir, et elle déjoue ce tour en jouant le jeu du recessus, en plaçant l'espace sensible et libidinal dans son discours même, le tour du trop. Ainsi est-il exprimé que la vraie notion, c'est la sensualité qui la donne, et que la transcendance est immanente ( $D F$, 70).

La leçon de la première partie de Discours, figure, est que le discursif ne peut pas prétendre à l'autonomie et l'auto-suffisance. Nous avons vu avec Saussure que la linguistique structurelle, tandis qu'elle est correcte, selon Lyotard, dans la mesure où elle démontre la primauté de langue par rapport à la parole, reste une description partielle de l'engendrement du sens car, en réduisant le sens à un système abstrait, elle ignore la négativité intentionnelle, la dimension référentielle aux bords du système. La phénoménologie de Merleau-Ponty, avec sa notion d'un corps qui n'est ni sujet ni objet, mais un mode d'être équivoque qui affecte toute la connaissance, fournit à Lyotard une voie au-delà l'insuffisance du structuralisme. La phénoménologie problématise le dualisme cartésien en refusant d'assimiler le voir au dire ${ }^{28}$. Or, elle s'effondre quand elle essaie de saisir directement le contact primordial du corps avec les choses avant le langage. Comme le montre Saussure, le langage, en tant que système de communication, est toujours déjà partout; nous ne pouvons donc pas contourner le médiateur suprême du langage. Or, comme nous l'avons vu, ceci ne veut pas dire pour Lyotard qu'on doit réduire le sens à un "effet " du mouvement transcendantal de la différence (Derrida) ${ }^{29}$, ou qu'on doit abandonner notre tentative de témoigner de ce que le langage relègue (Wittgenstein). Le logocentrisme de Hegel (dont Lyotard retrouve la trace dans Platon, mais qui continue à exercer une influence, trouvant son expression moderne selon Lyotard dans la préoccupation chez Derrida pour la suspension de l'immédiateté dans le langage), est critiqué pour sa relégation à un statut secondaire de la « couleur » du monde au nom de l'Idée. Cette crise du langage et de la connaissance atteint son apothéose avec la poésie de Mallarmé, une poésie critique qui figure l'altérité. La poétique de crise de Mallarmé défait la prétention du langage à l'ordre, sa suppression de l'altérité au nom de la totalité, et ceci, pour Lyotard, constitue sa valeur critique. Car la critique est liée inextricablement à un témoignage de l'insuffisance du langage et des systèmes symboliques, en donnant voix à ce qui les défait depuis l'intérieur. L'altérité figurale perturbe le langage de façon immanente, d'où sa dimension critique, car, pour Lyotard, il n'est jamais possible de capturer cette altérité entièrement à travers la théorie.

\section{Discours, figure II : L'art et le fantasme. De la phénoménologie à la psychanalyse}

Avec le triomphe de la poétique, Lyotard arrive cependant à une sorte d'impasse. Car avec Mallarmé, le figural est devenu en quelque sorte trop déterminé, trop lié à une pratique poétique particulière. C'est comme si la figure avait replacé le discours, réduisant la tension entre les deux. Or, comme Lyotard l'a montré, cette tension, cette instabilité, est essentielle si la figure doit avoir une potentielle critique. Avec le tournant dans la deuxième partie de Discours, figure vers une définition de l'art non pas en termes visuels, mais en termes de désir, empruntant un vocabulaire freudien, 
Lyotard essaie de sortir de cette impasse et de rendre au figural sa capacité transgressive.

\section{1. Entzweiung et la troisième négation}

Comme nous l'avons vu dans la section précédente, bien que le langage soit un outil insuffisant pour accéder à la réalité, il n'y a pas d'accès à la réalité en dehors du langage. Avec l'introduction de Freud, Lyotard postule une troisième forme de la négation, l'Entzweiung. Cette troisième forme de négation est considérée par Lyotard comme étant plus fondamentale que la première, où la signification est déterminée à l'intérieur d'un système linguistique, et que la deuxième, qui se trouve à l'extérieur du système mais auquel, néanmoins, le système se réfère. L'Entzweiung nous montre que le langage implique la négation de l'objet :

Ce que nous ne pouvons pas dire, nous le sommes, car, pour dire quelque chose, il faut le nier, en le mettant à distance de nous-mêmes comme ce qui est Autre que nous $(D F, 109)$.

Pour Lyotard, la psychanalyse est le seul discours à avoir rendu compte de cette négation primordiale et constitutive, par contraste aux négations du langage et de la référence, négations qui appartiennent au phénomène du langage.

Comme nous l'avons vu, la deuxième partie de Discours, figure démontre que, par surcroît, le langage entraîne l'exclusion du désir, une force avec laquelle il est lié inextricablement. Avec la séparation originaire, la réalité s'installe au pôle opposé à la subjectivité : l'acte de parole engendre la réalité. Comme l'exprime Gualandi, «si l'objectivité est l'enjeu du discours qui se fait "science", l'enjeu d'une philosophie qui refuse toute totalisation spéculative, c'est de montrer que le non-dire se cache dans le dire, et qu'à l'origine de tout processus de connaissance il y a du désir ${ }^{30}$ ".

La figure ne peut pas exister sans le discours, car elle en est un effet. Elle est le signe du non-dit, du « refoulé », de ce qui est nié par le discours. Avec le concept d'Entzweiung, le figural cesse d'être défini en termes de visible et devient un signe du processus primaire.

La tâche de la théorie devient maintenant de nous ramener au moment de la scission, de l'apparition du langage, qui est aussi le moment auquel l'autre du langage est refoulé. Ceci fait écho avec la façon dont la psychanalyse vise à découvrir les scènes originaires qui structurent notre conscient.

\section{L'art et le rêve}

Avec l'introduction de l'Entzweiung, Lyotard cherche à aller au-delà d'un art qui révèle le visible au bord du langage, comme le fait Mallarmé. Car c'est le désir, et non plus le visible, qui déforme les codes du langage. Or, comment le désir déforme-t-il les codes du langage ? Quel est le rapport entre le désir et la réalité ? En cherchant à dépasser une esthétique phénoménologique pour aller vers une esthétique (ou énergétique) libidinale, Lyotard se tourne vers l'étude des rêves de Freud. Car, en commençant par une distinction entre les pensées de rêve " manifestes » et " latentes », Freud démontre comment le rêve travaille le contenu latent pour le travestir et le transfigurer. Bien que, comme nous allons le voir, Lyotard prenne soin de distinguer le travail du rêve de l'art, 
le travail du rêve montre comment le désir déforme les structures de la représentation, et fournit donc un modèle pour une pratique esthétique critique.

51 Comme on le sait, les tentatives de Freud pour accéder aux opérations de l'inconscient et au contenu réprimé dans la pensée consciente l'ont amené à étudier en profondeur les fantasmes de la vie nocturne, les représentations que nous fabriquons pendant notre sommeil. D'où les célèbres mots de Freud, «L'interprétation des rêves est la voie royale qui mène à l'étude de l'inconscient $[. . .]^{31}$ ». Le rêve, selon Freud, est un accomplissement hallucinatoire de désirs réprimés. Compromis entre la censure et l'expression directe, il donne voix aux affects qui ne sont pas capables de trouver leur expression dans la vie diurne normale. Lyotard est très influencé par l'essai de Freud «Le travail du rêve » de L'interprétation des rêves, car il montre comment les processus inconscients pourraient «faire œuvre».

Selon l'essai de Freud, le rêve, à travers lequel des vœux potentiellement perturbants ou inacceptables sont rendus acceptables, entraîne des procédés de condensation, de déplacement, de représentation et de symbolisation. Freud fait allusion à un autre procédé qu'il nomme la révision secondaire. Ce dernier tisse les événements du rêve en un tout cohérent, tout en transfigurant encore plus le contenu originel de rêve. Selon Freud, l'analyse des matières brutes des rêves selon ses procédés peut nous emmener vers le contenu originel, avant que la censure ait eu lieu. C'est dans ce but qu'il établit une distinction entre le "contenu manifeste » (l'apparence) et le contenu latent (la réalité ou les vœux sous-jacents).

L'insistance de Lyotard dans la deuxième partie de Discours, figure, sur la " connivence radicale de la figure et du désir ${ }^{32}$ » est, comme nous l'avons vu, aussi un tournant vers Freud. La nature changeante du champ visuel trouve un corrélat dans les investissements mobiles du processus primaire.

Que veut dire Freud précisément par travail du rêve et comment ce travail, le travail de l'inconscient, se distingue-t-il de la pensée éveillée?

\section{1. Travail vs pensée}

L'assertion fondamentale de "Travail de rêve » est qu'il y a une différence qualitative entre la pensée éveillée (Gedanke) et le travail (Arbeit). Cette distinction peut être comparée à l'opposition hégélienne entre le sensible et le conceptuel. Cependant, le rapport dialectique entre les deux, présent dans le système de Hegel, est abandonné dans la conception de Freud. Avec Freud, le sensible est disloqué, ou libéré, du conscient $^{33}$. Voici pourquoi, comme nous allons voir, dans l'esthétique freudienne de Lyotard la déformation de la forme est plus importante que la formation de la forme, car la formation de la forme est liée au conscient et à la pensée.

\section{2. La forme comme transformation}

La phrase de Freud qui, pour Lyotard, est peut-être l'essentielle, et que le philosophe prend comme titre d'un de ses chapitres dans Discours, figure, est, « [Le travail de rêve] ne pense, ne calcule, ne juge absolument pas, mais se borne à ceci : donner une autre forme $^{34}$ ». Dans une note ajoutée en 1909, Freud remarque, «Le rêve n'est au fond rien d'autre qu'une forme particulière de notre, forme qui est rendue possible par les 
conditions de l'état de sommeil. C'est le travail de rêve qui produit cette forme et il est, lui seul, ce qu'il y a d'essentiel dans le rêve, ce qui explique sa particularité35 $»$.

Or qu'est-ce que cette non-forme paradoxale, une forme qui résulte de la déformation même de la forme? Avec le rêve, la forme n'est plus du côté de l'unité, qui implique forcément une forme de stase ou de finitude, mais du côté de la transformation, du changement et du mouvement. La forme, autrement dit, devient processus et non plus produit, la preuve d'un désir comme transformation plutôt qu'un désir comme investissement.

Si le rêve, pour Freud, n'est pas pensé de façon ordinaire, mais en tant que forme de pensée spéciale qu'il nomme travail, qui travaille? Ceci ne peut pas être le travail ordinaire d'un sujet conscient car le travail a lieu pendant le sommeil du sujet. Pour Freud, comme nous l'avons vu, la force derrière le travail du rêve est la force du désir ; le rêve est une forme de fantasme. Derrière le rêve, il y a le désir, c'est le désir qui rend visible sa présence à travers la forme : «Le rêve n'est pas la parole du désir, mais son œuvre ${ }^{36}$ ». Le désir n'est pas communiqué, il est senti.

L'œuvre du désir comporte une violence, la violence d'une transgression qui encore une fois rappelle l'Entzweiung: «Cette violence est primordiale: l'accomplissement imaginaire du désir consiste en cette transgression, qui réitère, dans l'atelier du rêve, ce qui s'est passé et ne cesse de se passer dans la fabrique du fantasme originaire ${ }^{37}$ ». La notion d'un fantasme originaire sera examinée de plus près dans la section VII. Il suffit de noter ici le rapport entre la transgression de la forme dans le rêve et la répétition ( la fabrique ») du fantasme originaire. Cette répétition implique le fait de mettre en scène l'accomplissement fantasmatique du désir.

\section{3. Latent et manifeste : quel rapport ?}

60 Pour Freud, les pensées latentes, la matière brute de la production du rêve, sont une forme de discours ou de texte : «Le discours qui est au fond du rêve est ce sur quoi le travail opère, celui-ci en fait sa matière ${ }^{38} »$. L'opposition établie par Freud entre le travail et la pensée est aussi une opposition entre le désir et le discours qui forme le matériel de l'activité productive du désir. Cette opposition est centrale pour comprendre le rapport entre le discours et le désir figural dans le rêve et c'est la nature de cette relation que Lyotard cherche à comprendre à travers Freud. En effet, comme le dit Lyotard, «Il convient, si l'on veut saisir vraiment l'intention de Freud, de prendre au sérieux l'opposition qu'il fait entre le Gedanke [pensées] et la Arbeit [travail], de prendre le "transformer" (umformen) du rêve au sérieux ${ }^{39}$ ". Le travail du rêve n'interprète pas les pensées latentes, mais les change. Le rapport Gendanke/Arbeit n'est pas un rapport d'interprétation. L'interprétation appartient à l'activité d'un sujet pensant qui dépend de l'abstraction d'un discours par rapport à son objet : «l'écart entre contenu latent (Traumgedanke) et contenu manifeste n'est pas du tout la distance vide, la transcendance, qui sépare un discours "normal" de son objet [...] Il n'est pas non plus celui qui sépare un texte et sa traduction dans une autre langue ${ }^{40} »$. La Arbeit change la nature du Gedanke, plutôt que d'abstraire à partir de lui. À travers la Arbeit, le Gedanke devient autre chose.

61 Si le rapport entre le travail et la pensée est un rapport de transformation, qu'est-ce qui est transformé précisément, et à quelle fin? Autrement dit, quelles sont les forces qui donnent lieu à l'événement du rêve ? Ce problème de la transformation créative, du 
rapport productif entre la pensée consciente et les procédés inconscients qui le soustendent, peut être compris comme le problème de fond de Discours, figure. Ceci est aussi le problème de la production du nouveau :

Le problème du travail du rêve est [...] celui de savoir comment, avec un énoncé pour matière, peut être produit un objet qualitativement différent, encore que signifiant (DF, 241).

Si les pensées inconscientes sont considérées par Freud comme un texte, «[d]e quelle manière un texte doit-il être travaillé pour que soit modifiée la nature de la position de sens qui y est logé ? ${ }^{41}$ »

\section{4. La distorsion (Enstellung)}

63 La notion de distorsion (Enstellung) est centrale pour une compréhension du travail chez Freud. Cette notion complique l'hypothèse de base de Freud qui tient que les rêves ont pour fonction le simple accomplissement du désir. En effet, le concept surgit de l'observation du fait que les rêves semblent souvent faire tout le contraire : «Freud se demande pourquoi, le rêve étant l'accomplissement d'un désir, son contenu présente souvent des échecs, des souhaits déçus, des désirs contrariés ${ }^{42}$ ».

Les opérations de la distorsion sont comprises comme la réponse à un besoin de censure dans le rêve. Le rêve est maintenant vu non pas comme un simple accomplissement du désir, mais comme l'accomplissement travesti d'un désir refoulé : « [L]'Enstellung a pour motif la censure et [il] fait de celle-ci un pouvoir exercé par une instance qui contraint le désir à se travestir [...] Le difficile n'est pas d'accomplir l'acte, mais de se débarrasser de ses traces ${ }^{43}$ ».

Avec cette idée, la simple opposition entre discours et figure devient de plus en plus problématique. Le désir désire-t-il sa propre censure ? Est-ce que le désir réside du côté du discours et de la figure?

La relation de transformation de latente à manifeste semble maintenant fonctionner pour dissimuler une transgression et elle le fait en changeant l'apparence de l'objet de répression, mais aussi en le mettant ailleurs, dans un nouveau contexte. Le parallèle entre le travail du rêve et le concept de la dissimulation dans L'Économie libidinale est clair $^{44}$. En cherchant à brouiller les traces de la transgression, l'Enstellung, la loi de la censure, crée du mouvement, et ce mouvement se passe en dehors de l'espace linguistique, en dehors des mouvements horizontaux, plats, qui appartiennent à cet espace. Le résultat des déplacements de l'Enstellung est la production d'une " épaisseur », d'une opacité.

Freud nous enseigne que « désir et répression naissent ensemble ${ }^{45}$ ». L'aspect violent du travail du rêve semble donc avoir deux sources, car il y a un véritable affrontement d'espaces au cœur du fantasme :

L'écrit appartient à un espace de lecture (lettres sans profondeur), l'opération de déplacement à une étendue gestuelle, visuelle, et le résultat du déplacement qui recueille en soi du lisible et du visible est illisible. C'est en cela qu'il y a quelque chose comme un meurtre : le désir avec sa dimension de profondeur défigure la table de la Loi. Et en même temps, du même coup, il est illisible, donc caché. Son occultation requiert la profondeur, qu'exclut le discours. Violence de la loi face au désir, violence du désir soulevant l'espace de la loi : nous avons ainsi les deux instances de la Traumarbeit, le vœu et la censure; et leurs deux violences, et l'indécidabilité de la première $(D F, 243)$. 
Comment la distorsion du rêve fonctionne-t-elle concrètement? Freud détaille ce que sont, pour lui, les quatre procédés du travail du rêve par lesquels la distorsion s'effectue. Chacun de ces procédés est important pour l'élaboration lyotardienne d'une esthétique figurale car elles fonctionnent en injectant l'opacité du sensible dans la transparence horizontale du discours, figurant ainsi l'inconscient: "chacune de ces opérations fait fond sur une spatialité qui, loin d'être celle où se tient la signification du discours (Traumgedanke), ne peut être que l'étendue plastique, sensible où le texte est supposé inscrit ${ }^{46} »$.

\section{Les quatre procédés mis en œuvre par le travail de rêve}

\section{1. La condensation}

69 La condensation explique la brièveté du rêve manifeste par rapport aux pensées du rêve. Elle implique la fusion d'idées différentes dans une image unique :

Le rêve est concis, pauvre et laconique, comparé à l'ampleur et à la richesse des pensées de rêve ${ }^{47}$. [...] [C]hacun des éléments du contenu du rêve se révèle être surdéterminé, être représenté de multiples façons dans les pensées du rêve ${ }^{48}$.

Ce processus de détermination multiple se manifeste dans la construction de personnes collectives ou composites et aussi dans des formations de mots qui ne semblent pas avoir de sens: les mots semblent être traités comme des objets. À travers la condensation, les mots deviennent des choses.

71 Comme l'exprime Lyotard :

La condensation doit être entendue comme un processus physique par lequel un ou des objets occupant un espace donné sont réduits à se loger en un plus petit volume [...] En conséquence, quand elle s'applique à un texte, elle a pour résultat de télescoper ou les signifiants [...] ou les signifiés [...] ou les deux, en des "objets" qui, en tout cas, ne sont plus spécifiquement linguistiques, et qui même sont spécifiquement non-linguistiques (DF, 243-4).

Elle exerce donc une certaine violence sur le langage, comprimant les écarts stables entre les unités linguistiques :

Écraser les unités signifiantes ou signifiées les unes contre les autres, les confondre, c'est négliger les écartements stables qui séparent les lettres, les mots d'un texte, mépriser les graphèmes invariants, distinctifs, dont ils sont faits, ignorer enfin l'espace du discours (DF 244).

\section{1. 1. Travail comme travestissement}

Qu'est-ce que la condensation nous dit sur le rapport entre le texte et le désir? Le contenu manifeste est-il un texte qui cache le désir derrière lui ? Si ceci était le cas, la condensation serait un travail par lequel le désir se travestit, le désir étant la force derrière le texte. Ou bien est-ce que le contenu manifeste, de l'autre côté, est comme l'ancien texte, le texte des pensées latentes, «forcé », travaillé ? Dans ce cas, le contenu manifeste ne serait pas un texte. Dans la première option, le contenu manifeste est un texte qui sert à dissimuler le désir, qui serait la matière première. Dans la deuxième, le texte serait la matière première, la pensée latente, et le rêve serait plutôt une chose, un produit, le résultat des opérations du désir sur le texte sous-jacent. 
74 Freud pense que les pensées latentes fonctionnent comme la pensée éveillée. Les pensées du rêve ont toutes les caractéristiques du processus de pensée que nous connaissons dans la vie éveillée : elles sont comme un texte. Quand elles sont assujetties à la pression du travail du rêve, ces pensées se sont dispersées, et les relations logiques entre les pensées de rêve ne sont pas respectées. Pour Freud, donc, il y a une distinction claire entre la condensation, le résultat d'une force de répression ou de censure, et le désir. Le désir serait donc le discours initial des pensées de rêve qui sont élaborées par la suite à travers la force de la censure, « la force qui écrase le texte, broie et mélange ses unités, est la censure. À suivre cette explication, il faudrait admettre que le désir est le discours initial du Traumgedanke (pensées inconscientes), le travail de condensation (et toute l'élaboration) étant le fait de la censure ${ }^{49} »$. Or cette vision de la place du texte et du désir dans le travail du rêve est contestée par Lyotard. Pour lui, la situation est plus complexe, car le désir est ambivalent par sa nature même. Il n'y a pas un être pensant entre la pensée du rêve et l'interprète du rêve qui décide de censurer ceci ou cela, c'est le désir même qui se travestit: "le désir est d'emblée texte bouleversé, le travestissement n'est pas le fait d'une intention de tromper qui serait celle du désir, mais le travail même est travestissement parce qu'il est violence sur l'espace linguistique ${ }^{50}$ ». Autrement dit, l'espace linguistique est le seul exutoire du désir : «Pas besoin d'imaginer que le Ça a quelque chose derrière la tête. "Le travail du rêve ne pense pas". La mobilité du processus primaire trompe par elle-même ${ }^{51}$ ".

Cette divergence entre Lyotard et Freud est importante, car l'ambivalence extrême au cœur du désir est cruciale pour la distinction faite par Lyotard entre l'art et le rêve et sa notion de critique. En effet, l'« oubli » de cette ambivalence dans des essais comme « Dérives » $(1972)^{52}$ et «Adorno come diavolo » $(1972)^{53}$ menace d'ébranler le projet critique de Lyotard, comme nous allons le voir par la suite.

Si l'idée d'une force pure d'un côté et de l'autre un discours est trop simple, si le travail est lui-même travestissement, comment le désir, les pensées du rêve et la censure s'articulent-ils? Le fantasme originaire, duquel le rêve est une répétition, est à la fois discours et figure, lettre et ligne. C'est le discours du désir qui constitue la matrice du fantasme originaire. La finalité du rêve est maintenant de répéter le fantasme originaire, mais en même temps de travestir cette répétition, «à la fois d'accomplir le désir, de répéter la forme matricielle en l'imprimant sur un matériel, et de le travestir, d'habiller cette forme avec des éléments issus de la réalité ${ }^{54} »$. Et l'intérêt du rêve n'est pas dans le contenu, qu'il faudrait dévoiler en essayant d'interpréter les pensées manifestes. Pour Lyotard, tout l'intérêt du rêve repose dans l'acte, l'acte de travestir : «Ce n'est pas le contenu du rêve qui accomplirait le désir, c'est l'acte de rêver, de phantasieren, parce que la Phantasie est transgression ${ }^{55}$ »

\section{2. Le déplacement}

77 La deuxième opération du rêve est le déplacement. Celle-ci décrit le processus par lequel le travail du rêve exige une transvaluation psychique de la matière du rêve :

Nous ne sommes pas loin d'avoir l'idée que se manifeste dans le travail de rêve une puissance psychique qui, d'une part, dépouille de leur intensité les éléments ayant une haute valeur psychique et, d'autre part, crée par la voie de la surdétermination, à partir d'éléments ayant une valeur moindre, de nouvelles valeurs qui parviennent ensuite dans le contenu de rêve. S'il en va ainsi, c'est que des intensités psychiques de chacun des éléments - transfert et déplacement qui ont pour conséquence 
visible les versions distinctes du texte entre le contenu de rêve et les pensées de rêve. Le processus que nous supposons ainsi est bel et bien la pièce essentielle du travail de rêve; il mérite le nom de déplacement de rêve ${ }^{56}$. oblige le désir à se travestir. À travers ce processus, une idée ou une image potentiellement perturbante qui appartient aux pensées latentes du rêve est remplacée par quelque chose de plus acceptable :

[L]a déformation de rêve nous est déjà connue; nous l'avons ramenée à la censure qu'exerce dans la vie de pensée une instance psychique à l'encontre d'une autre. Le déplacement de rêve est un des principaux moyens pour parvenir à cette déformation. Is fecit, cui profuit. Nous pouvons supposer que le déplacement de rêve se produit du fait de l'influence de cette censure, la défense endopsychique ${ }^{57}$.

Le déplacement et la condensation travaillent ensemble pour créer la structure particulière du rêve. En effet, pour Freud, le déplacement prépare la voie à la condensation. Lyotard décrit la relation de la façon suivante :

On a montré celle-ci [la condensation] liée à la surdétermination, mais surdéterminer suppose des modifications d'accent dans le texte initial de la pensée du rêve. En se condensant, celle-ci écrase certaines parties du discours, en laisse au contraire d'autres visibles. Prenez un texte écrit sur une feuille, froissez la feuille, les parties du discours y prennent, au sens propre, du relief. Imaginez qu'avant que la poignée de la condensation comprime la pensée du rêve, le déplacement ait renforcé certaines zones du texte de façon que lors de la contraction, elles résistent, restent lisibles. Le résultat est la « différence textuelle » entre Trauminhalt [contenu manifeste du rêve] et Traumgedanke [pensées latentes inconscientes] (DF, 247).

Ce qui est rendu visible à travers ces opérations est, cette fois, la différence textuelle. Le texte du rêve, comme un mixte latente/manifeste, devient une mobilité immobile ${ }^{58}$. Encore une fois, l'idée d'un désir qui est à la fois mouvement et stase est évoquée. Lyotard donne l'exemple de l'affiche publicitaire du film de Frédéric Rossif, Révolution d'octobre:

Les lettres du titre sont déformées de manière à produire le sentiment qu'un vent fait bouger le plan où elles sont écrites [...] Pourtant ce n'est qu'au début de la condensation. Si le vent soufflait plus fort, [...] certaines lettres disparaitraient complètement dans les replis, d'autres changeraient bel et bien de nature [...] Il arriverait que Révolution d'Octobre se lise Révon d'Ore, s'entende "Rêvons d'or " [...] Mais une telle Entstellung a nécessité un "choix» préalable; dans notre exemple, il faut que ce soient le début (RÉV, D'O) et la fin (ON, RE) qui restent visibles, qui résistent «au vent». Ce choix, c'est le travail de déplacement qui l'effectue en renforçant certaines zones du tissu, en les rendant plus rigides, c'est-àdire en leur donnant la possibilité de maintenir localement le texte " premier ». On peut imaginer la « différence textuelle » de cette manière. Il reste évidemment à le concevoir : si le désir est l'élément de la mobilité (vent ici, ailleurs eau) qui froisse le texte, peut-il être aussi celui de la rigidité qui en conserve des parties lisibles? Je ne connais que la notion de Forme, de Fantasme, qui puisse satisfaire à cette exigence recroisée ( $D F$ p. 247-8).

81 Or comment le désir peut-il être à la fois une force perturbatrice et stabilisante ?

\section{3. Considérations sur la représentabilité (Rücksicht auf Darstellbarkeit)}

82 La troisième opération dans l'étude de Freud est la figurabilité, ou la représentation. Ceci peut être considéré comme un deuxième type de déplacement, un processus par 
lequel les pensées sont transformées en images visuelles. Dans le premier type de déplacement, décrit ci-dessus, un élément est remplacé par un autre. Dans le deuxième, un élément verbal, qui appartient à la pensée initiale du rêve, s'exprime à travers une image : le non-représentable représenté par un symbole visuel. Le travail du rêve fait " apparaître la chose à partir du mot ${ }^{59}$ ». Freud décrit ici le but d'une telle substitution :

Cette deuxième sorte de déplacements survenant lors de la formation du rêve n'a pas seulement un grand intérêt théorique, elle convient aussi particulièrement bien pour élucider ce semblant d'absurdité fantastique sous lequel le rêve se déguise. Le déplacement se fait en règle générale dans une certaine direction, une expression incolore et abstraite de la pensée de rêve étant échangée contre une expression concrète et imagée de celle-ci. L'avantage partant, la visée de ce remplacement est évidente. Ce qui est imagé est pour le rêve apte à la présentation $[. . .]^{60}$.

Lyotard souligne le fait que, dans sa troisième opération, le rapport entre le désir et le texte est très différent. Plutôt que de perturber l'espace linguistique, le rendant opaque, la pensée du rêve est traduite de telle façon qu'elle quitte l'espace du texte complètement :

Ici il faut faire grande attention. Car ce n'est plus du tout de la même façon que le désir s'empare du texte. Par condensation et déplacement, il agit sur le lieu supposé de son inscription. Par figuration on pourrait dire que le désir, en outre, prend le mot au pied de la lettre ; le pied de la lettre, c'est la figure (DF 248).

Pour Lyotard, c'est le même processus que dans la peinture surréaliste, par exemple avec la légende des peintures de Magritte : «non pas des jeux de mots, mais des jeux joués par la figure aux mots ${ }^{61} »$. Le fait de prendre les mots au pied de la lettre penche vers la fonction de la désignation dans le langage, où les mots « indiquent » quelque chose.

Le fait d'« imager » le texte représente peut-être l'expression la plus directe du désir de toutes les opérations du rêve. Comme l'exprime Lyotard, « La chose qui vient à la place du mot, c'est le désir réalisé62 ${ }^{\prime}$. Ici, il semblerait, le visuel a triomphé sur le textuel. Pour Freud, c'est dans la poésie, ainsi que dans les rêves, que nous voyons cette opération par laquelle «le désir [...] prend le mot au pied de la lettre». La poésie figurale évoque donc le fantasme originaire :

En avançant dans cette direction, il est certain qu'on tombera de nouveau sur la question du fantasme, qui fait pivot. Les grandes figures linguistiques, de discours, de style, sont l'expression, en plein milieu du langage, d'une disposition générale de l'expérience, et le fantasme est la matrice [le médium ou la structure] de ce découpage, de cette rythmique imposée désormais à tout ce qui arrivera dans l'ordre de la «réalité » et dans l'ordre de l'expression. Ces figures, ainsi, figurent une figure première $(D F, 249-50)$.

\section{4. L'élaboration secondaire}

La quatrième opération est plus compliquée et plus révélatrice de la nature ambivalente du désir. Elle complique aussi la distinction entre le travail et la pensée établie par Freud. Selon le descriptif de Freud, il y a un agent psychique dans la formation du rêve qui est identique au travail de la pensée éveillée dans la mesure où elle sert à créer de l'ordre, construire des rapports et assujettir le matériel aux exigences de la cohérence intelligible. Pour Freud, l'élaboration secondaire appartient à la pensée normale. Le rapport entre les trois premières opérations et l'élaboration secondaire serait donc le même que celui entre la pensée éveillée et le matériel de la 
perception : «mise en ordre quasi pulsionnelle qui efface la différence du donné avec l'attendu et empêche de recevoir véritablement ${ }^{63} »$. Mais pourquoi une telle procédure serait-elle nécessaire? Pour Freud, l'élaboration secondaire sert de protection de la psyché du chaos de la différence pure en rabattant cette hétérogénéité sur l'ordre unifiant du langage: "Freud dit que la fonction de l'élaboration secondaire est d'effacer du rêve le style absurde, incohérent dans lequel les trois premières opérations, laissées à elles-mêmes, le produisaient [...] [0]n passe de l'énergétique à la linguistique qui est lisible ${ }^{64} »$.

Freud accorde provisoirement un rôle constructif, et non pas seulement répressif, à la force de la censure :

[T]out ce que comporte le rêve n'est pas issu des pensées de rêve, mais [une] fonction psychique qu'on ne peut pas différencier de notre penser vigile peut fournir des contributions au contenu de rêve. La question se pose maintenant de savoir si cela ne survient que tout à fait exceptionnellement, ou s'il revient à l'instance psychique, qui n'est par ailleurs active que comme censure, une participation régulière à la formation de rêve ${ }^{65}$.

Encore une fois, nous revisitons les questions qui se sont posées pendant notre discussion de la censure (Enstellung). Se pourrait-il que l'élaboration secondaire, ici la quatrième opération du rêve, ne soit pas en fait « secondaire ", comme le suggère son nom, mais constitutive ? Se pourrait-il que le désir soit en fait un langage et que nous nous trompions quand nous voyons une «origine» ou une réalité au-dessous du langage et de l'apparence ? C'est précisément ce paradoxe qui intéresse Lyotard:

Freud dit [de l'élaboration secondaire] que sa fonction est de faire du rêve un Tagtraum, une rêverie éveillée, de le doter d'une ordonnance conforme aux lois de l'intelligibilité ; il va même jusqu'à soutenir qu'elle relève de la pensée normale. En conséquence de quoi cette élaboration paraîtra en effet secondaire, seconde au processus primaire, imposant le langage articulé à un matériel dont Freud s'est évertué, dans la section portant sur la figurabilité, à montrer qu'il ignorait presque toutes les catégories de la pensée raisonnable. Bref « ce travail (qui) ne pense pas », voici qu'il recourt au discours de la pensée consciente ou préconsciente. Comment continuer à soutenir que les opérations qui transforment la pensée du rêve en son contenu sont réellement travail? Ne faut-il pas au moins faire une exception pour la quatrième qui paraît relever entièrement du langage? Mais le travail du rêve a pour fonction de rendre intelligible, selon Freud, qu'en tout cas il viole, cet ordre jouerait-il un rôle dans sa propre occultation? $(D F, 261)$.

Cette capitulation au langage avec la « mise en ordre » de la différence que le processus primaire implique n'est pas, soutient Lyotard, ce qu'elle semble être à première vue : "On a dit plus haut qu'il fallait peut-être classer au plan des pensées du rêve, non pas un discours, mais des fantasmes [...] Le fantasme n'est pas seulement de jour et de nuit, il est de façade et de fondation ${ }^{66} »$. Produit du fantasme, l'élaboration secondaire a donc une fonction de tromperie, suggère Lyotard. Le désir se sert du langage, mais ceci n'est qu'un stratagème, un pseudo-langage, un travestissement. Car le figural, de par sa nature même, refuse la rigidité et transparence du langage :

[C]e lisible est un pseudo-lisible. La signification lisible du rêve, son contenu immédiat ne peut pas être lu : et même quand il l'est, il ne doit pas l'être: Freud répète que nous ne devons pas traiter le contenu comme un texte, mais comme un objet. C'est que l'inscription, même quand elle a un sens (en latin, mais on a vu que c'est l'exception [...]) son sens est suspect, ne peut que leurrer l'interprète. Il faut ne pas croire à "rêvons d'or »; pour atteindre "Révolution d'octobre", caché sous le texte doré, il faudra reconstruire un texte primitif déconstruit par le travail, ou si l'on préfère, déconstruire l'édifice, la figure, construite par les opérations [...] Plus 
on se rapproche du vrai langage, plus on s'expose au vrai mensonge. La figure ne peut mentir, n'ayant pas prétention à l'univocité. L'intelligibilité est donc plutôt jouée, imitée, que vraiment satisfaite $(D F, 269)$.

Le fantasme inconscient investit donc le langage conscient pour se dissimuler :

le contenu emprunte à l'interprétation son outil, le langage articulé ; mais c'est pour le détourner de sa position linguistique et en faire un usage criminel, le texte étant pris comme chose, chose phonique, chose visible, et non assemblage de signes vides, de cénèmes $(D F, 269)$.

1 Cet usage « criminel » du langage nous rappelle le concept de la mimésis chez Adorno. À travers la mimésis, une nature refoulée s'exprime, elle trouve une voix. Ceci, pour Adorno, est une des fonctions fondamentales de l'art :

Devant la menace constante de sa propre réification, le sujet limite cette réification à travers le vestige mimétique, le plénipotentiaire d'une vie intégrale dans une vie endommagée où le sujet est réduit à une idéologie ${ }^{67}$.

On pourrait, dans l'optique qui nous intéresse, remplacer le mot « sujet » par le mot « désir ». Dans l'œuvre d'art, le fait de « donner voix » aux pulsions pré-subjectives, à une « nature immanente » qui rejette la fonctionnalisation par les structures sociales, ne peut avoir lieu que de façon dialectique. Autrement dit, la nature immanente doit interagir avec le pôle constructif de l'œuvre, dans une dialectique de la subjectivité avec l'objectivité. La mimésis décrit dans ce cas «l'affinité non-conceptuelle d'une création subjective avec son autre objectif et non-postulé68 $»$.

3 Si nous comprenons la mimésis comme une unité non-coercitive du subjectif et de l'objectif, l'élaboration secondaire donne lieu elle aussi à « une figure à lire ${ }^{69}$ ". Le désir pénètre, se joint avec l'espace linguistique lui-même, pour mieux déstabiliser cet espace. Plutôt qu'une force de répression, le langage sert paradoxalement comme un outil du désir. En jouant le jeu du langage, le désir fait son travail tout en restant dissimulé. L'élaboration secondaire n'est donc pas une opération postérieure à la condensation, le déplacement et la figurabilité :

Le désir ne travaille pas un texte donné en clair, pour le travestir ; il ne laisse pas entrer le texte, il le devance, s'y loge, et nous n'avons jamais que du texte travaillé, mixte de lisible et de visible [...] Il faut supposer une situation princeps où le refoulement et le retour du refoulé se constituent ensemble $(D F, 270)$.

Il sera utile à ce point de résumer brièvement l'étude du rêve de Freud. Qu'est-ce que Lyotard apprend de Freud autour des opérations du désir sur le langage, du rapport entre discours et figure? Quelles sont les questions qui se posent ici?

Le concept ambivalent de la censure, l'Enstellung, suggèrerait que le désir et ce qui le canalise ou l'entrave, ont un rapport co-constitutif: le désir et la loi naissent ensemble ${ }^{70}$. Les opérations de condensation, de déplacement et de figurabilité servent le besoin apparent du désir pour la censure à travers la surdétermination, la transvaluation et la figurabilité, respectivement. De plus, Freud explique l'intelligibilité du rêve à travers un processus d'élaboration secondaire, qui a lieu, pour lui, en quelque sorte " après » les trois premières opérations, pour les rendre cohérentes. Or, il reste à voir si, comme le soutient Freud, les pensées du rêve latentes sont structurées comme un texte et défigurées après, ou si en fait le désir est comme une force placée «derrière » le texte du rêve, qu'il porte comme un masque. Pour Lyotard, cette dernière hypothèse est vraie. Car les pensées latentes et manifestes se constituent en même temps, le désir n'apparaît que dans une forme dissimulée : 
Le travail du rêve n'est pas un langage; il est l'effet sur le langage de la force qu'exerce le figural (comme image ou comme forme). Cette force transgresse la loi ; elle empêche d'entendre, elle fait voir ; telle est l'ambivalence de la censure. Mais ce mixte est princeps, on ne le trouve pas seulement dans l'ordre du rêve, mais dans celui du fantasme "originaire» lui-même: discours et figure à la fois, parole perdue dans une scénographie hallucinatoire, violence initiale $(D F, 270)$.

\section{Art versus rêve}

le rêve montre comment le désir s'empare d'un texte, que nous dit-il de la façon dont le désir pourrait s'exprimer à travers l'art? Lyotard trouve dans le travail du rêve un modèle pour un art qui donne sa voix à la figure. Cependant comment Lyotard articulet-il art et rêve? Le rêve est-il une forme d'œuvre d'art créée lorsque l'artiste est en train de dormir ? La « vérité » de l'art est-elle la même « vérité » que celle du rêve ? La réponse à ces questions se trouve dans le rapport entre l'œuvre et ses formations fantasmatiques.

\section{1. L'art comme expression}

97 La psychanalyse considère souvent l'art, autant que le rêve, comme une expression du fantasme : à travers l'œuvre d'art, l'artiste donne sa voix à ses fantasmes, à ses désirs inassouvis. L'œuvre d'art est ainsi vue comme une envolée hors de la réalité extérieure et une extension de la réalité psychique (le terme de réalité psychique sera exploré plus loin). La psychanalyse est intéressée par l'art à cause de ce statut perçu. L'art « répète » le fantasme originaire :

[L]a figure où s'accomplit le désir n'est pas seulement l'image hallucinatoire. Celleci est elle-même une expression, l'expression temporaire, conjoncturelle d'une puissance figurale plus primitive, le fantasme originaire [...] Pour Freud, l'art doit être situé par référence au fantasme $(D M F, 56)$.

La réalité "psychique » de l'art opère selon le principe de plaisir qui, dans l'œuvre d'art, se déplace sans contrôle dans la réalité perceptive, ou le "principe de réalité ». Contrairement au principe de plaisir, le principe de réalité est caractérisé à la fois par la liaison de l'énergie psychique et par la mise à l'épreuve de la réalité de ce qui est représenté. Selon la psychanalyse, l'art en tant qu'image hallucinatoire échappe à ces exigences :

L'image hallucinatoire dans laquelle [le désir] s'accomplit procède d'un «état de détresse ", état de surcharge énergétique qui ne trouve pas issue dans la réalité et ravive par régression les traces de satisfaction passée. L'hallucination, onirique ou non, constitue le fait primitif de l'art, attestation d'une « réalité » autre que celle que donne la perception. Cette "réalité » que Freud appelle psychique relève du principe de plaisir; elle échappe à la double exigence qui résulte du principe de réalité [...] (DMF, 55-6).

Selon la psychanalyse, l'image hallucinatoire de l'art, comme celle du rêve, sert comme métaphore du fantasme originaire.

L'artiste est donc vu par la psychanalyse comme quelqu'un qui évite la réalité (réalité qui demande le renoncement à la satisfaction des pulsions) pour laisser libre cours à ses désirs. Ses fantasmes répètent un fantasme plus profond. L'art, donc, nous met en contact avec nos origines, il en est le produit. «[L]'artiste ne cache pas ses fantasmes, il leur donne forme en des objets effectivement réels et de surcroît la présentation qu'il 
en fait est une source de plaisir esthétique ${ }^{71} »$. En leur donnant forme, l'artiste extériorise ses fantasmes, il les met en scène. Il fait parler son désir, en le laissant s'investir, se réaliser dans des images hallucinatoires ${ }^{72}$.

\section{2. L'art comme jeu}

101 C'est autour du concept de jeu que Freud se sépare de la vision psychanalytique traditionnelle de l'art comme simple expression du fantasme. L'envolée hors de la réalité extérieure à travers l'art est aussi vue comme une ouverture en force, joyeuse et temporaire, de la réalité extérieure pour révéler une autre réalité, une réalité qui opère selon des coordonnées différentes : « Le plaisir de l'art est le plaisir du jeu : annonce est faite que, dans la réalité, la réalité va être écartée au bénéfice du plaisir ${ }^{73}$ ». Ce plaisir du jeu ne concerne pas pour Freud l'artiste seul, car l'art permet au public de jouir de ses propres fantasmes. Il crée un forum socialement acceptable pour la satisfaction du plaisir.

102 Alors que l'art, pour Freud, rapproche les deux pôles de la réalité et de la non-réalité, il le fait non pas en les identifiant, mais en soulignant la distance qu'il y a entre eux : « Le jeu ne réconcilie pas le fantasme et la réalité perceptive, en ce qu'il les rendrait immanents l'un à l'autre ; il prend plutôt acte de leur dissociation, tout en affirmant les droits du premier dans les enclaves pratiques au sein de la seconde ${ }^{74} »$. C'est en ce qu'il donne à voir la différence entre réalité intérieure et extérieure que l'art est expressif. C'est aussi par-là que l'art se distingue de la simple communication :

L'expression est la présence dans le processus secondaire, dans le discours et dans la représentation réaliste, d'opérations propres au système inconscient. Cette introduction consiste toujours dans la formation d'une figure [...] ; cette figure vient d'une « autre scène » que du lieu langagier, pictural, sculptural où elle se produit, elle est expression d'un sens autre, le sens qu'elle exprime n'est pas présent dans l'œuvre comme y est présente sa signification immédiate (DMF, 55).

Ce «sens autre » est un sentiment, un affect ou une immédiateté, quelque chose qui court-circuite la compréhension.

Si l'art, pour Freud, forme une figure avec la réalité, il ne transforme pas cette réalité. L'art reste plutôt au niveau du jeu, du non-sérieux. L'art ne change pas la réalité parce que la possibilité même, ou la nécessité de l'art résulte de la scission originelle qui engendre la réalité et le langage, qui donne lieu au manque, ouvrant un espace du désir que l'œuvre vient combler. En d'autres termes, sans réalité il n'y a pas de manque, sans manque pas de désir, et sans désir pas d'art. Comme l'indique Freud, «l'insatisfaction de l'artiste que produit la substitution du principe de réalité au principe de plaisir est elle-même une partie de la réalité ${ }^{75}$ ».

Lyotard fait écho à Freud dans son propre éloignement de l'approche psychanalytique de l'art:

L'artiste n'est pas un névrosé « victorieux », il n'est pas vrai que la grandeur de son œuvre soit en raison inverse de l'intensité du « désordre » psychique dont il souffre. Les poèmes de la folie de Hölderlin, les toiles peintes par Van Gogh à Arles et à Anvers, les écrits d'A. Artaud, l'interné de Rodez, sont là pour témoigner de la possibilité de principe que du fond de l'«aliénation" une vérité soit exprimée. L'inverse n'est pas vrai : la profondeur du trouble intérieur ne suffit pas à faire de la poésie (DMF, 61-62). 


\section{3. Le contenu de vérité de l'art}

106 L'art, donc, ne met pas en scène un désir accompli, mais plutôt un désir inaccompli. Il porte témoignage du fossé entre le principe de plaisir et le principe de réalité, qui signifie que l'art est de la vérité encodée :

[L]a fonction de l'art n'est pas d'offrir un simulacre réel d'accomplissement de désir, elle est de montrer par le jeu de ses figures à quelles déconstructions il faut se livrer, dans l'ordre de la perception du langage (c'est-à-dire dans l'ordre préconscient), pour qu'une figure de l'ordre inconscient - je ne dis pas: se fasse reconnaître, puisque les déconstructions dans lesquelles les «figures » se logent, font justement obstacle à une perception et à une intelligence claires - mais se laisse deviner par sa dérobade même: un bruit d'ailes, les pattes de colombe de Nietzsche : elle est de manifester sur elle-même l'inaccomplissement du désir (dont le répondant vécu est l'impatience et l'insatisfaction de l'artiste) (DMF, p. 57-8).

L'art a désormais comme fonction « ni de connaissance, ni de beauté, mais de vérité » :

$[\mathrm{L}] \mathrm{a}$ vérité se signale là où elle n'est pas attendue. Son irruption suffit à faire l'œuvre, non l'œuvre à la faire surgir. La force d'une expression littéraire ou picturale ne réside pas dans son harmonie (ni dans la « victoire » du moi), elle est ce qui tient et maintient ouvert, "libre », le champ des mots, des lignes, des couleurs, des valeurs, pour que la vérité s'y « figure » $(D M F, 60)$.

\section{4. Attention également flottante}

Comment donc l'artiste arrive-t-il concrètement à témoigner de cette vérité, de cette différence fondamentale ? Comment l'artiste maintient-il libre « le champ des mots, des lignes, des couleurs » et «des valeurs»? Lyotard emploie l'expression «attention également flottante " pour décrire cette ouverture à ce que la pensée consciente ou le principe de réalité empêche systématiquement. Les peintures de Cézanne, affirme-t-il, sont nées d'une telle « ouverture» :

Planté devant la montagne durant des heures, que fait Cézanne? Il associe librement, il maintient une attention égale, paritaire, à ce que la perception chosiste et gestaltiste nous fait ne pas voir, il déconstruit un ordre, une écriture, il veut voir la mauvaise forme, voir ce que la focalisation active, adaptative refoule à la périphérie du champ, les anamorphoses, les courbes, les obliques, les latérales $(D M F, 169)$.

109 Quelques exemples que j'ai choisis dans la sphère de la musique contemporaine serviront à illustrer l'idée de Lyotard un peu plus loin.

\section{4. 1. John Cage}

Dans une pratique esthétique dominée par le travail plus que par la pensée, ce qui importe, tout comme avec le travail du rêve, c'est non pas le produit, mais le processus. Cela implique un certain relâchement du contrôle subjectif ou de "l'attention", incarné en musique par l'approche "expérimentale » extrêmement influente de John Cage. Comme l'a indiqué Hermann Danuser :

Alors que notre musique [européenne] s'est développée sous la pression de la tradition, vers le contrôle, le systématique, organisée dans tous les détails [...] de la même façon le développement de Cage a pris une direction complètement différente : le son produit l'intéresse de moins en moins, il dépend du fait de jouer, est de moins en moins rationalisé, et le hasard, le hasard flexible, joue un rôle important $^{76}$. 
111 Wim Mertens a dénoté chez les compositeurs expérimentaux l'idée d'une esquisse d'une situation plutôt celle de la recherche de la production d'un objet achevé. Le morceau intitulé « 4'33" " est peut-être l'exemple ultime de cela :

Les compositeurs expérimentaux ne s'occupent pas d'objets temporels bien définis, mais plutôt ils esquissent une situation, un champ dans lequel un son pourrait advenir. Ce qui est important ce n'est pas le produit mais le processus de composition $^{77}$.

\section{4. 2. Helmut Lachenmann}

La notion de musique comme situation et comme quelque chose d'énergétique plus que d'intellectuel a été développée par le compositeur d'avant-garde Helmut Lachenmann. Le passage ci-dessous dans lequel Lachenmann distingue son approche de celle de Boulez, dont il voit la musique plus comme un texte que comme un champ ouvert ou une situation, fait écho à la phrase de Cage : «l'ancienne musique a à voir avec le concept et avec la communication, et la nouvelle avec la perception ${ }^{78}$ ", et résonne avec la distinction faite par Freud entre Traumarbeit et Traumgedanke:

Il y a une notion que vous connaissez probablement. Il s'agit de «musique concrète instrumentale ", un terme relatif à l'énergie d'où provient le son. Dans ce contexte, je me suis beaucoup intéressé aux bruits [...] Mais j'ai maintenant décidé que l'intérêt de la musique concrète ne réside pas dans les bruits, mais dans l'énergie d'un son. Et cette sorte d'énergie peut être produite, disons, par un pizzicato tout à fait normal sur un violon, ou par un unisson, ou par deux instruments jouant la même note, mais avec une légère différence dans les vibrations. La vélocité, la vitesse d'exécution sont aussi des composantes de l'énergie. Cette idée d'énergie reste pour moi la chose la plus importante.

On m'a demandé de présenter mon Troisième quatuor à cordes [...] C'est un peu artificiel, mais j'ai dit que certaines œuvres musicales peuvent être considérées comme un texte, c'est-à-dire comme un langage. Boulez, par exemple, utilise des titres comme Commentaire ou Clause : tous ces mots viennent de la littérature. Une phrase est également une partie d'un texte, du langage. Et pour moi, ou bien la musique c'est cela, ou bien c'est une situation, ce qui est complètement différent. Quand je parle de musique en tant que situation, je veux dire par là une situation auditive ou acoustique. Ce qui ne signifie pas que cette musique ne veut rien dire ${ }^{79}$.

113 Ces affirmations résonnent avec l'assertion du même Lachenmann tenant que : « la vérité se signale là où elle n'est pas attendue ", et que c'est l'irruption de la vérité qui fait œuvre, non pas l'intention de l'artiste de « dire », c'est-à-dire de signifier, quelque chose.

\section{4. 3. Karlheinz Stockhausen}

114 L'attention également flottante de Lyotard peut être comprise non simplement en termes d'acte de création artistique mais aussi dans l'acte d'écouter lui-même, comme l'indique Stockhausen à propos de son morceau Moment Form : « Le morceau aurait pu continuer indéfiniment [...] L'auditeur peut aller et venir quand il le veut ${ }^{80} »$

115 Mais en plus d'une "ouverture ", ou d'une attention également flottante (ce qui rappelle le concept de devenir chez Deleuze ${ }^{81}$ ), l'artiste, pour Lyotard, doit être dans un rapport critique au fantasme. L'hallucination peut être le "fait primitif de l'art». Toutefois, comme nous l'avons vu, le type d'art qui intéresse Lyotard est celui qui refuse ses propres tendances primitives, qui rejette cet accomplissement 
hallucinatoire. Le contenu de vérité de l'art est concomitant avec la sape (et dans le cas de Cage, le refus) de la représentation.

\section{5. Renversement}

Le processus par lequel l'art refuse ses tendances les plus profondes est encapsulé par Lyotard dans le terme de renversement. Ce concept marque la différence entre l'art et le simulacre de l'accomplissement du désir que l'on trouve dans le rêve et dans les approches psychanalytiques traditionnelles de l'art. Car l'art, en tant qu'anti-art, mime le fantasme (au sens adornien de mimésis) : il transgresse les règles du discours à la manière du rêve, par la distorsion, la condensation et la figuration. Cependant il le fait alors qu'il se déplace dans la direction opposée au rêve, en refusant que le fantasme fasse œuvre. L'art réorganise le fantasme en y injectant du mouvement. En tant que tel, l'art que soutient Lyotard représente une critique du fantasme, une critique de tout ce qui contrarie et limite le désir, qu'il soit artistique, économique ou politique. L'art nous rappelle que le désir peut être canalisé ou investi mais qu'il est en même temps mouvement et changement, cherchant en permanence de nouveaux investissements, et que cet aspect fluide du désir sera toujours présent pour défaire et mettre en mouvement les produits culturels ou les modes de pensée réifiés.

\section{6. Idéologie}

Dans beaucoup des essais de la période libidinale, réunis dans Des dispositifs pulsionnels et dans Dérives à partir de Marx et Freud, l'aspect stable du fantasme prend, pour Lyotard, une signification politique. Les formes idéologiques sont des formes qui subordonnent ultimement la différence à la répétition à travers la création d'un simulacre d'accomplissement. La «bonne forme » du simulacre est le résultat de la coopération d'Éros et de Logos, ou du principe de plaisir et du principe de réalité, comme dans le processus d'élaboration secondaire. Cette coopération, soutient Lyotard, est l'opération fondamentale de l'idéologie. L'idéologie sert alors à dissimuler la radicalité disruptive du désir à lui-même. Dans Discours, figure, ce détour proclamé pour mener la critique pratique de l'idéologie ${ }^{82}$, l'art est ce qui sape l'opération fondamentale de l'idéologie par le renversement des procédures idéologiques des formes culturelles.

118 Pour une meilleure compréhension de la procédure duale de répétition et de renversement dans l'œuvre d'art, il est utile de garder à l'esprit que pour Freud, le processus primaire est fait de deux tendances : Éros et la pulsion de mort. Éros est une tendance constructive. Concomitant avec le principe de réalité, il combine les énergies psychiques dans le but de stabiliser le mouvement dans le système psychique et de protéger le sujet de l'angoisse de l'hétérogéneïté non-liée. Dans le travail d'Éros, l'hétérogéneïté est subordonnée à une identité totale. La pulsion de mort est la tendance responsable du renversement. Elle cherche à déconstruire les identités stables, à défaire les investissements d'Éros (la théorie des tendances de Freud sera explorée plus en détail dans la section VI, ainsi que le rapport entre pulsion de mort et renversement) :

La transgression de la règle constitue la face visible de ce travail qui peut certes être assimilé à celui du rêve et en général aux opérations de processus primaire, mais qui les répète en les renversant parce qu'il les applique à l'œuvre même de ce processus, c'est-à-dire aux figures issues du fantasme. C'est par cet effort 
transgressif propre au désir d'écrire ou de peindre que précisément Mallarmé, Cézanne, Joyce ou Picasso inscrivent leur œuvre dans cet avènement du désir qu'est l'histoire de l'occident et l'inclinent vers une critique toujours plus radicale des contraintes poétiques ou plastiques, critique qui a son répondant dans la critique révolutionnaire des contraintes économiques, sociales et politiques (DMF, 65). Comment sa procédure critique est-elle menée ? Comment l'art met-il en mouvement les figures issues du fantasme?

\section{7. Renversement et seconde nature}

Un parallèle peut être tracé entre l'idée lyotardienne de critique de l'idéologie et la critique de la seconde nature chez Adorno. Adorno emploie un concept essentiellement lukacsien de seconde nature pour décrire l'idée que ce qui apparaît comme "naturel » et donné dans l'art et la musique est en fait socialement et culturellement prédéterminé et médiatisé. En d'autres mots, idéologique. Selon Lukács :

La nature est une catégorie sociale. C'est-à-dire que tout ce qui est tenu pour être naturel à tout niveau donné du développement social, même si cette nature est liée à l'homme quelle que soit la forme de son implication, à savoir la forme de la nature, son contenu, son extension et son objectivité, est socialement conditionnés3.

Adorno reprend cette notion de Lukács et comprend l'interaction de l'histoire et de la nature comme une partie d'une " réflexion sur la nature ", un "processus qui en effet est une réponse aux demandes de la matérialité, et qui la révèle comme "produit culturel" plus que comme "nature" " (Paddison 1993 : 72). L'implication de cette idée d'auto-réflexion est alors l'idée que le but de l'art est d'abord cognitif, en lien avec la révélation de vérités sociales au moyen du déchiffrement de la "seconde nature ». L'idée de l'art comme réflexion sur la nature trouve un écho dans la citation de Lyotard ci-dessous :

[Le travail de l'art] [...] renverse la relation de l'expression avec l'étendue ouverte par le retrait du sens, il ne se contente pas d'extérioriser en symptômes ses figures profondes, il expose, sinon la fantasmatique même, du moins ses traces, en disposant à leur rencontre un espace ouvert, un espace déconstruit, jusqu'à dénaturer les lois du langage et de la perception de façon que les opérations formatrices des figures de l'inconscient et de leurs traces puissent, dans le champ libre, produire d'autres figures, de nouvelles figures, qui alors seront poétiques ou plastiques (DMF, 65).

\section{8. Art Moderniste}

Avec la notion de renversement, Lyotard soutient un type d'art très particulier, le modernisme, qui après la proclamation de la fin de l'art, tourne l'art contre lui-même (d'où l'idée de « l'anti-art »). Suivant le schéma historique de Lyotard, l'art traditionnel a une fonction religieuse au sens étymologique du terme : intégré à la société, il sert à créer un lien, à forger une communauté à travers la propagation d'un code et d'un système de valeurs partagées. L'art traditionnel communiquait, mais à un niveau inconscient :

Dans cette société, la communication s'opère non pas selon les critères donnés par Freud et aussi par Marx - les critères de transformation pratique et de verbalisation

- mais par des formes - plastiques, architecturales - et par des rythmes qui permettent une sorte de « communication » au niveau des inconscients individuels. 
On a affaire à une société-art [...] (« Notes sur la fonction critique de l'œuvre », 1970, DMF, 233).

Aujourd'hui, affirme Lyotard, ce type d'art a disparu. À cause du capitalisme, l'art, depuis le XIX $X^{e}$ siècle, n'est plus intégré à la société : « Hegel le savait déjà et disait : pour nous, l'art est mort, maintenant, c'est le temps de l'esthétique » (DMF, 233). Cette mort de l'art est due au fait que les liens qui existaient dans les sociétés précédant le capitalisme ont été dissous par la logique économique de la loi du paiement au comptant (Marx) : l'art n'a tout simplement plus rien à relier, et les individus sont liés par la seule économie $^{84}$. L'art n'a donc plus de rôle de communication inconsciente, mais de révolution et de transformation des codes sociaux. Il n'est plus un forum d'échange symbolique, faisant usage d'un code ou d'un langage que chacun comprend. En tant que forme de critique, l'art doit révéler la base idéologique de toute affirmation de la cohésion comme une tentative trompeuse de reconstituer l'art ancien, qui n'a plus de signification dans la société d'aujourd'hui :

Ce que fait - ce que doit faire - l'art, c'est toujours de démasquer toutes les tentatives de reconstitution d'une pseudo-religion; c'est-à-dire que chaque fois qu'une espèce d' "écriture " - un ensemble de formes qui produit une résonance psychique et qui se reproduit - tente de se reconstituer, la fonction de l'anti-art, c'est de la démasquer comme idéologie, au sens marxiste du terme, comme une tentative de faire croire qu'il y a des modes de communication de ce type, " primaire ", dans nos sociétés, alors que ce n'est pas vrai (DMF, 234).

Lyotard donne l'exemple du Pop Art, critique au sens où il fait usage d'objets quotidiens mais d'une façon ironique. Les matériaux du Pop Art sont les objets fétiches de la vie quotidienne. Mais en fabriquant une distance ironique par rapport à eux, il brise, ou renverse l'illusion de leur valeur collective et de leur réalité :

Cela a été une des fonctions du Pop art, chez certains du moins : prendre ces objets qui ont l'air réels, des objets sur lesquels les gens sont d'accord, qu'ils valorisent, à travers lesquels ils communiquent, des affiches publicitaires ou des automobiles par exemple - et les déconstruire (DMF, 234) ${ }^{85}$.

\section{9. Forme et contenu}

Dans la théorie d'Adorno du modernisme esthétique, la dialectique de la nature et de l'histoire, le moteur qui est derrière le développement historique, prend la forme d'une «rupture entre le soi et les formes». Ceci, avancerai-je, est similaire au concept de renversement de Lyotard (cependant le déplacement de l'idée de fantasme et de désir est absent, remplacé par les notions de nature et de subjectivité non-aliénée). À travers la notion de rupture, Adorno explique la fragmentation des référents formels dans l'ère moderne, leur incapacité à se plier aux besoins expressifs de l'artiste. La désintégration d'un langage artistique commun reflète la crise sociale plus large décrite par Lyotard, à savoir la faillite de la cohésion et de la continuité dans les relations sociales. L'aliénation subjective peut être vue comme le résultat de cela. Cependant la fragmentation des œuvres dans l'art moderne a bien pour Adorno une fonction progressiste du point de vue des Lumières. La démystification, l'émancipation des mythes, est l'un des objectifs centraux du projet des Lumières. Comme Max Paddison l'a écrit à propos de la musique :

La désintégration des formes sert à révéler leur historicité, et la faillite d'un

«système référentiel » tel que la tonalité sert à révéler ses apparentes fondations 
« naturelles » comme étant en fait historiques - c'est-à-dire, comme une « seconde nature » liée à des déterminations culturelles particulières ${ }^{86}$.

Le concept de «mauvaise forme » de Lyotard fait écho à l'idée de la désintégration des formes. Dans l'essai «Sur le problème de l'analyse musicale » (1969), Adorno explique sa conception de la forme musicale. La forme est, pour lui, un concept dual, dénotant les œuvres d'art construites « du haut vers le bas » et également « du bas vers le haut ${ }^{87}$ ". La première sorte de forme, la "forme de fond ", est liée aux genres transmis et aux types formels. Ils représentent un niveau de collectivité. La seconde sorte, la «forme immanente » de l'œuvre individuelle, s'affirme contre la forme de fond, dans « une relation complexe de déviation du schéma ${ }^{88} »$. Adorno se réfère à ce second type de forme comme «structure ». "Par structure, écrit-il, je n'entends pas [...] le simple regroupement d'éléments musicaux selon les schèmes formels traditionnels, bien plutôt je comprends cela comme ayant à voir avec ce qui se passe, musicalement, en dessous de ces schèmes formels ${ }^{89}$ \%. Hans Keller a pris la même direction, mais en employant les termes d'avant-plan et d'arrière-plan: "L'arrière-plan se résume à la forme, que de nombreux morceaux ont en commun, et qui peut être trouvée dans les livres, l'avant-plan est la structure individuelle, qui arrive à la place de la forme, à moins que la musique ne soit ennuyeuse et satisfasse toutes les attentes ${ }^{90}$ ». C'est le second type de forme, la «structure » ou avant-plan, que le modernisme artistique pousse à l'extrême. L'idée de travailler avec des styles formels et des genres hérités (les bonnes formes de l'idéologie) et de les perturber de l'intérieur pour produire une mauvaise forme est importante dans le concept de renversement de Lyotard. Car l'artiste critique ne peut pas se tenir hors de l'histoire et de l'idéologie. Bien plutôt, il dépend de l'objet de sa critique :

[L]'artiste ne produit pas au-dehors des systèmes de figures internes, mais c'est quelqu'un qui essaie de se battre pour délivrer dans le fantasme, dans la matrice de figures dont il est le lieu et l'héritier, ce qui est proprement processus primaire et qui n'est pas répétition, 'écriture' (DMF, 236).

127 Pour Lyotard, l'opposition des termes de forme et de contenu n'est plus assez explicite. Parce qu'avec le renversement, une telle logique d'identité et d'opposition est remplacée par celle de différence :

Le renversement poétique porte bien sur «forme» et «contenu»; mais nous pouvons maintenant remplacer ces termes approximatifs par les concepts pertinents: tandis que le fantasme remplit l'espace de dessaisissement, l'œuvre dessaisit l'espace d'accomplissement. Le fantasme fait de l'opposition avec la différence ; le poétique refait de la différence avec cette opposition $(D F, 360)$.

Comment doit-on comprendre l'idée qui tient qu'avec la «mauvaise forme», les différences transgressives prennent la relève des oppositions d'Eros et de Logos? Pour rester dans la sphère de la musique, je poserai que, alors que dans la musique traditionnelle, toute déviation des schèmes en termes d'harmonie ou de genre retournera finalement à son point de départ, fournissant la "fermeture » finale et l'ultime satisfaction des attentes, avec la musique moderne et la rupture de l'harmonie tonale, une telle fermeture formelle est souvent absente : forme et contenu sont laissés irréconciliés :

Ce vieux vocabulaire de «forme » et « contenu » n'est pas inutile à condition qu'on le précise: dans le fantasme, le groupe pulsionnel produit des mises en scène à seule fin d'accomplir le désir. Cet accomplissement est le "contenu " et la «signification» de la fantasmatique: respectivement son sens quant à l'organisation pulsionnelle et quant au système d'affects. La forme n'y est jamais 
prise en considération pour elle-même. [La forme a un rôle de transformation], mais ces trans-formations restent subordonnées au principe de plaisir [...] les formes sont donc «libres", au sens où elles ne sont pas prises dans des processus liés et dans des constantes, comme c'est le cas de l'énergie captée dans les réseaux $\mathrm{du}$ processus secondaire, mais cette «liberté » dont témoignent leur mobilité et leur inconsistance, dont témoigne leur rejet, n'empêche qu'elles restent subordonnées au principe de jouissance ou peut-être plus exactement à ce qui, dans le principe de plaisir, appartient à l'accomplissement du désir $(D F, 359)^{91}$.

Pour autant une telle subordination de la forme au contenu n'est pas le cas avec le renversement, où l'unité est sacrifiée au nom de la vérité :

La profondeur de l'expérience intérieure est la même pour tous; ce qui est rare est la force de vouloir dévisager la figure profonde du désir, de lui ménager son espace de jeu, d'accepter l'angoisse de laisser ouvert le vide où elle pourra répercuter ses figures. L'artiste n'est pas quelqu'un qui réconcilie, mais qui supporte que l'unité soit absente $(D F, 383)^{92}$.

\section{10. Double renversement}

Nous gagnons une compréhension plus claire de la relation de l'art au fantasme, suggère Lyotard, si nous considérons le renversement comme un double mouvement. Le fantasme est un genre de renversement en ce que, comme nous l'avons vu dans l'étude du travail du rêve, il renverse la domination du discours sur la figure: « l'inclusion de la figure dans le discours se trouve renversée, le discours se présentant dans un espace figural ${ }^{93}$ ». Ce renversement reste subordonné au principe de plaisir. Le désir se représente à lui-même comme dans un miroir, il cherche à mettre en scène le fantasme pour accomplir, pour jouir de son propre accomplissement. Il ne fait que répéter le fantasme originaire. Il est donc autoréférentiel, comme dans l'exemple de l'emballage de la Vache qui rit donné par Lyotard:

Ce renversement simple est simplement fantasmatique, répétitif, spéculaire, c'est celui de la figure de la Vache qui rit sur le couvercle du fromage qui porte ce nom : la vache représentée porte pour boucles d'oreilles des fromages de la Vache qui rit, dont le couvercle est orné d'une vache parée de boucles d'oreilles, et ainsi de suite [...] Le simple renversement du rapport de la figure avec le texte, loin de renvoyer le désir à lui-même, l'accomplit et le perd dans sa récurrence infinie : il est probable que cette publicité accomplit en effet le désir (paranoïaque) de la fabrique de fromages, que la vache qui rit soit le monde, et celui-ci crème de gruyère $(D F, 383)$.

Le renversement critique, à savoir le double-renversement, implique non un investissement du désir mais une perte :

Le renversement est double, on l'a compris, pour la raison suivante : non seulement l'inclusion de la figure dans le discours se trouve renversée, le discours se présentant dans un espace figural, mais cette figuralité seconde ne consiste pas à répéter autour du discours la figure qui se trouvait déjà en son sein [...] Mais le renversement critique ne répète pas autour des constituants liés [...] la figure qu'ils portaient: ce qu'il répète ce sont les opérations qui rendent possibles cette figure parmi d'autres (DF, 383-4).

Avec le double renversement, l'art ne représente pas le désir, il le présente, en rendant visibles les opérations de représentation elles-mêmes. Car l'art produit l'acte de violence au cœur des systèmes symboliques :

L'œuvre est à au bord de sa rupture [...] Il n'y a pas de retournement, stricto sensu, parce qu'on ne cherche pas à dire la matrice profonde et à la dire dans un métalangage rigoureux [...] Mais ce n'est pas non plus un renversement simple, qui 
est le travail même du désir. C'est un double renversement: le travail de leurre est manifesté en tant que tel aux sens $(D F, 384)^{94}$.

L'art est donc à la fois fantasme et critique, rêve et vérité :

L'œuvre est un symptôme pour autant qu'elle est un ensemble de traces référables en principe à un fantasme originaire ; elle en diffère en ce qu'elle porte ces traces, les exhibe. Trace portant trace, représentation qui est elle-même représentant. Cela suppose le désir désiré, non pour le dire, le théoriser, mais pour le voir (« đedipe Juif » 1970, DMF, 169).

Le double renversement implique non pas une nouvelle représentation, une nouvelle finalité, mais l'absence même de finalité. C'est en tant que telle que l'œuvre renversée est une mauvaise forme :

Ces opérations sont alors isolées de leur finalité libidinale ; elles sont données à voir en elles-mêmes; elles ne conduisent plus seulement à l'accomplissement hallucinatoire du désir par lequel Éros poursuit ses fins jusque dans les situations de détresse ; elles apparaissent comme traces de la pure différence, comme zones de la détresse ; la pulsion de mort, le mouvement de la différence et à la différence, vient s'y déclarer en enveloppant les formations du plaisir, de la réalité et du discours $(D F, 384)$.

\section{11. La vérité de l'art versus la vérité de la psychanalyse}

5 En accordant à l'art un pouvoir de vérité, Lyotard doit à tout prix argumenter en permanence en faveur de son altérité ontologique. En effet, le but déclaré de Discours, figure est de dire la vérité de l'art sans la réduire à un discours théorique. Cependant, on pourrait arguer que le philosophe se repose trop lourdement sur le discours psychanalytique pour construire cette "altérité ». Même en rejetant la notion psychanalytique de l'art comme symptôme, Lyotard reste proche de Freud en adoptant sa notion de l'art comme jeu.

6 Lyotard tâche de prouver que la vérité de l'art n'est pas celle de la psychanalyse. Ce faisant, non seulement il essaie de distinguer l'œuvre d'art du symptôme, mais il essaie également de créer un écart entre le travail d'analyse et le travail de l'artiste. Même si les opérations sont identiques, soutient Lyotard, le but et la fonction sont différents.

Tout d'abord, alors que la fonction de l'art est de faire surgir la vérité, le but de la psychanalyse est la thérapie. Les deux ont donc un rapport différent au mouvement de régression, c'est-à-dire au mouvement de l'organisation secondaire vers les profondeurs de l'inconscient, la surface fantasmatique primaire. Dans l'analyse, le travail de réminiscence se convertit en un retour à la normalité, et donc en une réconciliation des processus primaire et secondaire, avec le but de la reconstruction du sujet. En revanche, la régression dans l'art n'a pas pour but la reconstruction d'un principe d'identité, mais plutôt la négation de cette identité. L'art a pour but de rester dans l'écart, dans la fissure entre principe de plaisir (le monde intérieur du sujet) et principe de réalité (ce monde intérieur de la perception).

Lorsque dans l'analyse le processus primaire, le fantasme, forme l'objet d'un discours théorique, le renversement, empêche la théorie, empêche toute théorisation ${ }^{95}$. 


\section{L'art et la mort} observés chez les victimes de la névrose traumatique, un état qui résulte des accidents qui impliquent un risque vital. Ce sont les rêves des patients, non pas leur vie éveillée, qui montre une tendance à répéter l'expérience traumatique de l'accident. Cette compulsion à répéter met en question l'hypothèse que les événements psychiques sont toujours régulés par ce principe de plaisir : «nous croyons que [le principe de plaisir] est chaque fois provoqué par une tension déplaisante et qu'il prend une direction telle que son résultat final coïncide avec un abaissement de cette tension, c'est-à-dire avec un évitement de déplaisir ou une production de plaisiri ${ }^{97}$ » Contre l'hypothèse du primat du principe de plaisir, Freud suggère maintenant qu'il existe un autre type d'instinct qui est régressif, qui cherche à renvoyer la vie à un état inorganique : «des tendances [sont] à l'œuvre au-delà du principe de plaisir, c'est-à-dire des tendances plus originaires que celui-ci et indépendantes de lui ${ }^{98}$ ". 
dynamique, considère les processus psychiques en termes de quantités mesurables. Le plaisir et le non-plaisir dans la psyché sont respectivement en rapport avec une baisse et une augmentation de la quantité d'excitation dans une période de temps donnée. Puisque le système psychique tend vers la stabilité « le principe de plaisir se déduit du principe de constance ${ }^{99} »-$ l'instabilité produit des sentiments de non-plaisir :

Nous nous sommes décidés à mettre en rapport le plaisir et le déplaisir avec cette quantité d'excitation présente dans la vie psychique qui n'est liée en aucune façon: relation telle que le déplaisir correspond à une élévation et le plaisir à une diminution de cette quantité. Nous ne visions pas par là un rapport simple entre la force des sensations et les modifications auxquelles nous les rattachons et encore moins - d'après tout ce que nous avons appris de la psychophysiologie - concevonsnous un tel rapport comme directement proportionnel; il est vraisemblable que le facteur déterminant de la sensation est le taux de diminution ou d'augmentation dans un temps donné ${ }^{100}$.

En dépit de cette tendance apparemment dominante au maintien de la stabilité dans l'appareil psychique, Freud reconnaît qu'il y a des moments où le principe de plaisir n'arrive pas à fonctionner correctement. Cependant, c'est en observant la réaction psychique au danger externe que Freud est amené à affirmer qu'il y a quelque chose « au-delà » du principe de plaisir, qui cherche un mouvement régressif, une tendance à répéter de façon active les expériences désagréables :

$[\mathrm{L}] \mathrm{a}$ vie onirique des névroses traumatiques se caractérise en ceci qu'elle ramène sans cesse le malade à la situation de son accident, situation dont il se réveille avec un nouvel effroi. C'est là un fait dont on ne s'étonne pas assez. On voit, dans l'insistance de l'expérience traumatique à faire retour même dans le sommeil du malade, une preuve de la force de l'impression qu'elle a produite. Le malade serait, pour ainsi dire, fixé psychiquement au traumatisme ${ }^{101}$.

Le trauma, en tant qu'expérience antérieure réprimée, doit être revécu dans le présent, autrement dit, expérimenté plutôt que rappelé ou représenté :

Le malade ne peut pas se souvenir de tout ce qui est en lui refoulé [...] Il est bien plutôt obligé de répéter le refoulé comme expérience vécue dans le présent au lieu de se le remémorer comme un fragment du passé, ce que préférerait le médecin ${ }^{102}$.

\section{3. L'Éternel retour}

Le lien ici entre l'idée de l'éternel retour, inhérente à la philosophie indienne et très importante dans la philosophie de Nietzsche, est notable. Cette "pensée de pensées", qui à la fois fascinait et épouvantait Nietzsche, comprend l'idée que l'univers se répète, et se répétera un nombre infini de fois. Selon cette vision, le temps n'est pas linéaire mais infini, cyclique, alors que toute chose dans le temps, tout corps concret, est fini.

La répétition du trauma chez Freud résonne avec cette idée, et la pulsion de mort semblerait nous rappeler notre finitude face au poids de ce temps cyclique devant lequel toute entité singulière doit, en fin de compte, capituler.

On pourrait considérer la sensation de stase, ou d'un présent perpétuel, que cherche la musique minimaliste, ou "répétitive ", comme une musique où la pulsion de mort prédomine. Terry Riley, par exemple, fait allusion au concept de stase à propos de la musique asiatique et la musique occidentale médiévale, les deux l'ayant profondément influencé :

J'ai l'impression que dans l'essentiel de la musique propre au monde occidental depuis le XIII ${ }^{e}$ siècle, climax et directivité ont été parmi les principes directeurs les 
plus importants, alors que la musique d'avant cette époque, des mélopées jusqu'à l'organum et Machaut, utilisait la stase comme point de structure, plus à la manière des systèmes musicaux orientaux ${ }^{103}$.

151 On peut considérer que cette musique refuse la représentation. Les événements musicaux, plutôt que de représenter quelque chose (une idée, une émotion ou un concept), sont sentis, expérimentés, dans l'ici et maintenant. Ceci nous rappelle la remarque de Cage : "La vieille musique a quelque chose à voir avec le concept et la communication, la nouvelle avec la perception ${ }^{104} »$.

Il n'y a pas de lien apparent dans cette musique entre la répétition et la différence. Avec la répétition comme principe d'organisation primaire, il est devenu clair pour Riley qu'il y a toujours quelque chose qui résiste à la répétition : aucune répétition ne sonne de la même façon :

Je crois que je remarquais que les choses ne sonnent pas de la même façon quand tu les entends plus qu'une fois. Et plus tu les entends, plus ils semblent être différents. Même si une chose reste pareille, elle change. Je me suis rendu compte que c'était la stase - ce dont La Monte et moi nous avions beaucoup parlé par rapport à ses morceaux «long-tone »- mais c'était la stase dans une application différente. À cette époque, les premières expériences commençaient à avoir lieu en Amérique, qui changeaient notre conception de l'écoulement du temps, et c'est ce que tu entends de fait dans la musique ${ }^{105}$.

\section{4. Fort/da}

Freud a remarqué dans les jeux d'enfant la même compulsion à répéter observée dans la névrose traumatique. Dans ce que Freud a nommé le jeu Fort/da, il observe un enfant mettant en scène de façon répétée la disparition et le retour de sa mère en jetant un jouet (qui symbolise, pour Freud, la mère) hors de sa vue, puis en le récupérant. Comme Freud l'exprime: «Le départ de la mère n'a pas pu être agréable à l'enfant ou même seulement lui être indifférent» $(A D, 60)$. Comment donc ce jeu qui répète une expérience désagréable du passé peut-il se réconcilier avec le principe de plaisir?

Il n'est pas douteux que la résistance du moi conscient et préconscient est au service du principe de plaisir; elle veut éviter le déplaisir que provoquerait la libération du refoulé tandis que nos efforts tendent à obtenir que ce déplaisir soit admis, en faisant appel au principe de réalité. Mais la compulsion de répétition, cette manifestation de force du refoulé, quel est donc son rapport au principe de plaisir ? ${ }^{106}$

Comment expliquer l'idée qu'«[I]l existe effectivement dans la vie psychique une compulsion de répétition qui se place au-dessus du principe de plaisir ${ }^{107}$ »? Comment se rendre compte du fait que le retour du refoulé est capable de surmonter le principe de plaisir? Quelles sont les conditions qui permettent au refoulé de franchir les structures résistantes du Moi et de se réaffirmer, en renversant la dynamique antérieure?

\section{5. La liaison et le système conscient}

Pour répondre à cette question, il est nécessaire de considérer brièvement la nature du système conscient tel que le voit Freud. Dans « Au-delà », Freud cherche à comprendre pourquoi le système conscient ne contient pas de traces de souvenirs, pourquoi les traces d'excitation venant du monde extérieur existent dans d'autres systèmes mais pas dans le système conscient. Comment expliquer une telle absence? Peut-être, suggère 
Freud, par le fait que le système conscient est exposé au monde externe. En effet, il se situe à la frontière entre l'intérieur et l'extérieur. Il sert donc comme une couche protectrice ou un bouclier, en neutralisant ou baissant l'intensité originelle des excitations externes.

Une excitation «traumatique » aurait donc le pouvoir de percer la couche protectrice, immobilisant le principe de plaisir. Ayant percé la couche protectrice, les quantités de stimuli doivent ensuite être maîtrisées pour qu'on puisse s'en débarrasser. Ceci est fait par le processus de liaison, un processus auquel nous avons déjà fait allusion :

[U]n système, s'il est lui-même fortement investi, est capable d'admettre un afflux supplémentaire d'énergie, de la transformer en investissement quiescent, c'est-àdire de la «lier» psychiquement. Plus son propre investissement quiescent est élevé, plus forte doit être aussi sa capacité de liaison; et inversement, plus son investissement est bas, moins le système sera capable de recevoir un afflux d'énergie et plus les effets de cette effraction du pare-excitations seront violents ${ }^{108}$.

157 Les rêves de la victime de la névrose traumatique, qui répètent le trauma dans la vie onirique du patient, semblent donc avoir comme fonction de maîtriser, de lier l'énergie excessive de façon rétrospective, de la même façon que l'enfant semble "prendre le contrôle " sur le départ de sa mère (sur lequel, en réalité, il n'a aucun contrôle) à travers la mise en scène artificielle du jeu. Cette fonction des rêves semblerait donc se différentier de l'idée courante que les rêves servent à accomplir les vœux qui restent inaccomplis dans la vie éveillée. Les rêves de la victime d'une névrose traumatique ne peuvent pas, pour Freud, être au service de l'accomplissement du désir :

Ces rêves ont pour but la maîtrise rétroactive de l'excitation sous développement d'angoisse, cette angoisse dont l'omission a été la cause de la névrose traumatique. Ils nous ouvrent ainsi une perspective sur une fonction de l'appareil psychique qui, sans contredire le principe de plaisir, est pourtant indépendante de lui et semble plus originaire que la recherche du gain de plaisir et l'évitement du déplaisir ${ }^{109}$.

La découverte d'une nouvelle fonction dans l'appareil psychique conduit Freud à réviser sa théorie des pulsions. La pulsion, mobile et non-liée, est comprise d'habitude comme quelque chose qui vise le changement et le développement. Ici, en revanche, elle est comprise comme une expression de la nature conservatoire de la substance vitale. Comment expliquer la co-existence des deux tendances dans la psyché et quel est le rapport de ces deux tendances?
Nous ne pouvons ici échapper à l'idée que nous sommes sur la piste d'un caractère général des pulsions et peut-être de la vie organique dans son ensemble, caractère qui n'a pas jusqu'à présent été clairement reconnu ou du moins pas expressément souligné: une pulsion serait une poussée inhérente à l'organisme vivant vers le rétablissement d'un état antérieur que cet être vivant a dû abandonner sous l'influence perturbatrice de forces extérieures; elle serait une sorte d'élasticité organique ou, si l'on veut, l'expression de l'inertie dans la vie organique ${ }^{110}$.

Cette inertie, vers laquelle tende la pulsion conservatrice, rappelle "l'unicité » qui sous-tend toute la vie, une unicité qui l'emporte, en fin de compte, sur toute vie particulière. En effet, Freud est mené à la conclusion radicale que l'objectif même de la vie est, en fait, non pas la propagation de la vie, mais l'accomplissement de la mort, la substance originaire :

S'il nous est permis d'admettre comme un fait d'expérience ne souffrant pas d'exception que tout être vivant meurt, fait retour à l'anorganique, pour des raisons internes, alors nous ne pouvons que dire : le but de la vie est la mort, et, en remontant en arrière, le non-vivant était là avant le vivant ${ }^{111}$. 
Cette tendance, soutient-il, doit être apparue simultanément avec la naissance de la substance vitale. En effet, les deux tendances sont inextricablement liées :

Il advint un jour que les propriétés de la vie furent suscitées dans la matière inanimée par l'action d'une force qu'on ne peut encore absolument pas se représenter [...] La tension survenue dans la substance jusque-là inanimée cherche alors à se réduire; ainsi était donnée la première pulsion, celle du retour à l'inanimé ${ }^{112}$.

161 Les pulsions d'auto-conservation sont désormais comprises d'une nouvelle façon, leur fonction étant de permettre à l'organisme de mourir à sa manière, de manière immanente. Freud assène qu'elles sont donc au service, ou subordonnées, à la pulsion de mort : « ces gardiens de vie ont eux-mêmes été à l'origine des suppôts de la mort ${ }^{113 "}$. Le contenu de la vie, pourrait-on dire, est en fait subordonné à sa forme. Lyotard répercute cette subordination du contenu à la forme dans son esthétique du renversement. Car un art dans lequel le contenu, ou principe de plaisir, règne sur la forme, en tant que pulsion de mort, serait une représentation fausse du rapport des deux pulsions dans le schéma de Freud ${ }^{114}$.

Pour Freud, cependant, les pulsions de mort doivent donc s'associer depuis le début avec les pulsions de vie; elles ne peuvent pas être dissociées. En l'absence d'une explication scientifique, Freud se tourne vers une explication mythique qui se trouve dans Le Banquet de Platon. Ce mythe retrace l'origine d'une pulsion régressive, un «besoin de rétablir un état antérieur ». Cet état date d'avant la division sujet-objet ou mâle-femelle ${ }^{115}$. C'est Aristophane qui développe l'idée suivante :

En effet, au temps jadis, notre nature n'était point identique à ce qu'elle est maintenant, mais d'autre sorte. Tout d'abord, l'humanité comprenait trois sexes et non pas deux, mâle et femelle, comme maintenant; non, il en existait en outre un troisième, tenant des deux réunis [...], l'androgyne. " Tout dans ces êtres humains était double; ils avaient donc quatre mains et quatre pieds, deux visages, des parties honteuses doubles, etc. Zeus se décida alors de partager chacun de ses êtres humains en deux « comme on coupe les cormes pour en faire des conserves [...]. Le corps étant coupé en deux, une nostalgie poussait les deux moitiés à se rejoindre. S'empoignant à bras-le-corps, elles s'enlaçaient l'une et l'autre, dans la passion de ne faire qu'un $[. . .]^{116}$.

La passion de ne faire qu'un est donc le désir d'anéantir l'opposition avec l'autre, de régresser vers le stade, avant le langage, où le sujet et l'objet ne forment qu'un :

Devons-nous, comme nous y engage le philosophe-poète, hasarder l'hypothèse que la substance vivante, au moment où elle prit vie, se déchira en petites particules et que celles-ci depuis lors tendent à se réunir à nouveau sous l'effet des pulsions sexuelles ? ${ }^{117}$

Le Je qui devient le Ça, cependant, implique aussi l'extinction du Je, donc la mort. C'est au risque de sa propre dissolution, donc, que l'art regarde la mort, la substance originaire, en face.

\section{6. L'art et le désir de voir la mort}

Pour illustrer la tâche paradoxale de l'artiste, Lyotard rappelle l'infortunée descente d'Orphée dans les ténèbres pour ramener sa femme Eurydice à la vie ${ }^{118}$. La récupération d'Eurydice fut acceptée par Hadès et Perséphone à condition qu'Orphée marche devant elle et ne la regarde pas jusqu'à ce que tout deux soient revenus dans le monde du dessus. Dans son angoisse cependant, dès qu'il eut atteint le monde du dessus, Orphée 
se tourna pour voir sa femme, oubliant l'accord et la perdit pour toujours. Le désir d'Orphée de revoir sa femme est en même temps le désir de voir la mort, car Eurydice n'était pas encore parvenue dans le monde du dessus lorsqu'Orphée s'est retourné pour la regarder. Avec l'extinction ou l'accomplissement du désir vient l'extinction de l'autre.

167 La tâche de l'art, de manifester la figure, est paradoxale, car dès que la figure est représentée, c'est-à-dire « réconciliée avec la loi du jour », alors elle n'est plus la figure, mais une métaphore de celle-ci :

Ce que l'artiste exprime, c'est la « figure » de l'inconscient (le fantasme originaire), qui est à la fois celle de son désir et celle de sa mort; il sait que dans sa nudité cette figure ne peut pas être supportée, que si elle doit être manifestée, c'est au prix d'être d'abord rapprochée de la lumière, réconciliée avec la loi du jour, remodelée selon la bonne forme et la choséité (DMF, 59).

En cherchant à court-circuiter la représentation et à se confronter à l'autre directement, d'un autre côté l'art s'éteint lui-même.

Orphée se retourne. Son désir de voir la figure excède son désir de la produire au jour. Orphée veut voir dans la nuit, voir la nuit. En cherchant à voir Eurydice il perd toute chance de la faire voir : la figure est ce qui n'a pas de visage, elle tue celui qui la dévisage parce qu'elle l'emplit de sa propre nuit [...] Il n'y a pas de « régression réversible » $(D M F, 59)$.

Avec cette notion de " régression réversible ", Lyotard fait référence au processus de la psychanalyse qui, du fait de sa fonction de thérapie, cherche à descendre dans l'inconscient afin de réaliser une réconciliation des processus primaire et secondaire, en «amenant au discours " l'inconscient et donc en soignant le patient. L'art, pour Lyotard, ne cherche pas une telle «fausse » réconciliation. C'est la psychanalyse, et non l'art, qui cherche à « faire une œuvre» :

[L]'artiste n'est pas descendu dans la nuit en vue de se mettre en état de produire un chant harmonieux, de produire une réconciliation de la nuit et du jour, et de se faire couronner pour son art. Il est allé chercher l'instance figurale, l'autre de son œuvre même, voir l'invisible, voir la mort. L'artiste est quelqu'un dans qui le désir de voir la mort au prix de mourir l'emporte sur le désir de produire. Il faut cesser de poser le problème de l'art en termes de création. l'œuvre n'est jamais que le témoin de son inaccomplissement (DMF, 59-60).

170 L'œuvre d'Yves Klein sur l'idée du Vide pousse cette impasse à ses limites, car en tentant d'accéder, à travers le médium limité de l'art, à ce qui est au-delà de la représentation et donc au-delà de l'art, ce avec quoi l'artiste se retrouve n'est rien, ou l'inaccomplissement de l'art, tout comme Eurydice, l'objet désiré, disparue lorsque Orphée tenta de la contempler directement.

\section{7. Le désir pour l'image}

171 Le désir est attiré par les images car la représentation est la seule façon pour le désir de s'exprimer. Le processus du renversement, guidé par la pulsion de mort, nous rappelle que la représentation voue cependant inévitablement l'objet à la mort. Comme l'indique le psychiatre Joseph $\mathrm{H}$. Smith :

Le désir se fait connaître au moyen de la représentation (image ou mot) qui se substitue à la chose et dans ce sens la voue à la mort. L'image et celui qui la crée, le mot et le locuteur, sont donc détournés, aliénés du réel. La représentation (le langage au sens large, compris comme structurant à la fois la création primitive de 
l'image et le discours) porte le désir à la lumière. La représentation est un signe dès le départ ce que chaque tournure est en un certain sens une perte, une division et une castration. L'achèvement de l'état de séparation dans lequel de telles tournures précoces se produisent est soi-même une perte de l'unité symbiotique, la castration symbolique culminante et préliminaire à la parole ${ }^{119}$.

\section{8. Critique de l'usage du concept de mort par Lyotard}

177 L'on peut cependant se demander quelle est l'utilité du concept de « mort » adopté par Lyotard pour clarifier, ou fournir un fondement aux propriétés trangressives de l'art. Si la mort décrit chez Freud une tendance régressive et destructrice dans le comportement humain, qui révèle la primauté de la pulsion de mort sur la pulsion de plaisir et que le but ultime de la vie est la mort, le désir de voir la mort chez l'artiste ne semble pas décrire exactement la même chose. Car ce que Lyotard semble défendre est plutôt le courage de faire face à la pure hétérogéneité, l'acceptation du fait que l'on ne peut affirmer avoir un contrôle total. Ce que Lyotard adopte alors, est en fait le contraire du vide immobilisé - c'est bien plutôt le mouvement et la plénitude, un 
témoignage de l'énorme et constante métamorphose de la complexité de la vie, sans essayer de la réduire ou de la stabiliser.

Cette distinction peut être clairement vue dans la description faite par Deleuze des forces active et réactive chez Nietzsche ${ }^{123}$. Le désir possède à la fois un aspect réactif, qui tend vers la fixation du désir et son accomplissement illusoire, et un aspect actif qui stimule ou incarne le mouvement et l'excitation. L'art critique doit renverser la subordination de l'actif au réactif dans les formes sédimentées de la pensée, et donc permettre le triomphe des forces actives.

179 À l'instar de l'Anti-๕dipe de Deleuze et Guattari, Lyotard attribue au désir un potentiel révolutionnaire et libératoire. Ce potentiel dépend de la théorie ultérieure des tendances de Freud, et en particulier de la notion de tendance de mort. La « double » nature du désir est essentielle. L'art moderne, pour remplir sa tâche critique, doit saisir ce qui, dans le désir, fait qu'il y a mouvement, de la différence et non de la répétition :

Ce qui est important, c'est que chaque fois qu'une "écriture ", qu'une école a commencé à se stabiliser, chaque fois que les artistes se sont mis à reproduire une facture, on a essayé immédiatement de trouver autre chose. Il y a une espèce de présence du désir dans l'art moderne, ou plutôt une présence de la pulsion de mort dans le désir - présence de ce qui dans le désir fait qu'il y a mouvement. Le sens du désir est composite : il y a dans le désir ce qui bouge, ce qui fait qu'autre chose apparaît et ce qui fait que c'est toujours la même chose qui revient. Le désir est pris dans une fantasmatique; $d u$ fait qu'il est pris dans quelque chose, il est compulsionnel, mais il est vrai aussi qu'il a une puissance de faire tourner cette fantasmatique, et cette puissance fait que le désir erre sur des objets différents. C'est la fonction que l'anti-art doit remplir (DMF, 235).

180 L'art conceptuel, avec son désir d'ordre et de contrôle total, subordonne, dans un sens hégélien, le sensuel au rationnel. Ce rejet de la sensualité en faveur d'un sublime rien, le dépassement de la vie, pourrait être vu comme un triomphe de la pulsion de mort. Un art qui conçoit la pulsion de mort dans un sens freudien ou réactif (comme nous l'avons vu la pulsion pour Freud se manifeste dans des émotions dépressives, inactives) pourrait appartenir à cette catégorie et peut être associé au travail de Joseph Kossuth, Roman Opalka et Yves Klein. One and Three Chairs de Kossuth (1965), expression visuelle du concept de Formes de Platon, cherche à réduire l'art au langage, aux concepts et aux définitions, mettant à l'écart ses aspects sensuels. Roman Opalka cherche une sorte d'œuvre absolue ; son travail est là-encore destiné à exprimer un concept, ici l'idée de l'infinité : "Toute ma vie une seule chose, la description du chiffre un à l'infinité. Une seule chose, une seule vie ${ }^{124} »$. Du blanc sur un fond gris, les peintures de nombres d'Opalka cherchent à effacer la couleur et l'émotion, la «matière » de l'art, et donc à réduire l'art à un idéal abstrait. Et enfin les peintures monochromes d'Yves Klein représentent une tentative de peindre un espace-couleur infini, le «monde de la couleur pure ${ }^{125}$ ", vidé des complications de la vie et du temps, ou de l'histoire, et bien loin de la préoccupation de la figuration narrative pour le quotidien. L'intention de Klein est de court-circuiter le matériel pour accéder à l'immatériel, l'idée absolue de Hegel. Dans tous ces exemples, l'art est envisagé comme la présentation, dans diverses formes, d'une seule et même idée. L'art, au-delà de la forme sensible, avait un noyau rationnel. Selon cette conception, l'art, comme la temporalité, ne serait que le concept existant selon la formule de la Phénoménologie de Hegel.

181 Un art qui incarne la pulsion de mort au sens lyotardien du terme ne serait pas, affirmerai-je, un sublime rien, mais un excès, un sublime chaos. Non pas classique mais 
baroque, non pas hégélien mais nietzschéen, une sorte de platonisme inversé. Ce serait un art du foisonnement, de l'excès, comme l'art hindou. Plutôt qu'une réduction de l'art à l'idée, l'esthétique de la transgression de Lyotard, la transgression des «bonnes formes ", semblerait nous emmener dans la direction d'une esthétique du laid ${ }^{126}$ :

La pulsion de mort n'est pas une autre pulsion, mais le sans-régime. Freud l'approche par la voie de la souffrance : cauchemars des névrosés traumatiques, compulsion de destin ou d'échec, répétitions de perte d'objet. Mais il ajoute que dans l'orgasme même, au cœur d'Eros et de la composition à ce qu'on dit, il y a encore l'errance, l'excès, l'anéantissement du réglé. Extrêmes souffrances, extrêmes joies; tensions supérieures, dépressions profondes. Le composé, le composable reste dans les normes d'intensité, dans des intensités moyennes, sous régime. $\mathrm{La}$ pulsion de mort se marque dans des sautes de tension, ce que Klossowski appelle des intensités, Cage des events. Dissonances, stridences, silences vraiment exagérés, laids (« Plusieurs silences », DP, 282).

Le laid, dès lors, non pas au sens d'une représentation de la laideur, comme dans la Vieille femme grotesque de Quentin Metsy, mais au sens d'une violente distorsion du familier, de l'habituel et du généralement accepté, une destruction de la beauté au sens conventionnel provoquant une intense réaction.

\section{9. Une esthétique du laid}


est connectée à ce statut de science. Chez Lachenmann, la "vérité » est comprise plus dans un sens adornien, comme la démystification des contradictions sociales et de l'idéologie.

En dépit de ce qui pourrait être vu ici comme un manque de clarté dans la terminologie de Lyotard, l'on peut pousser les choses un peu plus loin en se demandant si la stase totale et le mouvement total ou la saturation ne se ramènent pas en fait au même. Par exemple, un morceau de musique purement aléatoire ressemble de près à un morceau de sérialisme total dans lequel chaque paramètre est calculé et contrôlé dans les moindres détails. Dans les deux cas, chaque son semble exister en soi et pour soi: l'auditeur a donc l'impression d'une totale «déliaison» des énergies et d'une annihilation de l'expression subjective, d'une forme de capitulation devant l'objectivité. Le sérialisme total et l'aléatoire produisent tous deux un morceau qui semble statique, sans mouvement.

Ce paradoxe semble trouver son écho chez Freud, dans le lien suggéré entre jouissance, entre un excès de tension et mort.

\section{Les trois niveaux de la figure}

Dans le rêve, le désir figural agit sur le discours, le déformant pour accomplir le fantasme. L'art défait ce fantasme à travers le renversement, un concept lié à la pulsion de mort freudienne, cette pulsion qui défait toute construction vivante, dirigeant toute substance vivante vers un état de Nirvana. Or la figure ultime est une figure qui ne s'exprime ni à travers l'art ni à travers le discours. Le fantasme originaire de Freud, auquel nous avons fait allusion sans pourtant développer la notion, est la "matrice " qui sous-tend toute figuration. Toute représentation est une métaphore de ce fantasme auquel on ne peut jamais accéder directement. Avec le concept lyotardien de la "figure-matrice ", qui est une version du fantasme originaire de Freud, nous sommes amenés à la limite et du discours et de l'art, mais aussi de la théorie même de Lyotard.

L'art a servi à Lyotard de modèle pour un mode de pensée qui est critique de sa propre prétention à la totalité. Cependant, de même que l'opposition discours/figure mise en place au début du livre est ensuite déconstruite, de même cette priorité donnée à l'art est problématisée par Lyotard dans la seconde partie de Discours, figure. Car l'art, en tant qu'il dépend d'un code, n'accède pas directement au désir. On ne peut accéder directement à la figure en tant que processus primaire, ni à travers le discours, ni à travers l'art, car elle est par sa nature-même indicible et invisible. De l'autre côté de l'art et du discours, nous pouvons faire allusion au processus primaire sans jamais le saisir entièrement. De même que Freud recherche un fantasme originaire, de même Lyotard cherche-t-il maintenant à creuser plus profondément, au-delà des apparences, vers une force générative, qui informe et engendre, mais qui nécessairement transcende à la fois le discours et la figure. Cependant quelles sont les caractéristiques de cette réalité sous-jacente? La matrice de Lyotard a toutes les caractéristiques du processus primaire de Freud. En tant qu'il est la plus ancienne partie de notre esprit, d'où dérivent toutes les autres structures, il est le domaine de l'illogique. Primitif, chaotique et émotionnel, le processus primaire, ou Ça, est :

la partie sombre, inaccessible de notre personnalité ; le peu que nous en savons nous l'avons appris de notre étude du travail du rêve et de la construction des symptômes névrotiques, et l'essentiel de cela est de caractère négatif, et peut être 
décrit uniquement comme un contraste de l'ego. Nous approchons le id avec des analogies : nous l'appelons le chaos, un chaudron plein d'excitations bouillonnantes [...] il est rempli d'énergie venue des instincts, mais n'a aucune organisation, ne produit aucune volonté collective, mais seulement un effort pour apporter de la satisfaction aux besoins instinctifs sous réserve du respect du principe de plaisir ${ }^{129}$.

En tant que figure ultime, ou abstraction figurée, la matrice est l'origine irreprésentable de la représentation elle-même. En mettant en place trois niveaux de la figure dans l'art: image, forme et matrice, Lyotard nous amène à chaque niveau à un lieu plus profond en route vers cet espace différencié de l'inconscient lui-même. L'espace de l'inconscient ne doit pas être confondu ni avec l'espace structuraliste, où la réalité est située dans le système, ni avec l'espace phénoménologique, qui situe la réalité dans le pôle de la référence. L'espace du désir déconstruit ces deux espaces.

Quel est donc le rapport entre l'espace inconscient et chacun des trois types de figure? Jusqu'à quel point la figure peut-elle être assimilée au désir, ou bien jusqu'à quel point l'art fournit-il un miroir à cette réalité sous-jacente posée par Lyotard?

\section{1. La figure-image}

La figure-image, le premier niveau, appartient toujours au visible en tant que transgression de ses règles et conventions. Lyotard donne l'exemple d'un tableau de Picasso où le peintre dessine une femme dont la silhouette est représentée de façon multiple, avec plusieurs postures différentes dans la même image. Des perspectives hétérogènes de la même femme se chevauchent, rassemblant des points de vue différents. Comme l'exprime Lyotard :

La figure-image est celle qui se donne à voir sur la scène onirique ou quasi-onirique. Ce qui y subit violence, ce sont les règles de formation de la chose perçue. La figureimage déconstruit le percept, elle s'accomplit dans un espace de différence. Nous pouvons l'articuler avec précision: ce qu'elle déconstruit est le contour de la silhouette [...] On en a une illustration rigoureuse dans ce dessin de Picasso [...] où ce qui fait l'objet de la déconstruction, c'est le bord, la ligne qui marque qu'il y a point de vue unique et réifiant; la coexistence de plusieurs contours induit la simultanéité de plusieurs points de vue. La scène où cette femme dort n'appartient pas à l'espace «réel », elle tolère qu'en un même lieu et un même temps un même corps offre plusieurs positions. Indifférence érotique au temps, à la réalité, à l'exclusion des postures $(D F, 277)$.

Avec la figure-image, l'art demeure figuratif, et cependant les contours de la figure sont perturbés. Un autre exemple de la figure-image pourrait être trouvé dans les peintures de Francis Bacon.

L'« indifférence érotique » à laquelle se réfère Lyotard est un attribut clé de l'espace du désir, où rien n'est nié ou exclu, tout est affirmé et le temps linéaire de la réalité n'existe pas. David Harvey a pointé la compression de l'espace-temps comme un aspectclé de la postmodernité. Le mouvement esthétique que Harvey nomme postmoderne diverge avec son prédécesseur moderniste en cela qu'il questionne le fait que des «réalités radicalement différentes peuvent coexister, entrer en collision et s'interpénétrer ${ }^{130}$ ». Harvey fait référence au film Les ailes du désir de Wim Wenders, avec sa combinaison d'anges existant dans un temps éternel et d'humains vivant dans leur propre temps fini et social, comme exemple de cette compression postmoderne de l'espace-temps. Le roman : Do Androids Dream of Electric Sheep? par Philip K. Dick en est un autre exemple dans la mesure où il est un assemblage de culture chinoise ancestrale 
et de cybertechnologie futuriste. Les deux histoires rassemblent des temporalités incompatibles, à l'instar du processus primaire de Freud.

\section{2. La figure-forme}

La figure-forme opère à un niveau plus profond ; elle ne confond pas l'image elle-même car nous ne sommes plus dans la sphère de l'image, mais elle trouble la forme. Elle

[...] soutient le visible sans être vue, sa nervure ; mais on peut la rendre visible ellemême. [...] [L]a figure-forme inconsciente [...] serait une anti-bonne forme, une «mauvaise forme» [...] [une] énergétique indifférente à l'unité de l'ensemble, [']'élimination de toute figure reconnaissable: il semble bien que nous soyons passés du côté du délire bacchique, descendus dans le sous-sol où les 'invariants' [...] passent à l'ébullition, où l'énergie circule à toute vitesse d'un point à l'autre de l'espace pictural en interdisant à l'œil de se poser nulle part (DF, 277-9).

La figure-forme est une mauvaise forme "dionysiaque", par opposition à la bonne forme « apollinienne » (DF, 277). Comme exemple, Lyotard donne les action paintings de Jackson Pollock (" qu'on pourrait appeler passion painting ", suggère-t-il, traçant un lien entre le travail de Pollock et le désir, DF, 277). Lyotard compare le procédé de dripping de Pollock à un « délire bachique [...] où l'énergie circule à toute vitesse d'un point à l'autre de l'espace pictural en interdisant à l'œil de se poser nulle part, d'investir seraitce un instant sa charge fantasmagorique ici ou là » (DF, 277-8). Avec Pollock, il y a une « absence de toute construction au trait, et même de tout tracé » (DF, 277).

Les peintures de Cy Twombly des années cinquante et soixante, qui se passaient à cette époque de tout sujet figuratif, seraient un autre exemple du plan de pure immanence de la figure-forme. Avec ce deuxième niveau de la figure, nous avons fait un nouveau pas vers l'abstraction du processus primaire.

Mais que s'est-il passé exactement entre le premier et le second niveau? Quelle est la relation entre la confusion des contours d'un Picasso et l'absence de toute figuration dans un Pollock? Pour Lyotard, il y a une " différence totale de fonction » qui rend les deux espaces incompatibles. La clé se trouve dans leur relation au désir et au fantasme, car l'un sert l'accomplissement du désir, et l'autre son inaccomplissement. Ce n'est pas que Picasso soit pur fantasme, car les contours de la femme endormie sont troublés. Mais la femme reste reconnaissable, Picasso reste du côté du principe de plaisir. Les action paintings de Pollock, d'un autre côté, évitent la reconnaissance; ils sont du côté de la pulsion de mort :

L'espace du dessin de Picasso reste acceptable, même aimable: c'est l'espace imaginaire, sans doute arraché au silence de la psyché individuelle, et jeté sous nos yeux collectifs ${ }^{131}$; néanmoins le désir continue d'y trouver accomplissement, parce que l'objet (même déconstruit) continue d'être offert sur la scène représentative. Les couleurs formelles ou plutôt anti-formelles de Pollock, qui représentent le mouvement du désir lui-même et non plus de son objet hallucinatoire, ne peuvent pas être investies par le principe de plaisir ; le désir ne désire pas se voir, il désire se perdre, en se déchargeant sur et dans l'objet. L'espace de Pollock est un espace de charge maxima; pas de perte envisageable, parce que pas d'issue chosiste ou gestaltiste (note 19, DF, 278) ${ }^{132}$.

Dans le Picasso, le désir investit un objet. Dans le Pollock, l'énergie refuse de s'investir. Ce refus de s'investir rappelle la notion de dépense de Bataille, qui se fait le champion de l'idée d'une dépense improductive, ou d'une " perte pour rien ${ }^{133}$ ».

Pour Lyotard, le travail de Pollock témoigne ainsi de la pulsion de mort. 
Lyotard prête une perspective historique à la distinction entre figure-image et figureforme. Le surréalisme tombe dans la catégorie de la figure-image, alors qu'avec l'expressionnisme abstrait américain, la déconstruction "acceptable » du surréalisme cède la place à la déconstruction plus profonde de la figure-forme. En forgeant cette distinction, Lyotard semble suggérer que l'art a progressé vers une représentation de plus en plus fidèle du processus primaire sous-jacent dans tous les systèmes symboliques. En effet, l'expressionnisme abstrait est vu comme un renversement du surréalisme :

Du surréalisme au courant abstrait lyrique américain de l'après-guerre, il y a précisément le renversement de l'image figurale en forme figurale, l'activité déconstructive cesse de ne s'attaquer qu'aux silhouettes visibles et d'y surimprimer des contours visionnaires, elle s'en prend à l'espace même de la mise en scène, au tracé régulateur, au ressort de l'œil. Dali incarne la conservation acharnée de l'espace scénique, tandis que par Matta, Gorky, Pollock, le sondage et l'exhibition de son sous-sol commencent (note 19, DF, 278).

Cependant, le Pollock demeure néanmoins à l'intérieur de la sphère de la représentation. Ce n'est pas le mouvement du processus primaire lui-même, l'acte de trangression, mais une métaphore de celui-ci.

\section{3. Figure-matrice : au-delà de l'art et du discours}

Lorsque les deux premières figures figurent le processus primaire, seul le troisième niveau, la figure-matrice, se situe vraiment de l'autre côté de l'art et de la visibilité. Lyotard n'offre aucune représentation visuelle de la figure-matrice car elle est le terme qu'il emploie pour désigner le processus primaire lui-même. En tant que transgression de la notion même de l'espace, elle sous-tend la visibilité et le système entier des catégories tout en étant invisible elle-même. La figure-matrice engendre à la fois le discours et la figure :

Non seulement elle n'est pas vue, mais elle n'est pas plus visible qu'elle n'est lisible. Elle n'appartient pas à l'espace plastique, et pas non plus à l'espace textuel: elle est la différence même, et comme telle ne souffre pas ce minimum de mise en opposition qu'exige son expression plastique. Discours, image et forme la marquent pareillement, elle qui réside dans les trois espaces ensemble. Les œuvres d'un homme ne sont jamais que les rejetons de cette matrice... (DF, 278-9) ${ }^{134}$.

Encore une fois, la figure a été rédefinie. David Carroll résume efficacement les transformations de la figure dans le livre de Lyotard: "Au-delà du discours, il y a l'image ; au-delà de l'image, la forme ; au-delà de la forme, la matrice ou la différence elle-même. Autrement dit, au-delà du discours critique il y a l'art, et au-delà de l'art, le jeu différentiel des forces que l'art, dans un certain sens, à la fois manifeste et réprime à travers la formation et la déformation de la forme ${ }^{135}$ ». Ce schéma à trois niveaux reflète la structure de Discours, figure, avec sa définition et sa redéfinition du concept de la figure.

\section{3. 1. Forme matricielle comme bloc}

La matrice, «au-delà de l'intelligibilité », court-circuite la fixité d'une structure. Alors que matrice et structure, argumente Lyotard, sont toutes deux «invisibles et synchroniques", une structure est caractérisée par son intelligibilité et par les 
distances fixées entre les termes. Comme l'inconscient, la matrice "n'est pas faite d'oppositions maintenues de façon réglée ", elle ne connaît pas la contradiction. Elle est « entièrement sous la coupe de la différence » (DF, 338-339).

Cependant quelle sorte d'ensemble évite toute sorte de forme fixée ou d'identité ? Lyotard forge le terme «bloc » pour décrire un tel ensemble :

Par bloc, j'entends qu'à la différence des propositions d'un système, les poussées occupent simultanément un même lieu de l'espace (ici libidinal). Les écarts de production ne sont jamais observés [...] [0]n peut comprendre déjà que cette propriété de l'espace inconscient, qui est aussi celle du corps libidinal, d'avoir plusieurs lieux en un lieu, de bloquer ensemble ce qui n'est pas compossible, est le secret du figural : transgression des intervalles constitutifs de la représentation (DF, 339).

Il y a ici une résonnance entre l'idée de bloc et certaines conceptions récentes de la forme musicale. Dans les barres introductives de Gruppen de Stockhausen, l'auditeur se voit présenter de nombreux détails coexistants, chacun desquels forme le début de son propre processus structurel. Chaque détail suit sa propre direction quand le morceau se déroule. De la même façon, le concept lachenmanien de la structure musicale fait contraste avec celui, organique, de Schoenberg. Dans la conception de structure de Lachenmann, qu'il appelle une polyphonie de juxtapositions ordonnées, il n'y a pas une seule idée, mais un rassemblement de plusieurs idées, une sorte de montage de structures différentes ${ }^{136}$.

Étant donné que pour Lyotard, la matrice ne peut pas avoir d'équivalent dans l'art ou dans le discours, les métaphores qu'il emploie pour illustrer cette figure ultime sont tirées de Freud. Un tel exemple se trouve dans la référence faite par Freud dans Malaise dans la civilisation à la coexistence de trois périodes différentes dans la Rome moderne : ancienne, chrétienne et moderne. Rome est considérée par Freud comme étant nonreprésentable, car aucune de ces périodes peut être présentée par soi et en soi. La ville sert ainsi comme modèle de la différence, de la coexistence d'espaces impossibles qui, selon Freud, se trouvent côte à côte dans l'inconscient.

Une autre « image » de la matrice est tirée de l'analyse par Freud du fantasme Ein Kind. Cependant, avant d'étudier le lien entre ce fantasme et la matrice, il sera utile d'envisager l'analyse freudienne du fantasme en général et la façon dont elle a eu un impact sur la théorie esthétique libidinale de Lyotard.

\section{3. 2. La matrice : une origine sans origine}

210 Lyotard prétend que la matrice est l'origine non-présentable de la représentation, mais en même temps il estime qu'elle soutient le système des catégories avec l'absence d'une origine. Ceci rappelle l'idée freudienne que la mort est à l'origine de la vie. Avec cette affirmation paradoxale, Lyotard essaie de s'opposer à un discours des origines, y compris à celui de Freud quand il cherche l'origine du fantasme dans un fantasme originaire :

[L]a matrice fantasmatique loin d'être une origine, atteste l'inverse, que notre origine est une absence d'origine, et que tout ce qui se présente comme l'objet d'un discours originaire est une figure-image hallucinatoire, précisément placée dans le non-lieu initial (DF, 271).

211 Plus tard, Lyotard l'affirme de nouveau: «Je n'entends nullement étudier ici le problème de l'« origine »; de toute façon nous savons qu'elle est elle-même déjà, toujours déjà, une trace $[. .] ».(D F, 349)$. 
212 En quel sens la matrice peut-elle être considérée comme une origine sans origine ? Laplanche et Pontalis ont traité ce problème, une version de la question du réel et de l'origine du sens et de la valeur, dans un article qui traite de la recherche par Freud d'un fantasme originel (en tant que réalité), qui sous-tend toute manifestation du fantasme (comme apparence) ${ }^{137}$. La ligne générale de l'argumentation est résumée cidessous, car elle éclaire la déclaration paradoxale de Lyotard et reprend un grand nombre des thèmes abordés dans la deuxième partie de Discours, figure.

\section{La figure-matrice et le fantasme originel}

\section{1. Le fantasme: subjectif ou objectif?}

Il se pose un grand nombre de difficultés avec une définition du fantasme en opposition au réel, suggèrent Laplanche et Pontalis. Freud lui-même est piégé par cette logique binaire, qui postule une opposition entre un monde externe qui opère selon le principe de réalité, et un monde interne, imaginaire et subjectif, qui fonctionne selon le principe de plaisir. Pour Freud,

[...] le monde des fantasmes semble se situer tout entier dans le cadre de l'opposition entre le subjectif et l'objectif, entre un monde intérieur qui tend à la satisfaction par l'illusion et un monde extérieur imposant progressivement au sujet, par la médiation du système perceptif, le principe de réalité. L'inconscient apparaît alors comme l'héritier de ce qui, à l'origine, était le seul monde du sujet, soumis au seul principe de plaisir. Le monde des fantasmes est semblable à ces «réserves naturelles » que les nations civilisées se créent pour y perpétuer l'état de nature ${ }^{138}$.

214 Avec cette opposition, Freud postule deux formes de pensée qui sont incompatibles l'une avec l'autre : l'une soumise à l'épreuve de réalité, l'autre, la création de fantasmes, soumise seulement à une logique du désir.

Le problème avec cette opposition est que si l'objet de recherche de Freud, le fantasme, appartient seulement au champ de l'imagination, le statut scientifique de cette recherche est mis en question. Contraint par sa propre logique binaire, Freud est obligé d'inventer le concept de « réalité psychique » :

Faut-il reconnaître aux désirs inconscients une réalité? je ne saurais dire [...] Lorsqu'on se trouve en présence des désirs inconscients ramenés à leur expression la dernière et la plus vraie, on est bien forcé de dire que la réalité psychique est une forme d'existence particulière qui ne saurait être confondue avec la réalité matérielle ${ }^{139}$.

216 Que veut dire Freud par ce concept paradoxal ? Freud est en train de suggérer que le fantasme possède un contenu objectif, et que comme tel il n'est pas purement l'expression d'un désir subjectif. Mais quel est ce contenu objectif ? Le contenu objectif que Freud cherche à découvrir se trouve dans les origines présumées du fantasme, qui lui confèrent une qualité intemporelle et universelle. Il est en train de suggérer qu'il y a quelque chose de collectif dans le fantasme individuel. Ses tentatives de théoriser la naissance de la sexualité éclairent un peu plus la question de la réalité psychique. L'hésitation de Freud est ici reprise par Laplanche et Pontalis :

Cette " réalité » psychique, nouvelle catégorie sans cesse occultée chez Freud, il ne suffit pas de la désigner d'emblée comme le «symbolique » ou le «structural ». Si elle est retrouvée et reperdue par Freud, ce n'est pas seulement l'effet d'une carence de l'outil conceptuel : sa relation - structurale elle-même - au réel et à 
l'imaginaire fait toute sa difficulté et son ambiguïté telles qu'elles apparaissent dans le domaine central du fantasme ${ }^{140}$.

\section{2. La théorie freudienne de la sexualité : une impasse}

217 La théorie de la sexualité infantile de Freud, conçue après l'abandon de son ancienne théorie de la sexualité, attribue à la sexualité une fonction biologique. Le fantasme sexuel, dans cette nouvelle conception, n'aurait aucune base dans la réalité, mais serait plutôt le résultat d'une activité auto-érotique. Autrement dit, le fantasme sexuel serait un fantasme pur qui se présente comme un vrai souvenir. De tels « souvenirs ", insiste Freud, ne sont pas véritables, mais sont destinés à dissimuler une sexualité endogène en représentant la sexualité comme une irruption externe plutôt que quelque chose qui est immanent au sujet. Ici, ce n'est pas le désir qui se dissimule dans la réalité comme dans le travail du rêve, mais la réalité qui se dissimule dans le désir.

218 L'idée d'une sexualité endogène est venue à Freud comme une façon de dépasser son ancienne théorie de la séduction, qui cherchait à désigner une origine objective au fantasme sexuel. Les difficultés rencontrées par Freud éclairent le problème plus général des origines.

219 La théorie freudienne de la séduction sexuelle consiste en une tentative d'articuler sexualité et refoulement. La sexualité, selon sa théorie, a ses origines dans un événement traumatique. Le refoulement du traumatisme est la deuxième phase du traumatisme que Freud organise en deux parties : le rapport sexualité/refoulement est temporel. Le premier événement est la « scène de séduction » pendant laquelle l'enfant subi une avance sexuelle par un adulte. À ce stade, l'enfant n'est pas capable d'intégrer l'événement: pour l'instant il n'a pas de sens. Car l'enfant ne peut pas encore expérimenter l'excitation sexuelle, il n'a pas encore en place une dimension sexuelle. L'événement, ayant eu lieu à un très jeune âge, ne se manifeste pas de nouveau avant l'adolescence. La deuxième étape du traumatisme implique le souvenir de la « première scène ", une souvenance qui entraîne un mécanisme de défense, le refoulement. Selon cette théorie donc, la sexualité est imposée sur le sujet depuis l'extérieur, mais au moment du refoulement adolescent, l'événement, déjà internalisé, s'impose depuis l'intérieur du sujet même : la source de l'événement est à ce moment immanente. On peut donc dire que le traumatisme vient à la fois de l'intérieur et de l'extérieur : « [d]e l'extérieur puisque c'est de l'autre que la sexualité arrive au sujet, de l'intérieur puisqu'il jaillit de cet externe intériorisé ${ }^{141} »$.

220 Mais comment un traumatisme peut-il avoir son origine à la fois à l'intérieur et à l'extérieur du sujet? Le paradoxe de la version temporelle des origines de la sexualité de Freud est décrit de la façon suivante par Laplanche et Pontalis :

Comment [...] concevoir la formation de ce déjà-là ? Comment la première scène 'sexuelle pré-sexuelle' a-t-elle pu prendre signification pour le sujet? Dans une perspective qui tend à réduire la dimension temporelle à la chronologie, il faut, ou bien s'engager dans une régression infinie, chaque scène ne prenant valeur sexuelle que par l'évocation d'une scène antérieure sans laquelle elle n'aurait simplement rien été pour le sujet, soit s'arrêter arbitrairement à une " première » scène malgré ce qu'elle comporte d'inconcevable ${ }^{142}$.

En termes lyotardiens, on pourrait demander comment l'événement vient à signifier, comment ce qui ne peut pas être signifié vient à s'intégrer dans un système symbolique qui lui attribue du sens. Cet événement est-il externe ou interne au discours ? Y a-t-il 
un moment durant lequel figure et discours sont séparés? Pour Laplanche et Pontalis, toute division temporelle est nécessairement une illusion. Car comment peut-il avoir une irruption depuis l'extérieur avant toute distinction entre le dedans et le dehors? Comment peut-il y avoir « un sujet d'avant le sujet et recevant son être, son être sexuel, d'un extérieur d'avant la distinction intérieur-extérieur ${ }^{143}$ »?

En effet, toute tentative de saisir une réalité avant ou au-delà du langage est forcément insatisfaisante, car on ne peut pas avec certitude distinguer la vérité de la fiction. Le fantasme est-il vécu ou simplement inventé ? Comme Freud l'a lui-même remarqué, « il n'existe dans l'inconscient aucun indice de réalité de sorte qu'il est impossible de distinguer l'un de l'autre la vérité et la fiction investie d'affect ${ }^{144} »$. De plus, à chaque fois que l'on parle d'une origine, on met en avant un principe supérieur. On ne peut donc jamais parler d'origine, mais seulement d'un résultat de l'origine. Comme il y a toujours un déjà-là, on trouve seulement des origines relatives, secondaires : l'origine reste éternellement indicible.

\section{3. Le fantasme transcendant}

Face au dilemme de la fuite de la scène ultime, Freud introduit une nouvelle notion, Urphantasien. Les Urphantasien sont des fantasmes transcendants. L'origine du symptôme est donc placée hors de portée de l'expérience subjective. Comme l'expriment Laplanche et Pontalis, avec les Urphantasien :

on assiste à une véritable mutation de l'exigence du fondement: puisqu'il s'avère impossible de déterminer si, avec la scène primitive, nous avons affaire à un événement vécu par le sujet ou à une fiction, il faut rapporter ce qui fonde en dernière analyse le fantasme à un en-deçà, à quelque chose qui transcende à la fois le vécu individuel et l'imaginé ${ }^{145}$.

Si les mêmes fantasmes sont créés, avec le même contenu, par des individus différents, il doit y avoir une structure organisatrice qui vient avant le fantasme. Freud justifie cette antécédence avec une explication phylogénique. Selon cette explication, les fantasmes sont des expériences vécues aux temps originaires de la famille humaine desquelles le sujet est devenu aliéné. À travers ce processus d'aliénation, la réalité de fait est devenue réalité psychique ; une réalité constante, ou universelle, qui transcende l'expérience individuelle :

C'est donc encore une fois un réel qui est postulé en deçà des élaborations fantasmatiques, mais un réel dont Freud ne manque pas de souligner le statut structural et l'autonomie par rapport aux sujets qui, eux, en sont absolument dépendants. Il va même très loin dans ce sens puisqu'il admet la possibilité, entre le «schème» et les expériences individuelles, d'une discordance qui serait une condition du conflit psychique ${ }^{146}$.

Laplanche et Pontalis suggèrent qu'il y a des similarités entre ce réel qui s'impose à l'imaginaire et l'ordre symbolique de Lacan et Lévi-Strauss. Chez Lacan, comme avec l'Entzweiung de Freud, le passage de l'imaginaire au symbolique implique le moment de division entre le moi et l'autre, réalité physique et réalité psychique, et en même temps l'origine du refoulement. L'ordre symbolique est fondé par le principe de réalité (contrairement à l'ordre imaginaire qui est fondé par le principe de plaisir) et est organisé selon des règles et des lois. Le sujet est donc d'une certaine façon structuré par ces règles et lois, mais le clivage entre le Moi et l'autre reste actif, et le sujet, donc, reste différencié. 
Or l'explication phylogénique de Freud, comme le montrent Laplanche et Pontalis, est, encore une fois, très problématique. L'opposition même entre événement et constitution, que nous avons vue dans la théorie abandonnée de la sexualité, réapparaitt ici. Car il n'est pas clair à quel point la réalité de fait (externe) devient réalité psychique (interne):

Sous le masque pseudo-scientifique de la phylogenèse, dans l'appel aux traces mnésiques héritées, il faudrait donc savoir reconnaître la nécessité où se trouve Freud de postuler l'antériorité d'une organisation signifiante par rapport à l'efficacité de l'événement et de l'ensemble du signifié. Dans cette pré-histoire mythique de l'espèce, s'affirme l'exigence d'une pré-structure inaccessible au sujet, échappant à ses prises et à ses initiatives, à sa « cuisine » intérieure... Mais Freud sera littéralement pris au piège de sa conceptualisation ; il retrouverait, dans cette fausse synthèse qu'est le passé de l'espèce humaine conservé en schèmes héréditairement transmis, l'opposition qu'il cherche en vain à dépasser de l'événement et de la constitution ${ }^{147}$.

L'étude freudienne de la paranoïa semble soutenir la thèse que "l'origine du fantasme est intégrée dans la structure même du fantasme originaire ${ }^{148}$ ». Autrement dit, l'événement et la constitution sont synchrones. L'origine $d u$ fantasme n'est pas quelque chose d'externe, bien plutôt elle est inhérente au fantasme même. Le fantasme, en tant que scène de la représentation, contient en même temps l'origine de la représentation.

\section{4. L'origine est immanente}

Cette conclusion paradoxale dépend de l'importance accordée par Freud à l'entendu, comme prototype du signifiant qui a rapport à l'origine de la signification. Selon Freud, le fantasme commun d'être à l'écoute contient un bruit. Freud décrit le cas d'une paranoïaque qui prétend avoir été observée pendant qu'elle était couchée auprès de son compagnon. Elle croit avoir été observée car elle a entendu le déclic d'un appareil photographique. Ce bruit, qui fait intégralement partie du fantasme, fait écho à la scène primitive où les parents réveillent l'enfant, ou alors à celle où l'enfant, écoutant ses parents, a peur de se trahir en faisant du bruit. Il y a quelque chose qui apparaît comme une répétition à l'intérieur même du fantasme de l' «événement original ", événement qui pour Freud a généré tout fantasme ultérieur d'être à l'écoute : «le bruit invoqué par la patiente reproduit dans l'actuel l'indice de la scène primitive, cet élément à partir duquel a pu prendre toute l'élaboration fantasmatique ultérieure ${ }^{149}$ ». Ce bruit peut être compris comme ce qui réveille le sujet de son état hallucinatoire et imaginaire, l'indice d'un réel, de quelque chose d'extérieur, qui provoque la scission du moi et de l'autre et l'entrée du sujet dans l'ordre symbolique : «L'entendu [...] rompt la continuité d'un champ perceptif indifférencié et en même temps fait signe [...] mettant le sujet en position d'interpelé150 ». Le fantasme sert à expliquer, à donner $d u$ sens à ce qui parait énigmatique.

distinction faite par Freud entre l'événement et le fantasme peut être traduite comme la distinction lyotardienne entre figure et discours: le discours conscient, comme une sorte de fantasme, une scène de la représentation, sert à donner du sens, à maîtriser, à lier la figure inconsciente.

Laplanche et Pontalis soulignent trois types de fantasmes chez Freud:

- Les fantasmes des origines (la scène primitive dépeint les origines de l'individu)

- Les fantasmes de la séduction (la scène primitive dépeint les origines de la sexualité) 
- Les fantasmes de la castration (la scène primitive dépeint les origines de la différence sexuelle).

"Dans leur contenu même", écrivent-ils, "dans leur thème (scène primitive, castration, séduction [...]), les fantasmes originaires indiquent aussi cette postulation rétroactive : ils se rapportent aux origines ${ }^{151} »$. Si l'entendu, comme origine, est structurel, c'est en même temps dans le contenu même, le thème de ses fantasmes, qu'on trouve le "statut de déjà-là des fantasmes originaires ${ }^{152}$ ». Structure, thème et fonction convergent :

dans l'indice que fournit le champ perceptif, dans le scénario construit, dans la recherche modulée des commencements, se donne sur la scène du fantasme ce qui « origine » le sujet lui-même ${ }^{153}$.

La différence elle-même, la division du sujet, est contenue dans le fantasme originaire lui-même et réactivée, répétée, avec chaque fantasme subséquent. Fond et forme convergent. C'est en ce sens que l'origine du fantasme est «toujours déjà, une trace $[. .] ».(D F, 349)$, car il n'y a pas de fantasme sans l'absence ou l'inaccessibilité de l'objet. Freud nous enseigne que le désir et la violence naissent au même moment, d'où l'idée que l'origine est intégrée à la structure même du fantasme. Si l'origine est immanente à la structure même, il devient clair encore une fois que figure et discours sont engendrés ensemble.

\section{5. Origine du fantasme : conscient ou inconscient ? Façade ou fond?}

234 Si fond et forme convergent dans le fantasme, la distinction faite par Freud entre le conscient et l'inconscient devient problématique. Quel est le statut métapsychologique $\mathrm{du}$ fantasme? Quel est son rapport avec la topologie freudienne des systèmes inconscients, préconscients et conscients?

Freud a attribué le même nom, Phantasie, à l'activité mentale inconsciente et à la rêverie diurne, qui a lieu au niveau de l'imagination consciente, car il voulait insister sur la parité du fantasme conscient et inconscient. Pour lui, le fantasme inconscient est du fantasme conscient refoulé, et qui est donc devenu pathogène. Le travail du rêve semblerait rapprocher ces deux pôles, favorisant la thèse de la double nature du fantasme. Ceci met en question l'idée d'un fond inconscient, avant le langage, sa «façade».

Au début, Freud semble dévaloriser l'élaboration secondaire comme ruse, comme une forme de défense. Or en fait Freud propose quelque chose de très différent. L'élaboration secondaire n'est tout simplement pas considérée comme une forme de dissimulation ou de censure consciente afin de rendre acceptable les contenus inconscients :

Les fantasmes de désir que l'analyse découvre dans les rêves nocturnes se révèlent être des répétitions et des remaniements de scènes infantiles; ainsi, dans plus d'un rêve, la façade du rêve nous désigne de façon immédiate le véritable noyau du rêve, qui se trouve déformé parce qu'il est mêlé à un autre matériel. » Ainsi les deux extrémités du rêve, et les deux modalités de fantasme qui s'y retrouvent, semblent sinon se rejoindre, du moins communiquer de l'intérieur et comme se symboliser l'une et l'autre ${ }^{154}$.

Le fantasme conscient et inconscient, les pensées du rêve latentes et manifestes, semblent coïncider de façon immanente: le fantasme contient en son cœur son 
contraire apparent. Si la figure est à l'origine du discours, de la même façon le discours est à l'origine de la figure. Comme le dit Lyotard, le fantasme est « figuralité, différence, défi à tout système réglé d'oppositions", mais il est aussi "de quelque manière une "écriture", une configuration répétitive, un crible, dans lequel viendra se laisser prendre et se faire "signifier" tout ce que le hasard de la rencontre, restes diurnes, épisodes de la vie quotidienne, jettera à la tête du sujet » (DF 348-9). Le fantasme est à la fois différence et répétition.

\section{6. Ein Kind wird geschlagen : une logique de la différence}

Comme nous l'avons dit auparavant, l'analyse par Freud du fantasme Ein Kind sert comme modèle pour Lyotard de la figure-matrice, car dans ce fantasme règne une logique non pas de la différence mais de l'opposition. Freud montre dans son analyse qu'Ein Kind est un fantasme qui s'auto-déconstruit. Comme le dit Lyotard, dans ce fantasme, ce que nous observons est l'« absolu de l'anti-synthèse, utopie » (DF, 354).

Freud, comme nous l'avons vu, s'intéressait à la question de la réalité dans la scène primitive ou traumatique. Pour lui, les fantasmes expérimentés par ses patients étaient des présentations métaphoriques d'un fantasme fondamental. Avec l'analyse d'Ein Kind, l'opposition entre le réel et l'imaginaire est déconstruite. En effet, le fantasme est vu comme possesseur d'une sorte de réalité particulière, qui n'est ni vraiment réel ni vraiment imaginaire.

Le but de Freud est d'expliquer la construction de fantasmes de violence entre ses patients. Il voit dans ces fantasmes l'origine de la différence entre les sexes. Freud commence son analyse par une série de fantasmes manifestes sur le thème «Un enfant est battu » et montre comment la phase finale du fantasme se produit après avoir être passé par différentes étapes dans lesquelles l'action de battre est exécutée et subie par des sujets et objets différents. La découverte essentielle de cette analyse particulière, comme le soutient, est que le fantasme lui-même peut se voir attribuer une histoire qui explique certains arrangements ou permutations au cœur même de sa structure ${ }^{155}$.

Freud reconstruit les trois phases du fantasme "Un enfant est battu », en montrant comment chaque phase se transforme en la phase suivante :

Phase A : un enfant éprouve du plaisir en observant la correction d'un rival. Ce rival est quasiment toujours un autre enfant, d'habitude un frère ou une sœur. Le symbole de l'autorité qui bat est le père.

Phase B : Lors de cette phase, l'enfant qui produit le fantasme le retourne contre lui-même, car c'est désormais cet enfant qui est battu. Pour Freud, l'enfant, en renversant la Phase $\mathrm{A}$, cherche à réprimer l'amour incestueux qu'il a pour son père.

Phase C: Celle-ci est la forme du fantasme telle qu'elle se présente aux adultes. L'enfant qui est battu est désormais un autre enfant (comme dans la Phase A) et la personne qui bat est devenue un symbole général de l'autorité. Le patient, le sujet, est de nouveau celui qui observe la scène de violence. Le plaisir masochiste de la Phase B est devenu un plaisir sadique ${ }^{156}$.

Pour Lyotard, ce fantasme représente la transgression de la forme même :

Le fantasme Ein Kind est bien une forme prise par la transgression: il y a une scansion « horizontale » du représenté de la fustigation, du signifié « $\mathrm{X}$ bat $\mathrm{Y}$ ». Mais en tant que formé de couches superposées, que figure feuilletée, ce fantasme est la transgression de cette forme : la scansion « verticale » qui transforme la figure Le père bat l'enfant en figure Un enfant est battu en passant par Je suis battue par le père, 
obéit à la compulsion d'un rejet, nommément d'une régression [...] Les figures de chaque phase sont défigurées l'une après l'autre du fait de la superposition d'une nouvelle figure engendrée par le rejet. L'ordre qui s'esquisse et où le désir se laisse prendre (l'ordre « $\mathrm{X}$ bat $\mathrm{Y} »)$ est constamment déconstruit $(D F, 354)$.

La matrice-figure de Lyotard, en tant qu'espace de la différence pure, est donc très proche $d u$ fantasme freudien qui se transgresse de façon répétée. Comme l'exprime Lyotard, « [...] la "forme" à laquelle nous avons affaire avec le fantasme n'est pas une bonne forme. Elle est certes une forme dans laquelle le désir reste pris, la forme prise par la transgression; mais elle est aussi la transgression, au moins potentielle, de la forme » $(D F, 350)$. La forme de la matrice qui refuse d'identifier avec elle-même est à la fois fantasme et renversement, transgresseur et transgressé.

\section{7. La matrice est l'œuvre de la pulsion de mort}

L'analyse freudienne du fantasme mène Lyotard encore une fois à une nouvelle définition de la figure. Avec le fantasme Ein Kind, écrit-il, «nous comprenons que le principe de figuralité, qui est aussi celui du dé-jeu, est la pulsion de mort [...]» (DF, 354). Le rôle du fantasme, qui opère, insiste-t-il, selon la logique de la pulsion de mort, est de nous rapprocher du Nirvana, car une forme qui s'auto-détruit en permanence est une forme qui engendre la jouissance. La forme de Ein Kind, explique Lyotard, " obéit à la compulsion de rejet, [...] et la fonction de ce rejet est de surcharger l'appareil en excitation $[. .] ».(D F, 354)$. La décharge soudaine d'excitation qui résulte d'une logique de la transgression accomplit la jouissance mais, en même temps, nous approche de la mort :

La jouissance n'est pas la mort, mais en même temps qu'elle est la décharge de la tension, elle confère pourtant comme la mort l'obscurité, qui est l'anéantissement de la représentation, et le silence, qui est celui des mots $(D F, 351)$.

\section{8. La pulsion de mort et l'éternel retour}

Ce que Freud cherchait à comprendre dans son analyse du fantasme, le jeu fort/da, le cauchemar..., soutient Lyotard, était « le retour éternel du même ${ }^{157}$ ", quelque chose qui se trouve au-delà du principe de plaisir. Le retour éternel du même engendre une configuration qui n'est pas celle d'un système représentatif lié, car de tels systèmes ne possèdent pas le caractère itératif que Freud cherchait à expliquer. La compulsion à répéter nous rappelle la présence de quelque chose qui se trouve "à l'extérieur " du langage et d'une pensée identitaire. Ainsi, ce n'est pas la répétition du même (Eros) qui intéresse Lyotard, mais plutôt ce qui est rejeté dans le processus :

Dans le retour ou la répétition, [la pulsion de mort] n'est pas ce qui fait que cela revient, mais que cela s'en va, ce qui fait que la formation (figure-forme, figure-image, énoncé, ici phase du fantasme) ne se maintient pas, ne peut se maintenir identique à soi. Elle est le re- du retour ou de la répétition, mais au sens du rejeter, non du revenir. Elle n'est pas le jeu, mais le dé-jeu, ce qui déjoue ; le déplacement. La digression qui est dans la régression $(D F, 353-354)$. 


\section{Les limites de l'esthétique libidinale de Lyotard}

Avec l'idée de la matrice et de la pulsion de mort, Lyotard prétend avoir accédé au réel, quoiqu'un réel en mouvement perpétuel. Ce réel est "la différence ", qui indique l'absence d'une origine de la représentation. En effet, avec la figure-matrice, Lyotard prétend avoir « mis la main » sur « la vérité de la différence »:

Le figural [...] ne déconstruit pas seulement le discours, mais la figure en tant qu'image reconnaissable ou forme bonne. Et sous le figural, la différence, non la trace tout court, la présence-absence tout court, indifféremment discours ou figure, mais le processus primaire, le principe de désordre, la poussée à la jouissance ; non un intervalle quelconque séparant deux termes dans le même ordre, mais une rupture absolue d'équilibre entre un ordre et un non-ordre. En fouillant cette épaisseur de la pseudarché, nous allons peut-être mettre la main sur la vérité de la différence, déjà palpée dans l'ordre sensible, dans l'ordre du champ visuel, mais où elle n'est que métaphore : le champ pseudarchaïque est son champ propre [...] (DF, 328).

Avec la matrice comme principe nouveau, transcendantal, de la réalité, le réel compris de façon conventionnelle est donc redéfini. L'espace incompossible et irrationnel de la matrice est désormais le principe supérieur, c'est-à-dire, la base du réel. Cette vision de la réalité s'oppose à une vision rationnelle selon laquelle le tout spatio-temporel est calculé à travers l'addition de ses parties constitutives. Comme nous l'avons vu, la notion de bloc va aussi contre l'idée conventionnelle de la structure comme compossibilité intelligible ${ }^{158}$.

Nous ne pouvons pas nous empêcher de nous demander si l'idée de la matrice en tant qu'origine absente ne représente pas en réalité une origine voilée, ce qui voudrait dire que Lyotard est aussi coupable d'une métaphysique du désir, et d'une pensée des origines que Freud. De plus, on pourrait se demander si l'inconscient n'est pas en fait tout simplement une métaphore de plus pour le réel. Il se pourrait bien que l'art et le discours soient insuffisants, mais qui peut dire que la théorie psychanalytique l'emporte sur d'autres théories quant à la vérité ? On pourrait soutenir que, avec son concept de la figure-matrice en tant que pulsion de mort, Lyotard risque d'absolutiser la théorie freudienne de la libido de la même façon qu'il a abandonné la poétique de Mallarmé à la fin de la première partie de Discours, figure. La matrice de Lyotard ellemême prend l'apparence d'une figure-image hallucinatoire.

\section{Conclusion}

En dépit de l'intention affichée de Discours, figure, faire «dire » au discours ce qui ne peut pas être signifié avec les systèmes symboliques, mener le figural à l'expression en utilisant l'art comme modèle, ouvrant ainsi la voie à une critique de l'idéologie en général, le livre s'achève avant que ces buts ne soient atteints. Car même l'art s'avère être un medium insatisfaisant pour mener à l'expression l'indicible: pour dire l'indicible il doit cesser de dire quoi que ce soit. Le tournant vers Freud au beau milieu du livre n'aide pas à résoudre le dilemme, et ne fait que mettre en lumière le même problème.

En effet, après la publication de l'Économie libidinale, trois ans après Discours, figure, Lyotard a abandonné le projet libidinal, allant même jusqu'à qualifier sa propre pensée à cette période de "méchante ». Cependant, comme nous le verrons dans la section 
finale, la tentative de Lyotard d'« aller au-delà » de la libido emprunte elle-même un chemin semé d'embûches.

\section{L'ambiguïté dans la position de Lyotard}

Il y a un Freud oublié dans une telle lecture, c'est celui qui a osé écrire qu'un investissement n'est jamais abandonné par la libido pour un meilleur (DMF, 13).

Il existe une ambiguïté fondamentale pendant toute la période libidinale de Lyotard qui a des implications quant à sa théorie esthétique ainsi que son attitude politique et philosophique. Je pense que l'on peut observer cette ambiguïté dans Discours, figure mais aussi dans les deux recueils d'essais de la même période : Dérive à partir de Marx et Freud et Des dispositifs pulsionnels. Parfois, quand il soutient un art critique qui opère à l'intérieur des paramètres du langage artistique existant, tout en résistant à la clôture, Lyotard parait proche de la dialectique négative d'Adorno. Ici, l'art est mis en équation avec la critique. À d'autres moments, en essayant d'être fidèle à l'hétérogénéité radicale du désir, il rejette catégoriquement cette définition de l'art en adoptant une approche a-critique, une énergétique, qui annonce, semble-t-il, la fin de l'art et la dissolution de la catégorie de l'esthétique. Une telle position semble remettre en question le projet critique déclaré de Discours, figure: "Ce livre-ci n'est lui-même qu'un détour pour mener à [la critique pratique de l'idéologie] » $(D F, 19)$. Car la position affirmative peut être comprise comme un déni de l'histoire et de l'aliénation, qui est lui-même de nature idéologique. On peut aussi imaginer cette ambivalence comme une oscillation permanente entre la modernité, une politique d'émancipation implantée dans une dialectique de l'histoire, et la postmodernité, qui abandonne tout grand récit de ce genre.

Par exemple, l'idée de renversement, une forme d'autoréflexivité, et de critique des formes culturelles idéologiques, est centrale dans Discours, figure. Comme nous l'avons $\mathrm{vu}$, de nombreux exemples issus de l'art auxquels Lyotard se réfère dans son texte (Mallarmé, Klee, Picasso, Magritte, et autres) appartiennent à ce que l'on comprendrait communément comme faisant partie du mouvement esthétique du " modernisme ».

Cependant, lorsque Lyotard a écrit la préface à la collection Dérive (1972) qui continue la tâche déclarée de Discours, figure, le philosophe avait déjà changé de position, en insistant sur le fait que Dérive, ainsi que Discours, figure, étaient trop critiques et pas assez affirmatifs (c'est-à-dire libidinaux) :

L'idée, affirmative, du dispositif est, je le répète, ce qui fait défaut à presque tous ces essais. La catégorie de la figure y reste prisonnière du réseau de la pensée négative, nihiliste (DMF, 18).

Autrement dit, en assimilant l'esthétique à la critique, Lyotard accuse ces essais de prendre une position trop adornienne. Il lance en même temps un défi au discours critique lui-même, car le discours critique reste enraciné dans une quête du savoir, et le savoir, par sa nature même, canalise, lie et réprime la libido, il travaille en excluant l'autre :

Est-ce que vous ne voyez pas que critiquer, c'est encore savoir, mieux savoir ? Que la relation critique est encore inscrite dans la sphère de la connaissance, de la prise de conscience et donc de la prise de pouvoir? Il faut dériver hors de la critique. Bien plus : la dérive est par elle-même la fin de la critique $(D M F, 15)$.

La critique, pour Lyotard, est trop hégelienne : « Entre une position et une autre, il y a déplacement, non dépassement ; dérive et non critique, événement et non négativité » 
(DMF, 15-16). Le concept de la dérive est, paradoxalement, un appel au discours critique à aller au-delà de la négation, et certaines formes d'art, encore une fois, semblent incarner cette nouvelle position affirmative, tout comme l'art devait ouvrir la voie vers une critique de l'idéologie présente dans Discours, figure:

Les courants les plus modernes [en art] [...] placent la pensée critique, la dialectique négative devant un défi considérable: ils produisent des œuvres affirmatives, et non critiques [...] Le philosophe et le politique (celui que vous lirez ici) auraient aimé se contenter après Adorno de se servir des arts comme de matrices formelles de renversement ; la position nouvelle [...] est la fin de la critique (DMF, 20-21).

Ici nous pouvons remarquer comment le concept de renversement, essentiel à la distinction faite par Lyotard entre l'œuvre d'art et le rêve dans Discours, figure, est rejeté car trop adornien. Comme l'a suggéré David Carroll, la position affirmative que prend Lyotard est une sorte d'image renversée de Hegel. Hegel a annoncé la fin de l'art, car pour lui, la philosophie devrait incorporer l'art et passer à un niveau plus élevé. Lyotard ici proclame la fin de la critique non pas en l'incorporant dans un mouvement dialectique, mais en sortant de celle-ci ${ }^{159}$.

Le problème que Lyotard a avec la critique ou avec la théorie en général pendant sa période libidinale vient du fait que la critique reste forcément dans les limites de ce qu'elle critique. Comme l'exprime Lyotard au début de la section d'Économie libidinale intitulée "Un désir nommé Marx », «[...] on s'en moque de critiquer, puisque c'est se maintenir dans le champ de la chose critiquée et dans la relation dogmatique, voire paranoïaque du savoir » $(E L, 117)$. Son projet pendant cette période est d'ébranler la position dominante, "virile », de la théorie : «Recommencer la révolution, [...] c'est abandonner la position virile $[. .] ».(E L, 146)$. La théorie doit accepter qu'elle est fragmentaire et partielle, qu'elle ne peut pas être le système unifié, total, qu'elle prétend être.

Il serait utile à ce point d'examiner les déclarations faites par Lyotard sur Adorno. Adorno et Lyotard traitent tous deux des mêmes problèmes et assignent une position centrale à l'art. Néanmoins, comme nous l'avons vu, ils arrivent à des conclusions différentes. Dans l'essai, «Adorno come diavolo » (1972) ${ }^{160}$, Lyotard se prononce contre Adorno, en décrivant la position de ce dernier comme étant une position de théologie négative :

La dissipation de la subjectivité dans et par le Kapitalisme, Adorno, comme Marx, y voit une défaite; il ne pourra surmonter ce pessimisme qu'en faisant de cette défaite un moment négatif dans une dialectique de l'émancipation et de la conquête de la créativité. Mais cette dialectique n'est pas moins théologique que le nihilisme de la perte du sujet créateur, elle est sa résolution thérapeutique dans le cadre d'une religion, ici religion d'histoire [...] L'art est une espèce de Christ dans sa fonction dénonciatrice. Quant à la rédemption effective, elle est encore plus éloignée que dans la christologie, et elle doit l'être, l'art n'est pas réconciliateur, c'est sa force, se tenir dans le nihilisme, l'assumer, ainsi le manifester (« Adorno come diavolo », DP, 115-6).

Selon la dialectique négative d'Adorno, l'art doit se garder de toute réconciliation et rester farouchement à l'intérieur du moment négatif, l'utopie restant fermement implantée dans l'avenir, d'où la caractérisation par Lyotard de la dialectique négative comme " religieuse » : les sacrifices d'aujourd'hui seront compensés demain.

261 Cependant, pour Lyotard, la perte de sens de l'art dans la modernité (comme nous l'avons vu, l'art moderne se caractérise par la perte du caractère «religieux » de l'art 
traditionnel, "religieux » étant pris dans son sens étymologique, c'est-à-dire sa fonction de lier les gens) ${ }^{161}$ doit être considérée de façon affirmative, et non tragique. L'esthétique libidinale renverse donc la théorie critique, en affirmant ce qui reste négatif (arbitraire, non-dialectique, irrationnel) dans la théorie d'Adorno. Adorno, en demeurant dans la critique, prend la position nostalgique de diable dans un monde sans dieu, ne donnant sa faveur qu'à des « œuvres sataniques » :

La totalité manque $=$ il n'y a pas de dieu pour concilier $=$ toute conciliation ne peut être présente que dans son impossibilité, parodiée = elle est œuvre satanique. Vous avez beau remplacer dieu par le diable, le préfixe sur- par la vieille taupe sousterraine, vous restez dans le même dispositif théologique. Vous passez du nihilisme honteux au nihilisme affiché. L'œuvre d'Adorno comme celle de Mann et de Schoenberg est marquée par la nostalgie. Le diable est la nostalgie de dieu, dieu impossible, donc possible justement comme dieu («Adorno come diavolo», DP, 125).

Cette position affirmative est reprise dans l'essai "Capitalisme énergumène » (1972) ${ }^{162}$, une discussion de L'Anti-@Edipe de Deleuze et Guattari qui oppose la Aufhebung hégélienne à une forme d'oubli nietzschéen, dépeignant L'Anti-Eđdipe comme un livre acritique :

L'Anti-@Edipe, malgré son titre, n'est pas un livre critique. Plutôt un livre positif, pulsionnel, comme l'Antéchrist, une position énergétique inscrite en discours, où la négation de l'adversaire ne se fait pas par Aufhebung, mais par l'oubli [...] Vous trouverez dans ce livre de Deleuze et Guattari un mépris affiché à l'endroit de la catégorie de transgression (et donc implicitement de tout Bataille) : c'est que ou bien l'on sort tout de suite sans perdre son temps à critiquer, simplement parce qu'on se trouve placé ailleurs que dans la religion de l'adversaire, ou bien l'on critique, on garde un pied dedans, tandis qu'on a l'autre dehors, positivité du négatif, mais en fait néant de ce positif («Capitalisme énergumène », DP, 11).

L'oubli, comme alternative à la critique, mime la nature nomade du désir. Non pas une conquête, mais une dérive sans fin: «il n'y a pas de frontière franchie, pas de transcroissance, pas de critique; il y a un déplacement, le désir se nomadise dans un autre espace, un autre dispositif s'est mis à fonctionner, ça marche autrement, et si ça marche, ce n'est pas parce qu'on a fait la critique de l'autre vieille machine » $(D P, 11)$.

Cependant, la citation ci-dessus semble ignorer l'importance de la critique dans L'AntiEdipe, la notion de la critique immanente caractéristique du modèle kantien. Dans L'Anti-CEdipe, le mécanisme critique est dans une relation d'immanence avec les machines désirantes. Toutefois, pour le Lyotard affirmatif d'Économie libidinale, comme nous l'avons vu, la critique est nécessairement liée à la position de l'adversaire et doit être rejetée catégoriquement, ce qui pourrait expliquer le fait qu'il qualifie l'Anti๔Edipe de livre a-critique. Sa position radicale dans L'Économie libidinale est formulée de la façon suivante : « Pas besoin de faire la critique de la métaphysique (ou de l'économie politique, ce qui est la même chose) [...] plutôt être dedans et l'oublier, c'est la position de la pulsion de mort $[. .] ».(E L, 11)$. Ailleurs, Lyotard écrit :

[L]e piège tout simple consiste à répondre à la demande de la théorie vaincue, et cette demande est : mettez quelque chose à ma place. Or l'important est la place, non le contenu de la théorie. C'est la place de la théorie qu'il faut vaincre. Et cela ne peut se faire que par déplacement et fuite $(E L, 129)$.

Le rejet de la critique par Lyotard entraîne une dissociation entre désir et manque, en faisant du désir une force positive. 
Lyotard est donc passé de la critique au rejet de la critique pour la libido. Pourtant, vers 1979 et la préface à la deuxième édition du recueil d'essais Des dispositifs pulsionnels, le balancier est reparti à l'inverse. Ici, la position libidinale est rejetée comme étant naïvement affirmative. Les rôles sont inversés car la critique relègue la position libidinale. Le libidinal, ce qui est ontologiquement à l'extérieur, est devenu trop déterminé ontologiquement: il est une autre forme de la métaphysique, explique Lyotard. En effet, le libidinal n'est pas assez critique ou auto-critique. Sa seule défense est qu'elle a servi à 'secouer les choses' : «Quant à la métaphysique du désir ou de la pulsion qui déborde ici, qu'au moins elle apparaisse comme ce qu'elle était : un coup ${ }^{163}$ ». Cette dénonciation continue à travers les œuvres post-1979 de Lyotard qui démontrent un attachement croissant à la critique. Dans l'essai de 1984, «La Peinture du secret à l'ère postmoderne: Barucello ${ }^{164}$ » Lyotard va jusqu'à poser Kant et la critique kantienne contre Freud; et dans L'Enthousiasme, il identifie encore une fois la critique avec la politique (comme il l'a fait, par exemple, dans "Sur la théorie", $\left.1970^{165}\right)$, tout comme la première partie de Discours, figure avait identifié la critique avec l'art.

267 La position libidinale est une tentative de passer au-delà des limites de la théorie. Mais le problème avec une telle tentative est qu'elle dissimule le conflit de discours et figure, du langage et des forces libidinales derrière le langage, qui constitue le potentiel critique de l'art dans Discours, figure.

En effet, une raison d'être de la nature changeante du rapport entre discours et figure, critique et affirmation, pourrait résider selon moi, dans la nature fondamentalement ambivalente du désir lui-même. Comme Lyotard le fait remarquer, suivant en cela Freud dans ses discussions sur le fantasme, le désir et la loi naissent ensemble. Le fantasme ne peut donc jamais être libéré, et prétendre autre chose serait adopter une position idéologique fondée sur l'illusion et ainsi annuler la possibilité de la critique. L'ambivalence au cœur de l'esthétique de Lyotard peut être comprise comme une oscillation entre deux aspects contradictoires du fantasme : le fantasme comme ce qui cherche à s'accomplir et comme le moyen contraignant de cet accomplissement; ou bien le fantasme comme figure et discours, désir et inaccomplissement du désir ( $c f$. la description de la nature contradictoire du fantasme, chapitre VII). Toute tentative de donner priorité à un pôle de l'antagonisme au détriment de l'autre rencontre nécessairement des difficultés, car elle ferme les yeux sur l'ambivalence fondamentale du désir qui fait que le désaccord entre discours et figure ne peut jamais être résolu ${ }^{166}$.

\section{Musique critique, musique affirmative}

L'ambiguïté de la position théorique de Lyotard est renforcée par ses références artistiques. Je propose ici de décrire brièvement deux d'entre elles, toutes deux faisant partie du domaine de la musique : John Cage et Luciano Berio. Je ferai référence encore une fois à l'essai « Adorno come diavolo », mais aussi à « Plusieurs silences » et « A few words to sing ».

Il sera aussi fait référence à la Philosophie de la nouvelle musique d'Adorno.

Dans La philosophie de la nouvelle musique, Adorno établi une opposition entre un Schoenberg «progressif » et un Stravinsky « régressif ». Ici c'est Stravinsky qui assume le rôle de diable, son montage musical étant vu par Adorno comme quelque chose de faux, voire de pathologique, un jeu superficiel de masques : 
L'Histoire du soldat - pièce centrale de Stravinsky qui à la fois raille le concept de chef-d'œuvre illustré encore par Le Sacre - éclaire toute sa production. Presque pas un seul des mécanismes schizophréniques qu'étudie la psychanalyse, comme par exemple le dernier livre d'Otto Fenichel, qui ne trouverait ici les équivalents les plus convaincants. L'objectivité négative de l'œuvre fait penser elle-même à un phénomène de régression. Ce phénomène est connu par la théorie psychiatrique de la schizophrénie "comme dépersonnalisation"; selon Fenichel, c'est un mouvement de défense contre un trop puissant narcissisme. L'aliénation de la musique par rapport au sujet et sa relation contemporaine avec des sensations corporelles trouvent une analogie pathogène dans les hallucinations corporelles de ceux qui perçoivent leur corps comme un objet étranger (PNM, 180).

L'œuvre de Schoenberg, en revanche, est proclamée par Adorno comme étant l'incarnation de la vérité et de l'authenticité. Le processus de composition " authentique» qu'Adorno décrit ressemble d'une façon marquée à l'opération de renversement décrite par Lyotard à la fin de Discours, figure (un processus critiqué dans « Dérive » comme étant trop adornien) :

Les œuvres sont réussies dans la mesure où elles donnent forme à la contradiction et où, au cours de ce processus, elles la font réapparaître dans les marques de leur imperfection alors que d'une part la force de la contradiction fait fi du processus créateur et détruit les œuvres (PNM, 37).

Avec «Adorno come diavolo », la position «théologique» tenue par le philosophe allemand est renversée. En prenant implicitement la place de Stravinsky où Adorno prend celle de Schoenberg, Lyotard épouse la musique non-dialectique de Cage et Kagel. Cage, pour Lyotard, exemplifie la position affirmative, fondée sur l'écoulement libre du désir et des intensités et sur le renoncement au contrôle subjectif. C'est un art qui est passé au-delà de la critique et au-delà du temps téléologique; chez Cage il n'y a ni nostalgie ni anticipation. Lyotard applique la méthode aléatoire qui caractérise les compositions de Cage (Cage utilisait souvent le Yi King ou d'autres dispositifs similaires pour déterminer l'ordre des événements) à l'ordre d'idées sans son propre essai :

J'ai déterminé six idées (dialectique, critique, indifférence, position, théologie et expression, affirmation) sous lesquelles j'ai distribué toutes mes réflexions en forme d'items. Un premier tirage a affecté à chacune de ces idées la face d'un dé. Un deuxième tirage (au dé, encore) a permis d'établir la série diachronique d'apparition des idées. Un tirage au sort (petits papiers portant les chiffres de 1 à 20) a ensuite déterminé quel item, le 5 ou le 14 par exemple, appartenant à telle idée (par exemple indifférence), prendrait place au rang $\mathrm{n}$ de la série. Sont laissées indéterminées plusieurs dimensions : la durée de chaque item, la durée des blancssilences qui les séparent, le chromatisme (on aurait pu concevoir plusieurs sortes d'écriture), etc. L'artiste est devenu le simple réalisateur de ses propres intentions [Adorno], plus : d'intensités, qui ne lui appartiennent pas. «We are getting rid of ownership ", " our poetry now is the realisation that we possess nothing »: Cage. L'artiste ne compose plus, il laisse aller le désir en son dispositif. Cela est affirmation ("Adorno come diavolo », DP 123).

Cage est mentionné en outre par Lyotard dans l'essai « Plusieurs silences » (1972) :

Quand Cage a dit: il n'y a pas de silence, il dit: aucun Autre ne détient la domination sur le son, il n'y a pas de Dieu, de Signifiant comme principe d'unification, de composition. Il n'y a pas de filtrage, des blancs réglés, d'exclusions; donc plus d'œuvre non plus, plus la clôture qui détermine la musicalité comme région. Nous faisons de la musique tout le temps, dès que nous cessons d'en faire une, nous en commençons une autre, comme après la vaisselle, on se brosse les dents et on va se coucher : bruits, bruits, bruits. Et ce qu'il y a de plus sage, c'est d'ouvrir nos oreilles immédiatement et d'entendre un son dans sa soudaineté avant que 
notre pensée ait quelque chance de le transformer en quelque chose de logique, d'abstrait ou de symbolique (A Year from Monday) («Plusieurs silences », DP, 301).

Seulement un an avant la publication d'«Adorno come diavolo" et "Plusieurs silences », Lyotard a publié «A Few Words to Sing » (1971) un essai sur la Sequenza III pour voix de Luciano Berio. Ici Lyotard cherche à montrer précisément le potentiel critique de l'art, et dans ce dessein il se sert du concept de renversement décrit à la fin de Discours, figure. Le paragraphe introductif, par exemple est le suivant (la résonance avec le passage sur la magie rompue dans l'interview de Helmut Lachenmann cité dans le chapitre V. est notable) :

La fonction de l'art et de la politique est de faire rêver les gens, d'accomplir leurs désirs, de ne pas leur permettre de les réaliser, de transformer le monde, de changer la vie ; offrir une scène au désir pour qu'il y monte sa pièce fantasmatique, lui, le metteur en scène. Il faut donc retrouver les opérations communes au rêve (ou au symptôme), à cet art et à cette politique, et les manifester. Une telle manifestation est immédiatement critique. Cette critique est ce qui reste à faire avec l'art (et la politique) maintenant (DMF, 248).

Tandis que la musique de Cage représente une ouverture, un cadrage sur des sons quotidiens ("Nous faisons de la musique tout le temps, dès que nous cessons d'en faire une, nous en commençons une autre, comme après la vaisselle, on se brosse les dents et on va se coucher: bruits, bruits, bruits »), celle de Berio reste liée aux paramètres du langage musical traditionnel. La musique, pour Lyotard, est un quasi-langage, et à l'intérieur de ce langage le figural est au travail, comme dans le rêve, il produit :

[...] des effets de sens par la transgression des divers niveaux: organisation temporelle (rythme, développement), écarts entre les éléments (gamme), discontinuité proprement dite des éléments (existence des notes), composition des éléments entre eux, matière sonore des objets réputés musicaux (DMF, 252).

La transgression des règles du langage, qui refuse la constitution ultérieure d'un nouveau langage, et la fonction critique, sont liées inextricablement, à travers la notion du renversement :

Renversez la proposition: toute transgression de ce type vaudra comme trace $d u$ processus primaire, c'est-à-dire obligera l'auditeur à saisir le caractère secondaire, langagier, écrit, de la musique à laquelle son oreille est accordée et dans laquelle se marque cette trace. Cette transgression aura alors une fonction critique, aussi longtemps du moins qu'elle ne sera pas à son tour connotée, c'est-à-dire replacée comme opération constitutive (rhétorique par exemple, mais elle peut être un niveau plus élémentaire) dans un nouveau langage ( $D M F, 252)$.

La position de Cage a été critiquée pour sa tentative de rabattre l'art sur la vie, de l'identifier avec la "nature », comme si l'art et la matière de l'art demeuraient en dehors de l'histoire ${ }^{167}$.

En adoptant la position libidinale comme une alternative à la théorie et à l'art, Lyotard, aussi, peut être tenu pour coupable du même «naturalisme naïf » que celui pour lequel Cage a été critiqué, comme s'il était possible simplement de renoncer à l'Entzweiung, la scission originaire, et de rabattre la subjectivité sur objectivité, le discours sur la figure. Le musicien et le philosophe, dans leur tentative d'abandonner la raison subjective, avancent une solution utopique au problème de la contradiction entre l'art et la réalité. La suppression du contenu dialectique peut être vue comme l'équivalent d'un déni de l'histoire. Comme l'a écrit Wim Mertens :

Avec la méthode aléatoire de Cage le mouvement non-dialectique de la musique du $\mathrm{xx}^{\mathrm{e}}$ siècle a atteint son sommet. Ce mouvement se caractérise par la substitution $\mathrm{du}$ 
concept de processus par le concept de l'œuvre et par la dissolution de la contradiction entre forme et contenu. Idéologiquement, ceci a comme résultat une solution (utopique) de la contradiction entre l'art et la réalité et le remplacement du temps historique par le temps-macro ${ }^{168}$. l'arbre de la connaissance. Ce qui a commencé comme une protestation contre l'aliénation s'est terminé par un rejet de la subjectivité comme étant la source de tous les maux. En lieu et place de l'histoire, le mythe est maintenant proposé comme modèle. Comme l'a dit Clytus Gottwald : «Selon Cage, une fois que le sujet a été réduit au silence, on retourne à l'être pur. » Et Hans Curjel a écrit que "Cage refuse le choix. La dualité historique de l'esprit et de la matière, la vie et l'art, est abandonnée. » Le projet esthétique de Cage mène donc de façon logique à un projet éthique, qui anticipe la fin de l'histoire : la fin de l'expansion économique et de la domination politique et, par conséquent, le renoncement à la société de consommation. Le nihilisme musical est accompagné par une politique de nihilisme social, qui, à travers l'unité illusoire de la vie et de l'art, a pour résultat l'indifférence historique ${ }^{170}$.

\section{L'impasse du libidinal}

\section{Au-delà de la moralité}

Avec L'Économie libidinale, Lyotard semble avoir atteint un point de non-retour, ayant poussé la position affirmative à l'extrême. Suite à ce « livre méchant ", d' " effronterie, impudeur, et provocation ", comme Lyotard l'a décrit plusieurs années plus tard, le philosophe s'est détourné de la problématique libidinale pour se tourner vers Kant. Lyotard s'est inspiré de Kant pour « sauver l'honneur de la pensée » (PE, 32-34). Il s'est appuyé sur Kant pour élaborer une notion postmoderne de la justice, un concept entre critique et affirmation: «Le Différend répare les défauts de L'Économie libidinale; c'est une tentative de dire les mêmes choses mais sans se débarrasser de problèmes aussi importants que la justice ${ }^{171}$ » Avec L'Économie libidinale, Lyotard en est arrivé à abandonner une fois pour toutes le dualisme qui était à la base de Discours, figure en faveur d'une "métaphysique du désir ${ }^{172}$ ", et cependant le résultat final a été de se rendre compte de la futilité d'opposer un "bon" désir révolutionnaire à un « mauvais » désir fasciste, comme démontre la critique suivante de l'Anti-CEdipe :

- Donc là-dessus vous récusez l'éthique spinoziste ou nietzschéenne, qui sépare les mouvements de plus-être et ceux du moins-être, d'action et de réaction ? - Oui, redoutons de voir réapparaître à la faveur de ces dichotomies toute une morale et toute une politique, leurs sages, leurs militants, leurs tribunaux et leurs prisons. Où il y a intensité, il y a labyrinthe, et déterminer les sens du parcours, souffrance ou allégresse, est l'affaire des consciences et de leurs directeurs. Il nous suffit que la barre tourne pour que fusent les spirales imprévisibles, il nous suffit qu'elle ralentisse et s'arrête pour que s'engendrent la représentation et la pensée claire.

Appareil, $10 \mid 2012$ 
Donc pas de bonnes et de mauvaises intensités, mais l'intensité ou sa décompression. Et comme on l'a dit et on le redira, l'une et l'autre dissimulées ensemble, le sens caché dans l'émotion, le vertige dans la raison. Ainsi point de morale, plutôt une théâtrique ; point de politique, plutôt un complot (EL, 54-55).

S'il n'y a "pas de bonnes et de mauvaises intensités ", n'importe quelle politique, esthétique ou discours peut être affirmée, et le résultat final est une forme d'indifférence généralisée et une impasse politique. Autrement dit, la force critique de l'antagonisme entre discours et figure établie dans Discours, figure, une force qui a pris la sémiologie comme tâche, est perdue dans la totalisation de la position libidinale. Le tournant postérieur de Lyotard vers le concept postmoderne de la justice peut être vu comme une tentative de rectifier l'amoralisme autodestructeur de la posture libidinale. $\mathrm{Au}$ moment de L'inhumain cependant, Lyotard avait fait une nouvelle volte-face, doutant de la possibilité d'utiliser Kant :

Même ce qu'il peut y avoir d'inquiétant chez Kant à cet égard, ce qui n'est pas anthropologique mais proprement transcendantal, et ce qui, dans la tension critique, va jusqu'à briser l'unité plus ou moins présupposée d'un sujet (humain), comme c'est le cas, qui me semble exemplaire, de l'analyse du sublime ou des écrits historico-politiques, même cela, on l'expurge. Sous prétexte de retour à Kant, on ne fait qu'abriter le préjugé humaniste sous son autorité ${ }^{173}$.

\section{La fin de l'art}

Il semblerait que cette même logique autodestructrice habite l'esthétique de Lyotard. Comme nous l'avons vu, Lyotard critique les approches traditionnelles psychanalytiques de l'art, qui traitent l'art comme un symptôme trouvant expression et donc accomplissement à travers l'œuvre d'art. Le résultat de cette critique est la valorisation d'une pratique artistique qui va à l'encontre d'elle-même et contre son inclination la plus profonde: pour que l'art devienne l'anti-art, il doit désirer l'inaccomplissement du désir, son propre manque de finalité, son insuffisance. L'hétérogénéité et la non-représentabilité extrêmes du désir doivent, paradoxalement, être attelées par l'art s'il doit manifester la vérité. Avec la figure-matrice, l'origine irreprésentable de la représentation, Lyotard a poussé le libidinal à travers et au-delà des limites de l'art, courant ainsi le risque de la dissolution de celui-ci. L'art est ici décrit au moment de sa propre dissipation : «L'œuvre est au bord de sa rupture » (DF, 384), car une énergétique pure, une non-forme libidinale ne laisse place ni au discours ni à l'art. En effet comme nous l'avons vu, Lyotard sape la possibilité du discours critique en général, et par conséquent la force de son propre discours critique. Comme dans le mythe d'Ulysse, l'art et le discours peuvent atteindre cette limite, mais provoquent inévitablement leur propre destruction quand ils s'aventurent au-delà d'elle.

286 Lyotard remet donc en question la possibilité du discours critique en général, et ainsi, la force de son propre argument.

\section{Adorno : une solution?}

Lyotard a-t-il eu raison d'abandonner la position libidinale? Pouvons-nous être d'accord avec lui quand il prétend qu'elle n'a été qu'un «coup»? Peter Dews soutient que nous ne devrions pas rejeter sans réserve ce corps de pensée à la manière de Lyotard à partir de l'Économie libidinale. Sans toutefois prendre la voie autodestructrice de L'Économie libidinale, Il faudrait plutôt selon lui en conserver certains aspects, tels 
que la critique du structuralisme et de la tentative de Lacan de réduire l'inconscient à un texte. Dews affirme que c'est Adorno qui montre le passage par-delà l'impasse de la problématique libidinale, car il garde l'idée de l'antagonisme entre les forces discursives et figurales sans néanmoins totaliser la position libidinale.

Adorno et Horkheimer dans La dialectique de la raison décrivent un soi divisé contre luimême, en affirmant que le rapport entre le conscient et la répression de la «nature intérieure » est constitutif du soi et est une contradiction inévitable à laquelle le sujet ne peut pas échapper. En effet, comme le dit Adorno dans la Dialectique négative: "L'opposition du penser à ce qui lui est hétérogène se reproduit dans le penser luimême comme sa contradiction immanente ${ }^{174}$ ».

La recherche lyotardienne sur le non-identique, l'irrationnel, ce qui élude la raison et les concepts parait, quand elle est poussée à l'extrême, exiger la dissolution totale du chaos en pulsion.

Le seul choix qui reste à Lyotard est donc celui d'abandonner la notion de la répression discursive avec laquelle il a commencé, autrement dit, de prendre la position affirmative selon laquelle l'intensité est déjà partout. Puisque Lyotard suppose ce conflit nécessaire entre l'hétérogénéité de désir et l' « unité » répressive du conscient, il arrive à la conclusion qu'« il n'y a pas de Moi dont la fonction serait de lever, de renverser le refoulement » (DF 357).

291 Cependant, là où Lyotard établit un parallèle entre l'ego et la répression, et entre le chaos des pulsions et la libération, Adorno voit un statut ambivalent dans le conscient et l'inconscient. Car, comme l'indique Dews, ce n'est qu'à travers l'ego, qui organise la libido, que les êtres humains peuvent faire des choix et des prédictions, ce qui les libère de la contingence de la nature interne et externe. Adorno et Horkheimer expliquent ce processus dans le chapitre sur L'Odyssée de La dialectique de la raison.

Dans l'épisode des Sirènes de l'Odyssée, Ulysse doit réprimer sa nature interne, pour se préserver de la menace de "se perdre dans le passé », et pour ne pas céder au leurre de la pulsion pure d'avant la formation de l'ego. «La préservation de soi réussit seulement dans la mesure où, comme résultat de la régression imposée sur soi-même, le développement du soi échoue ${ }^{175}$ ». Ceci est la nature double qui est constitutive de la subjectivité : le coût d'une telle préservation du soi est la perte de la spontanéité. «Le sujet absolu ne peut s'extraire de son empêtrement", écrit Adorno dans Dialectique négative, « les liens qu'il voudrait arracher, ceux de la domination, ne font qu'un avec le principe de la subjectivité absolue ${ }^{176} »$.

293 Dans l'essai « Sociologie et psychologie », Adorno écrit :

Bien que, soi-même psychique à l'origine [l'égo] est censé arrêter le jeu des forces intérieures et le maîtriser contre la réalité : ceci est un des critères principaux pour déterminer sa "santé ». Le concept de l'ego est dialectique, à la fois psychique et extra psychique, un quantum de libido et le représentant de la réalité externe ${ }^{177}$.

Le sujet, donc, n'est pas pour Adorno une entité absolue, mais est scindé, emprisonné dans son appareil de survie. Ulysse, confronté à l'allure dangereuse et enivrante du chant des Sirènes, n'envisage que deux solutions pour assurer sa propre survie et celle de son équipage. Il ordonne à tous les membres de l'équipage de se boucher les oreilles avec de la cire, et exige qu'on l'attache au mât du navire: ainsi, alors qu'il peut entendre le chant et son attraction irrésistible, il ne peut pas se conformer à son désir :

Des mesures comme celles qui ont été prises sur le navire d'Ulysse par rapport aux

Sirènes forment une allégorie prémonitoire à la dialectique de la raison. Comme la 
capacité de représenter est la mesure de la domination, et la domination est la chose la plus puissante qui puisse être représentée [...], alors la capacité de la représentation est le véhicule du progrès et de la régression en même temps ${ }^{178}$.

lyotardienne d'une "critique de l'idéologie » puisse espérer s'accomplir sans se saper elle-même en atteignant une position stable et déterminée ontologiquement avec un dedans et un dehors propres, comme cela semble être le cas dans la métaphysique de la libido. Car une telle position est l'antithèse de la pensée critique, déterminée comme elle l'est par le mouvement incessant et sans finalité, par l'inaccomplissement perpétuel.

\section{BIBLIOGRAPHIE}

Adorno Theodor, Philosophie de la nouvelle musique, Paris, Gallimard, 1962.

Adorno Theodor, "Sociology and Psychology", New Left Review, n 47, 1968.

Adorno Theodor, Dialectique négative, Paris, Payot, 1978.

Adorno Theodor, Aesthetic Theory, G. Adorno and R. Tiedemann (ed.), London, Routledge, 1984.

Adorno Theodor, Quasi una fantasia: Essays on Modern Music, London, Verso, 1992.

Adorno Theodor, "On the Problem of Musical Analysis" (1969), in Essays on Music, Richard Leppert (ed.), Berkeley, University of California Press, 2002.

Adorno Theodor, Horkheimer Max, Dialectique de la raison, Paris, Gallimard, 1974.

Barthes Roland, L'obvie et l'obtus : Essais Critiques III, Paris, Seuil, 1982. 
Bataille Georges, « La notion de dépense », La part maudite, Paris, Minuit, 1949.

Baudrillard, Pour une critique de l'économie politique du signe, Paris, Gallimard, 1972.

Carroll David, Paraesthetics: Foucault, Lyotard, Derrida, New York, Methuen, 1987.

Danuser Hermann, « Rationalität und Zufall - John Cage und die experimentelle Musik in Europa ", Asthetik im Widerstreit : Interventionen zum Werk von Jean-François Lyotard, Wolfgang Welsch und Christine Pries (ed.), VCH, Weinheim, 1991.

Deleuze Gilles, Nietszsche, Paris, PUF, 1965.

Deleuze Gilles, Parnet Claire, Dialogues, Paris, Flammarion, 1996.

Dews Peter, Logics of Disintegration: Post-structuralist thought and the claims of critical theory, London, Verso, 1987.

Freud Sigmund, « Au-delà du principe de plaisir » (1920) in Essais de psychanalyse, Paris, Payot, 1981.

Freud Sigmund, L'interprétation du rêve, Euvres complètes vol. IV, Paris, PUF, 2004.

Grant Iain Hamilton, “Introduction”, Libidinal Economy, London, Continuum, 1993.

Gualandi Alberto, Lyotard, Paris, Perrin, 2009.

Harvey David, The Condition of Postmodernity, Cambridge MA, Blackwell, 1990.

Heathcote Abigail, Libertating Sounds: philosophical perspectives on the music and writings of Helmut Lachenmann, mémoire de master en musicologie, université de Durham, 2003.

Heathcote Abigail, « De la musique comme situation. Entretien avec Helmut Lachenmann », Circuit : musiques contemporaines, vol. VII n ${ }^{\circ} 1,2007$, p. 79-91.

Hockings Elke, “Helmut Lachenmann's Concept of Rejection”, Tempo, n 193, july 1995.

Keller Hans, Essays on Music, Christopher Wintle (ed.), Cambridge, CUP, 1994.

Laplanche Jean, Pontalis Jean-Bertrand, « Fantasme originaire, fantasme des origines, origines du fantasme », Les temps modernes, $\mathrm{n}^{\circ} 215$, avril 1964.

Lyotard Jean-François, Discours, figure, Paris, Klincksieck, 1971.

Lyotard Jean-François, Dérive à partir de Marx et Freud, Paris, Union générale des Éditions, 1973.

Lyotard Jean-François, Des dispositifs pulsionnels, Paris, Union générale des Éditions, 1973 et 1979 (2 éd.).

Lyotard Jean-François, L'Enthousiasme. La critique kantienne de l'histoire, Paris, Galilée, 1986.

Lyotard Jean-François, L'inhumain. Causeries sur le temps, Paris, Galilée, 1988.

Lyotard Jean-François, Pérégrinations, Paris, Galilée, 1990.

Marx Karl, Engels Freidrich, Le manifeste du Parti communiste (1848), Paris, UGE / 10/18, 1962.

Mertens Wim, American Minimal Music, London, Kahn \& Averill, 1983.

Nassif, Jacques, « Le fantasme dans “On bat un enfant” »vol. 7, Cahiers pour l'Analyse, mars 1967.

Paddison Max, Adorno's Aesthetics of Music, Cambridge, CUP, 1993.

Polin Claire, "Why Minimalism Now ?" in Music and the Politics of Culture, Christopher Norris (ed.), London, Lawrence \& Wishart, 1989.

Schwartz Robert, Minimalists, London, Phaidon, 1996. 
Smith Joseph H., Arguing with Lacan: Ego Psychology and Language, New Haven, Yale University

Press, 1991.

Storr Anthony, Freud, A Very Short Introduction, Oxford, OUP, 2001.

Van Reigen Villem, Veerman Dick, “An Interview with Jean-François Lyotard”, in Theory, Culture and Society, 5, 1988.

\section{NOTES}

1. Jean-François Lyotard, Discours, figure, Paris, Klincksieck, 1971.

2. Ibid., p. 11.

3. Ibid., p. 13.

4. Ibid., p. 18.

5. Peter Dews, Logics of Disintegration: Post-structuralist thought and the claims of critical theory, London, Verso, 1987, p. 110.

6. Ibid., p. 109.

7. Lyotard, 1971, p. 14.

8. «La lettre est le support d'une signification conventionnelle, immatérielle, à tous égards identique à la présence du phonème. Et ce support s'efface derrière ce qu'il soutient : la lettre ne donne lieu qu'à la reconnaissance rapide, au bénéfice de la signification » $(D F, 211)$. La ligne, cependant, contrecarre la simple, reconnaissance : «Cette lenteur requise par le figural vient de ce qu'il oblige la pensée à abandonner son élément, qui est le discours de signification, où le tracé n'est pas accueilli pour lui-même (pas plus que le son dans la parole) parce qu'il n'est qu'un élément distinctif ou significatif dans le tableau des significations. Il lui faut sortir de la transparence communicable; la façon dont le sens est présent dans la ligne (dans tout constituant de la figure) est ressentie comme opacité par l'esprit habitué au langage. Un effort presque sans fin est exigé pour que l'œil se laisse capter par la forme, se laisse communiquer l'énergie qu'elle détient » $(D F, 218)$.

9. Dews, 1987, p. 111.

10. David Carroll, Paraesthetics: Foucault, Lyotard, Derrida, New York, Methuen, 1987, p. 37.

11. Lyotard, 1971, p. 31.

12. Ibid., p. 121.

13. Ibid., p. 110.

14. Ibid., p. 109.

15. Ibid., p. 33.

16. Ibid., p. 34.

17. Frege cité par Lyotard, 1971, p. 107.

18. Lyotard, ibid., p. 125 et 127.

19. Dews, 1987, p. 118 (je traduis).

20. Lyotard, 1971, p. 41.

21. Ibid., p. 129.

22. J'emprunte ce terme utilisé par Peter Dews par rapport à Deleuze et Guattari (Dews, 1987, p. 132).

23. Roland Barthes, L'obvie et l'obtus : Essais Critiques III, Paris, Seuil, 1982.

24. Ibid., p. 43-45.

25. Lyotard, 1971, p. 62.

26. Adorno cité par Paddison, Adorno's Aesthetics of Music, Cambridge, CUP, p. 51 (je traduis).

27. Lyotard, 1971, p. 68. 
28. Le dualisme cartésien se réfère au fait que Descartes entendait démontrer qu'il existe une distinction entre l'âme et le corps.

29. «On pourrait soutenir [...] que Derrida ne nie pas que nous expérimentions une dimension référentielle du langage [...] Or, la logique de la position de Derrida le pousse inévitablement à conclure que le référentiel ne peut posséder qu'un statut secondaire et dérivatif » Dews, 1987, p. 114-115.

30. Alberto Gualandi, Lyotard, Paris, Perrin, 2009, p. 48.

31. Freud cité par Storr, 2001, p. 46, je traduis.

32. Lyotard, 1971, p. 271.

33. Carroll, 1987, p. 39.

34. Sigmund Freud, L'interprétation du rêve, Euvres complètes vol. IV, Paris, PUF, 2004, p. 558.

35. Freud, 2004, note 2, p. 558.

36. Lyotard, 1971, p. 239.

37. Ibid., p. 239.

38. Ibid., p. 241.

39. Ibid.

40. Ibid., p. 241.

41. Ibid.

42. Ibid.

43. Lyotard, 1971, p. 241-242.

44. "Pourquoi "économie libidinale" ? Pour montrer ce qu'il y a de passionnel dans l'économie politique et accessoirement de politique dans les passions [...] On rompt donc avec toute sémiotique, toute dialectique, toute critique même, qui sont des pensées du négatif. On affirme les intensités d'affects qui se dissimulent dans "la pensée" et la recherche des significations " Lyotard, Économie libidinale, Paris, 1974 (texte de couverture).

45. Lyotard, 1971, p. 242.

46. Ibid., p. 243.

47. Freud, 2004, p. 321.

48. Ibid., p. 326.

49. Lyotard, 1971, p. 245.

50. Ibid.

51. Lyotard, 1971, p. 245.

52. Lyotard, 1973a, p. 5-21.

53. Lyotard, 1973b, p. 115-134.

54. Lyotard, 1971, p. 246.

55. Ibid., p. 247.

56. Freud, 2004, p. 352.

57. Ibid., p. 352-353.

58. Le terme « mobilité immobile » apparaît très tôt in Discours, figure : « Ce livre-ci proteste : que le donné n'est pas un texte, qu'il y a en lui une épaisseur, ou plutôt une différence, constitutive, qui n'est pas à lire, mais à voir ; que cette différence, et la mobilité immobile qui la révèle, est ce qui ne cesse de s'oublier dans le signifier » (DF, p. 9, les italiques sont de moi).

59. Lyotard, 1971, p. 245.

60. Freud, 2004, p. 384-385.

61. Lyotard, 1971, p. 248.

62. Ibid. p. 249.

63. Lyotard, 1971, p. 262.

64. Lyotard, 1971, p. 268-269.

65. Freud, 2004, p. 540.

66. Lyotard, 1971, p. 262. 
67. Theodor Adorno, Aesthetic Theory, G. Adorno and R. Tiedemann (ed.), London, Routledge, 1984, p. 171 (je traduis).

68. Adorno, 1984, p. 80 (je traduis).

69. Lyotard, 1971, p. 270.

70. «Le désir ne parle pas, il violente l'ordre de la parole. Cette violence est primordiale » (Lyotard, 1971, 239).

71. Lyotard, 1973a, p. 56.

72. Cette idée d'un art qui échappe complètement au principe de réalité apparaît hautement simpliste et peu en accord avec l'observation faite par Lyotard du fait que le désir est toujours travesti.

73. Lyotard, 1973a, p. 57.

74. Ibid.

75. Freud cité par Lyotard, 1973a, p. 56.

76. Hermann Danuser, «Rationalität und Zufall - John Cage und die experimentelle Musik in Europa ", Asthetik im Widerstreit: Interventionen zum Werk von Jean-François Lyotard, Wolfgang Welsch et Christine Pries (ed.), VCH, Weinheim, 1991, p. 99 (je traduis).

77. Wim Mertens, American Minimal Music, London, Kahn \& Averill, 1983, p. 108 (je traduis).

78. John Cage cité par Claire Polin, "Why Minimalism Now?" in Music and the Politics of Culture, Christopher Norris (ed.), London, Lawrence \& Wishart, 1989, p. 226 (je traduis).

79. Abigail Heathcote, «De la musique comme situation. Entretien avec Helmut Lachenmann », Circuit, vol. 17, n 1, 2007, p. 81.

80. Karlheinz Stockhausen cité par Mertens, 1983, p. 101 (je traduis).

81. Gilles Deleuze et Claire Parnet, Dialogues, Paris, Flammarion, 1996, p. 7-10.

82. "Cela est de grande importance pour la pratique, pour la critique pratique de l'idéologie. Ce livre-ci n'est lui-même qu'un détour pour mener à cette critique, et s'il nous a fallu attendre longtemps que tombe notre propre résistance à l'écrire, c'est assurément (entre autres) par crainte d'être séduit, détourné de cette fin, médusé par le langage. Ce qu'il en est de sa fonction pratique, ce qui y demeure actif, chaud, il ne m'appartient pas d'en juger » (Lyotard, 1971, p. 19). 83. Lukács cité par Paddison, 1993, p. 33 (je traduis).

84. Karl Marx et Friedrich Engels, Le manifeste du Parti communiste (1848), Paris, UGE / 10/18, 1962, p. 22-23. Je tiens à remercier Germinal Pinalie pour cette référence à la loi du paiement au comptant.

85. Il semble y avoir une contradiction dans le schéma historique du développement de l'art de Lyotard. Lyotard dit que l'art sous le capitalisme est aliéné (l'art religieux par opposition rendait possible la «communication inconsciente») et en même temps il soutient, avec Freud, que l'impossibilité de la vraie communication est à l'origine-même du langage, la fissure originelle.

86. Paddison, 1993, p. 31 (je traduis).

87. Ibid., p. 181 (je traduis).

88. Theodor Adorno, "On the Problem of Musical Analysis" (1969), in Essays on Music, Richard Leppert (ed.), Berkeley, University of California Press, 2002, p. 181 (je traduis).

89. Ibid., 164.

90. Hans Keller, Essays on Music, Christopher Wintle (ed.), Cambridge, CUP, 1994, p. 124-125 (je traduis).

91. "[L]a puissance "utopique" ou transgressive n'est pas celle qui l'emporte dans l'organisation fantasmatique, elle est tenue en bride par Eros, par l'exigence de maintenir l'appareil à un certain niveau de tension qui témoigne de son caractère différencié. Cette fonction du fantasme est de remplir le vide laissé par le retrait de l'objet, par l'hallucination négative : défense contre l'angoisse » $(D F, 359)$.

92. Les italiques sont de moi.

93. Lyotard, 1971, p. 383. 
94. Un exemple de ce que Lyotard veut dire par double renversement, ou renversement critique peut être vu dans le concept de magie rompue de Lachenmann. Le passage suivant tiré d'un entretien avec le compositeur est tellement révélateur qu'il convient de le citer en entier :

«Je pense qu'une des particularités de l'art européen, et qu'on ne trouve dans aucune autre culture, est l'idée de magie rompue. L'idée d'art, de musique disons, est magique. Dans le théâtre japonais nô ou dans le kabuki, c'est différent. La musique y est associée à la religion ou au pouvoir, à l'amour ou à la mort, au pouvoir ou au printemps, bref, à tous les objets de fascination collective. La musique techno, d'autre part, est un happening magique. [...] La musique pop, c'est de la musique magique, et c'est la même chose pour la musique soi-disant symphonique : écouter du Mozart, par exemple. Les auditeurs veulent de la magie, ils veulent du Mozart en tant que magie. Mais Mozart n'était pas seulement de la magie, il était de la magie rompue. Et c'est pourquoi les gens de Vienne le trouvaient si ennuyeux. Ils ne voulaient pas aller à ses concerts parce que c'était trop compliqué pour eux. »

"[...] "Rompue" ne veut pas dire "détruite". "Rompre" signifie interrompre ou suspendre la fascination irrationnelle par un moment d'attention. [...] À l'époque de Bach, les chorals protestants avaient une fonction. Les chorals n'étaient pas faits pour que l'on s'assoie et qu'on les écoute; ils étaient faits pour être chantés par tous les gens réunis. Leur fonction était de faire prier pendant l'office, de rendre un culte à Dieu, de chanter pour Dieu. Puis voilà M. Bach qui arrive et les harmonise. Les gens étaient vraiment furieux parce qu'il avait interrompu l'office et les obligeait à écouter ce qui se passait. Ils voulaient le congédier parce qu'il avait rompu la magie. Il ne voulait pas vraiment la rompre, il voulait seulement s'en servir pour créer quelque chose. C'est là l'idée de créativité au-delà des limites de ce qui est joli, ou de ce qui est accepté, au-delà des limites conventionnelles, au-delà de la magie.»

«Créer de la magie est si facile. Un grand nombre de compositeurs le font. Ils n'ont qu'à aller au supermarché de la magie, à prendre un tam-tam, un glissando, un cluster, ou certaines composantes électroniques [...] C'est une sorte d'agencement de situations magiques. Et les gens disent que c'est intéressant. Mais "intéressant" égale "ennuyeux"! Je ne veux pas écouter des choses intéressantes: je veux être touché. Les sons doivent penser. Les meilleures pièces dérangent. Il y avait les grandes symphonies de Mahler, qui duraient une heure ou plus. Puis Schoenberg est venu avec sa Symphonie de chambre, condensée en un seul mouvement. Les gens ont été complètement horrifiés. Ce fut unanime. Ou bien on commence à écouter attentivement quelque chose et on se laisse fasciner par ce que l'esprit a fait de cette chose, ou [...] Voilà le dilemme : la magie ou l'esprit? L'esprit doit dominer la magie. Et dominer la magie signifie interrompre la magie. Imaginons une situation complètement absurde : vous avez rassemblé tout le monde dans un stade pour un match de football. Quand la Coupe du Monde aura lieu en Allemagne, il y aura une magie incroyable. J'aimerais que pour une fois les joueurs jouent avec deux ballons. Oh, ils seraient tellement furieux! Ou bien qu'ils ne cessent de frapper le ballon en direction des spectateurs au lieu de l'envoyer sur le terrain: briser les règles. Ce serait extraordinaire, ça me plairait. Et les gens commenceraient à penser: "Nous sommes complètement dingues, voulez-vous bien nous dire pourquoi il y a des millions de personnes qui regardent cela ?" ( (Lachenmann in Heathcote, 2007, p. 86-87).

95. Pour Gualandi, la tentative de Lyotard de distinguer la vérité de l'art de celle de la psychanalyse est vouée à l'échec: "On notera combien ce "double renversement" de finalité pratique, cette substitution de l'oreille analytique à l'œil artistique, ne trace qu'une ligne très faible entre le discours théorique et la vérité artistique, aussi faible qu'on pourrait même affirmer que la place que Lyotard réserve ici à l'art par rapport à la psychanalyse est presque indiscernable de la place que Hegel lui donnait dans son esthétique. De fait, la vérité de l'art, n'est-elle pas ici une sorte de signe sensible de la vérité qui sera par la suite systématisé et utilisée dans un but pratique par le savoir analytique ? [...] Lyotard devrait affirmer que la vérité de l'art est plus profonde et transgressive que tout discours psychanalytique. Mais c'est 
justement ce que, arrivé à ce point, il n'est plus capable de dire, et qu'il est donc obligé de taire " (Gualandi 2009, p. 57).

96. Ibid., p. 54.

97. Sigmund Freud, «Au-delà du principe de plaisir » (1920) in Essais de psychanalyse, Paris, Payot, 1981, p. 49.

98. Ibid, p. 62 .

99. Ibid., p. 51.

100. Ibid., p. 50.

101. Freud, 1981, p. 56-57.

102. Freud, 1981, p. 64.

103. Riley cité par Schwartz, 1996, p. 23 (je souligne, je traduis).

104. John Cage cité par Polin, 1989, p. 226 (je traduis).

105. Terry Riley cité par Schwartz, 1996, p. 35. Les peintures de Bridget Riley explorent aussi le rapport contradictoire entre la différence et la répétition. Si on contemple de façon prolongée les œuvres de Riley, les images abstraites et à deux dimensions semblent se mettre en mouvement et adopter une apparence tri-dimensionnelle. Le concept d' " hallucination structurelle » d'Helmut Lachenmann suit le même principe. Lachenmann, en faisant référence à la technique de réduction rythmique et textuelle dans son Tanzsuite mit Deutschlandlied, remarque qu'" Avec la réduction totale au son aigü du piano, un monde de perception hautement différentié s'ouvre de nouveau grâce aux accentuations différentes du même son et à travers l'assourdement et pédalement simultané avec des niveaux de résonance différents qu'on ne peut pas tout simplement "composer", mais on doit libérer l'expérience d'abord en excluant, et assourdant, les choses en trop." (Helmut Lachenmann, Musik als existentielle Erfahrung: Schriften 1966-1995, Wiesbaden, Breitkopf \& Härtel, p. 134 (je traduis). Voir aussi Abigail Heathcote, Libertating Sounds: philosophical perspectives on the music and writings of Helmut Lachenmann, mémoire de master en musicologie, université de Durham, 2003, p. 174-187.

106. Freud, 1981, p. 66.

107. Ibid., p. 69.

108. Freud, 1981, p. 79. C'est cette fonction de liaison, une fonction du principe de plaisir destinée à contenir l'angoisse en maîtrisant le stimulus que la pulsion de mort, comme une pulsion de déliaison d'énergie psychique, cherche à défaire.

109. Freud, 1981, p. 81-82.

110. Ibid., p. 88.

111. Freud, 1981, p. 91.

112. Ibid.

113. Freud, 1981, p. 92.

114. On pourrait se demander comment se fait-il que la pulsion de mort, qui d'un côté semble pouvoir être représentée comme se mouvant librement, tel un processus inconscient, puisse en même temps être une pulsion qui erre vers l'extinction de tout mouvement, c'est à dire la stabilité ultime.

115. Freud, 1981, p. 118.

116. Ibid.

117. Ibid., p. 119.

118. Si la fonction de la répétition est de rendre possible la liaison rétrospective des énergies non-liées et l'abaissement consécutif de l'excitation, c'est selon Lyotard, la fonction de l'art de résister à ce processus de liaison et de maintenir instables le flux d'énergie et le niveau d'excitation. En résistant à ce processus de liaison, l'art témoigne de la pulsion de mort soustendant toute activité vitale (créative). Il est cependant important de se souvenir de l'apparente divergence dans l'emploi du terme " pulsion de mort " par Freud et Lyotard. Le terme entre dans la terminologie de Freud pour décrire une compulsion paradoxale à répéter envisagée chez le 
patient souffrant de névrose traumatique : il décrit un symptôme à guérir. Pour Lyotard en revanche, cette pulsion devrait être mise à profit et exploitée, en lui laissant le champ libre. En donnant « voix » à la pulsion de mort, l'art gagne l'accès à la différence elle-même, avant la formation de l'identité et de l'opposition. Lyotard n'est pas intéressé par la stase et la mort mais par le mouvement des intensités pures, intensités qui sont des individuations qui existent en elles-mêmes et ne sont pas « fixes » ou déterminées par quelque chose en dehors d'elles-mêmes. Pour lui, ce n'est pas une force conservatrice ou rétroactive, mais une force critique, transgressive qui sape les fausses formes de la pensée.

119. Joseph H. Smith, Arguing with Lacan: Ego Psychology and Language, New Haven, Yale University Press, 1991, p. 22-23.

120. Ibid., p. 33.

121. Freud, 1981, p. 126.

122. Ibid., p. 127.

123. Gilles Deleuze, 1965 , p. 166.

124. http://fr.wikipedia.org/wiki/Roman_Opałka.

125. http://fr.wikipedia.org/wiki/Yves_Klein.

126. « Tout art est re-présentatif, [...] dans ce sens qu'il est reversant, qu'il renverse le rapport de l'inconscient et du préconscient, qu'il procède à des insertions du second dans le cadre du premier. Ce renversement recrée de la différence, de l'événement. Il s'accompagne d'une certaine laideur. Celle-ci est l'affect correspondant à la présentation des opérations primaires, elle est l'angoisse dans l'ordre esthétique. Ce renversement ne suppose nullement la domination de l'inconscient par la conscience : il suppose le refus de cette domination » $(D F, 383)$.

127. Elke Hockings, “Helmut Lachenmann's Concept of Rejection”, Tempo, n 193, juillet 1995 (je traduis).

128. Lachenmann, «Le beau dans la musique d'aujourd'hui", www.entretemps.asso.fr/Bohy/ Biblio/Traduc/beautif.htm.

129. Freud cité par Storr, 2001, p. 61 (je traduis).

130. David Harvey, The Condition of Postmodernity, Cambridge MA, Blackwell, 1990, p. 41.

131. Ceci rappelle le jeu collectif auquel il est fait référence dans la théorie esthétique de Freud.

132. Les italiques sont de moi.

133. Le thème de l'échec (l'œuvre n'est jamais que le témoin de son inaccomplissement) est développé chez Baudrillard, cf Pour une critique de l'économie politique du signe.

134. Les italiques sont de moi.

135. Carroll, 1987, p. 41 (je traduis).

136. Lachenmann 1996, p. 18.

137. Jean Laplanche et Jean-Bertrand Pontalis, «Fantasme originaire, fantasme des origines, origines du fantasme », Les temps modernes, $\mathrm{n}^{\circ} 215$, avril 1964.

138. Ibid., p. 1835.

139. Freud, 1981.

140. Laplanche et Pontalis, 1964, p. 1838.

141. Laplanche et Pontalis, 1964, p. 1841.

142. Ibid., 1842.

143. Ibid.

144. Freud cité par Laplanche et Pontalis, 1964, p. 1843.

145. Laplanche et Pontalis, 1964, p. 1850.

146. Laplanche et Pontalis, 1964, p. 1851.

147. Laplanche et Pontalis, 1964, p. 1852.

148. Ibid., p. 1853.

149. Ibid.

150. Laplanche et Pontalis, 1964, p. 1854. 
151. Laplanche et Pontalis, 1964, p. 1854.

152. Ibid., p. 1855.

153. Ibid.

154. Freud cité par Laplanche et Pontalis, 1964, p. 1859 (je souligne).

155. Jacques Nassif, «Le fantasme dans "On bat un enfant" » vol. 7, Cahiers pour l'Analyse, mars 1967.

156. Jacques Nassif, «Le fantasme dans "On bat un enfant" » vol. 7, Cahiers pour l'Analyse, mars 1967.

157. Freud cité par Lyotard, 1971, p. 352.

158. Gualandi, 2009, p. 51.

159. Carroll, 1987, p. 42.

160. Jean-François Lyotard, Des dispositifs pulsionnels, Paris, Union générale des Éditions, 1973, p. 115-133.

161. La résonnance entre la fonction de liaison chez Freud et le fait que la religion lie est notable : la religion apparaît donc comme du fantasme collectif qui sert à atténuer l'angoisse.

162. Lyotard, 1973b, p. 7-52.

163. Lyotard, « Dispositifs III », 1979.

164. Lyotard, Traverses, mars 1984.

165. «[...] la fonction de la théorie n'est pas de comprendre seulement, mais de critiquer. C'est-àdire contester, de retourner une réalité, des rapports sociaux, des rapports de l'homme avec les choses et avec les autres, qui sont visiblement insupportables. Et pour moi, la dimension de la politique, c'est cela » (DMF, 210).

166. On pourrait affirmer qu'un des moyens de lire le travail de Lyotard dans son ensemble, et la constante oscillation, ou "tension critique» entre deux positions mutuellement exclusives, serait en termes de libido, ce lieu où des réalités opposées coexistent. En effet, comme le suggère Hamilton-Grant, "les cycles régulés de critique révolutionnaire, et les arcs bégayant qui marquent sa mémoire, sont eux-mêmes d'incompossibles fragments de la Besetzung critiquelibidinal duplice, déplacés et défigurés au long du flot irracontable de la libido » (Iain Hamilton Grant, «Introduction », Libidinal Economy, London, Continuum, 1993, p. xxxi, je traduis). Une telle lecture libidinale de Lyotard, cependant, qui pourrait elle-même être qualifiée de métaphysique, se place au-delà de notre étude.

167. On peut aussi trouver cette tentative de "nettoyer " la matière artistique de ses origines historiques ou contextuelles dans la musique concrète de Pierre Schaeffer, et l'école de composition électro-acoustique qui cherchait à dé-familiariser les sons de la vie quotidienne. La musique concrète instrumentale, c'est-à-dire la production de sons inhabituels au moyen d'instruments acoustiques traditionnels, de Helmut Lachenmann, représente une tentative d'aligner cette pratique de défamiliarisation tout en refusant d'ignorer l'historicité inévitable des sons.

168. Mertens, 1980, p. 109 (je traduis).

169. Ibid., p. 116.

170. Ibid., p. 116 (je souligne).

171. "Interview with Jean-François Lyotard", in Theory, Culture and Society, 5, 1988, p. 278, je traduis.

172. Lyotard, 1979.

173. Lyotard, L'inhumain. Causeries sur le temps, Paris, Galilée, 1988, p. 9.

174. Adorno, Dialectique négative, Paris, Payot, 1978, p. 119.

175. Adorno 1974, p. 86.

176. Adorno, 1978, p. 46.

177. Theodor Adorno, "Sociology and Psychology", New Left Review, n 47, 1968, p. 85.

178. Adorno 1974, p. 34-35. 
179. Carroll, 1987, p. 49.

180. Adorno, "Vers une musique informelle» in Quasi une fantasia: Essays on Modern Music, London, Verso, 1992.

\section{RÉSUMÉS}

Ce mémoire se focalise sur les textes esthétiques de la période libidinale de Jean-François Lyotard, et plus particulièrement sur la notion de la figure comme une force qui sous-tend et perturbe le discours. Via l'acte de renversement du fantasme, l'artiste fait parler cet autre exclu du discours, ouvrant ainsi la voie à une critique de l'idéologie. Ce travail examine également les raisons pour lesquelles, juste après la publication de l'Économie libidinale, Lyotard abandonne la position libidinale, pour se tourner vers Kant et la question du jugement, et finalement remettre en question la validité d'un tel geste. Son hypothèse est qu'il existe une ambivalence au cœur de la position libidinale de Lyotard qui le piège dans une oscillation permanente entre une position critique et affirmative. Cette ambivalence est présente déjà dans trois textes clés qui portent sur l'esthétique et la politique libidinales: Discours figure, Dérive à partir de Marx et Freud et Des dispositifs pulsionnels.

\section{INDEX}

Mots-clés : affirmation, artiste, critique, discours, fantasme, figure, idéologie, libidinal, renversement

\section{AUTEUR}

\section{ABIGAIL HEATHCOTE}

Abigail Heathcote a fait un master recherche sur la musique et les écrits du compositeur Helmut Lachenmann à l'université de Durham au Royaume-Uni et s'est ensuite tournée vers l'esthétique et la philosophie en faisant un master en philosophie à Paris 8 . Elle a enseigné la communication dans plusieurs universités et grandes écoles dans la région parisienne et travaille actuellement en tant que formatrice des professionnels à Paris. 